\title{
Field Performance Evaluation of a Disposable Sampler for Inhalable Heavy Metal Aerosols
}

\author{
Peter John Grimson
}

Follow this and additional works at: https://researchrepository.wvu.edu/etd

\section{Recommended Citation}

Grimson, Peter John, "Field Performance Evaluation of a Disposable Sampler for Inhalable Heavy Metal Aerosols" (2017). Graduate Theses, Dissertations, and Problem Reports. 5715.

https://researchrepository.wvu.edu/etd/5715

This Thesis is protected by copyright and/or related rights. It has been brought to you by the The Research Repository @ WVU with permission from the rights-holder(s). You are free to use this Thesis in any way that is permitted by the copyright and related rights legislation that applies to your use. For other uses you must obtain permission from the rights-holder(s) directly, unless additional rights are indicated by a Creative Commons license in the record and/ or on the work itself. This Thesis has been accepted for inclusion in WVU Graduate Theses, Dissertations, and Problem Reports collection by an authorized administrator of The Research Repository @ WVU. For more information, please contact researchrepository@mail.wvu.edu. 


\title{
Field Performance Evaluation of a Disposable Sampler for Inhalable Heavy Metal Aerosols
}

\section{Peter John Grimson}

Thesis submitted to

The Statler College of Engineering and Mineral Resources at West Virginia University

In partial fulfillment of the requirements for the degree of

\author{
Master of Science \\ In \\ Industrial Hygiene
}

Xinjian He, Ph.D., Chair

Eun Gyung Lee, Ph.D.

Steven E. Guffey, Ph.D.

Department of Industrial and Management Systems Engineering

Morgantown, West Virginia

2017

Keywords: aerosols, heavy metals, air sampling, inhalable particulates

Copyright 2017 Peter Grimson 


\section{Abstract}

\section{Field Performance Evaluation of a Disposable Sampler for Inhalable Heavy Metal Aerosols}

\section{Peter Grimson}

Reliably sampling worker exposures to aerosolized particulates is an integral part of many industrial operations. The production of inhalable particulates in the presence of workers is a common issue and one that should be closely monitored by health and safety professionals. Regulatory agencies such as the Occupational Safety and Health Administration and the Mine Safety and Health Administration have specific standards that are legally enforceable pertaining to particulate aerosol exposure limits. Therefore, in many industrial operations, air sampling of workers is an essential part of maintaining regulatory compliance.

Although many airborne particulates can pose significant health risks, the costs of air sampling are prohibitive to gathering data from every worker in many workplaces. In order to help mitigate the costs of exposure assessment, a disposable sampler was designed in order to collect inhalable aerosols. The sampler has been evaluated in a laboratory setting, but this study compared the performance of the newly developed disposable inhalable aerosol sampler to the current models in an industrial setting. The industrial environment utilized for this study was a large copper electrorefinery. Workers were fixed with two pumps, one attached to the current technology (IOM sampler by SKC) and the other to the newly designed disposable sampler. Samplers were attached to opposing lapels of workers and they were monitored for the duration of their work shift. Area samples were also collected where aerosol particulate exposures have been consistent and measurable. The faces of the samplers were placed next to each other for the area samples, collecting data from the ambient air conditions. This study found differences between the DIS and IOM sampler for exposure measurements-with a pvalue of 0.005 , the ANOVA statistical analysis rendered a rejection of the null 
hypothesis, which states that the two samplers are not different on a statistically significant level. Using a linear regression analysis of the data, the adjusted $\mathrm{R}^{2}$ value was 0.1622 and the Pearson's correlation coefficient was 0.423 for the 51 sample pairs, further substantiating the differences between these samplers. Changes to the design are suggested to make the disposable inhalable sampler more user friendly prior to commercialization. 


\section{Acknowledgements}

This study was conducted with the help of the West Virginia University School of Engineering and the National Institute for Occupational Safety and Health (NIOSH). In

particular, I would like to acknowledge Dr. Eun Gyung Lee who lent a tremendous amount of support and guidance, serving as an excellent mentor and Bill Chisholm for his substantial contributions in the laboratory. 


\section{Abbreviations}

$\begin{array}{ll}\text { IPM } & \text { Inhalable particulate mass } \\ \text { d } & \text { Wind velocity } \\ \mu \mathrm{m} & \text { Aerodynamic diameter } \\ \text { DIS } & \text { Micrometer }\left(1 \mathrm{E}^{-6} \mathrm{~m}\right) \\ \mathrm{CFC} & \text { Disposable inhalable sampler } \\ \text { RSD } & \text { Relative standard deviation } \\ \text { IPD } & \text { Interior wall particle deposition } \\ \text { LPM } & \text { Liter per minute } \\ \text { LOQ } & \text { Limit of quantitation } \\ \text { PEL } & \text { Permissible Exposure Limit } \\ \text { ICP-MS } & \text { Inductively coupled plasma mass spectrometry }\end{array}$




\section{List of Figures}

Figure 1: ISO/CEN/ACGIH sampling conventions (source: Lidén and Harper, 2006)................. 2 Figure 2: Experimentally determined inhalability in calm air, by different research groups. Error bars represent standard deviations (source: Lidén and Harper, 2006) ...................................... 6

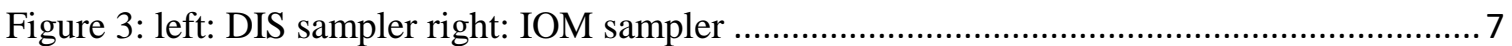
Figure 4: Direction-averaged sampling efficiencies at $0.5 \mathrm{~m} \cdot \mathrm{s}^{-1}$ (source: Aizenberg et al., 1999

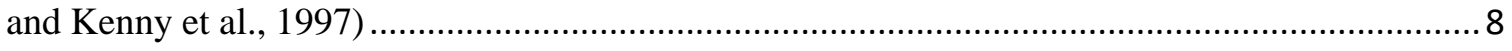

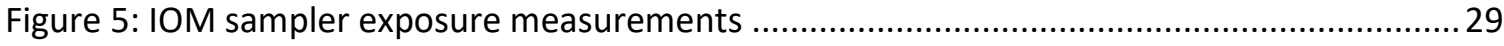

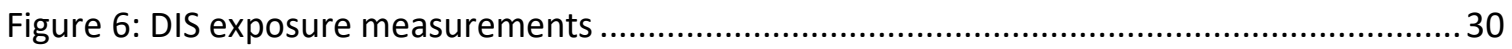

Figure 7: IOM vs. DIS transportation loss scatter plot ............................................................ 31

Figure 8: Ratio of concentrations between the DIS sampler and the IOM sampler using raw data

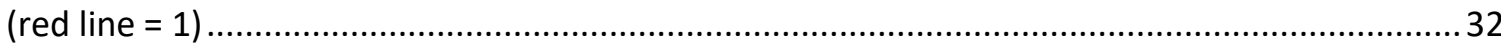

Figure 9:Log-transformed mass concentrations between pairs of samplers. The diagonal line represents 1:1 relationship.

\section{List of Tables}

Table 1: Slope factor for linear regression (forced through the origin) shown as the ratio of sampling efficiency to mannequin aspiration efficiency (source Sleeth and Vincent, 2012) ........11

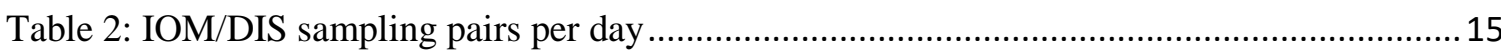

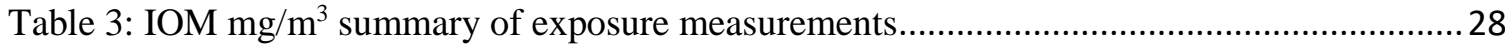

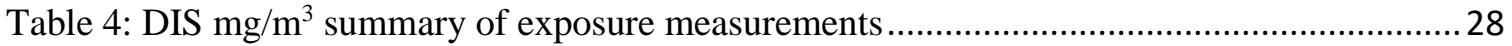

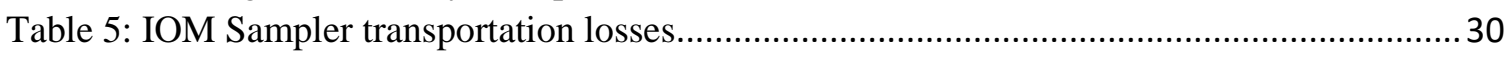

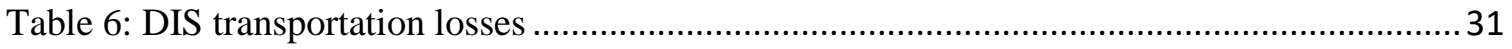

Table 7: SAS regression analysis results, including Pearson Correlation...................................... 34

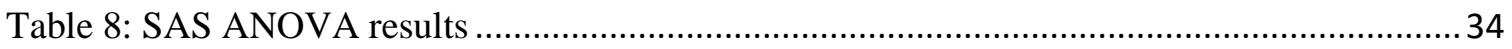




\section{Table of Contents}

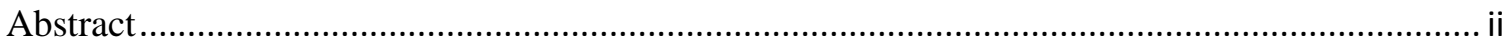

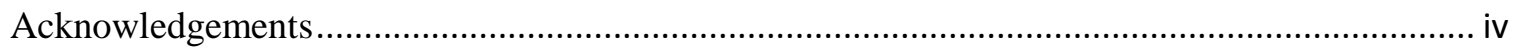

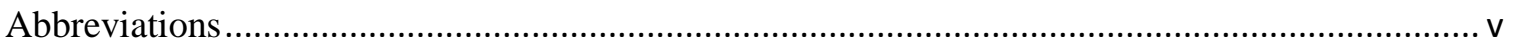

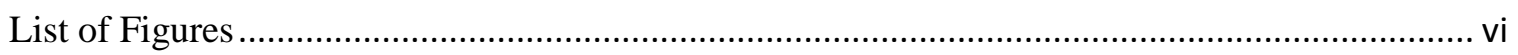

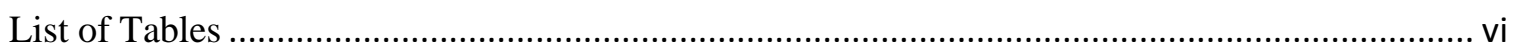

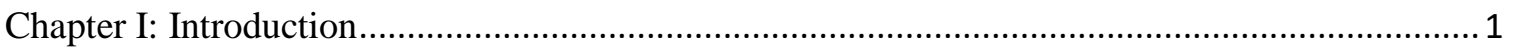

Chapter 2: Literature Review ............................................................................................... 4

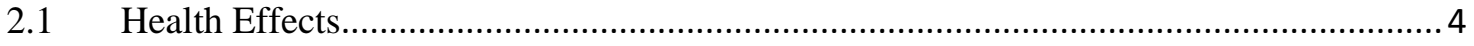

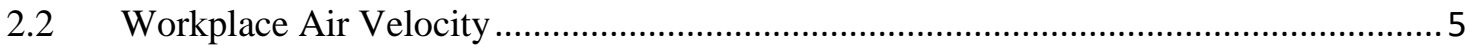

2.3 Currently Available Inhalable Samplers ..................................................................... 7

2.3.1 Sampler Efficiency at $\geq 0.5 \mathrm{~m} \cdot \mathrm{s}^{-1}$ Wind Velocity Studies................................... 8

2.3.2 Sampler Efficiency at $<0.5 \mathrm{~m} \cdot \mathrm{s}^{-1}$ Wind Velocity Studies................................... 10

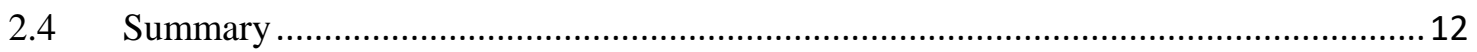

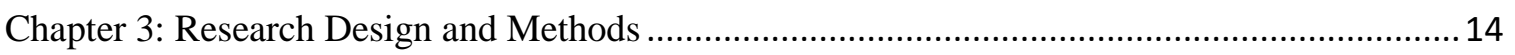

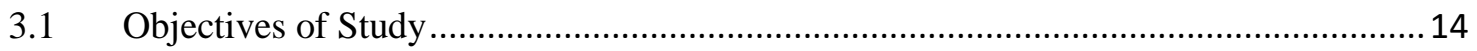

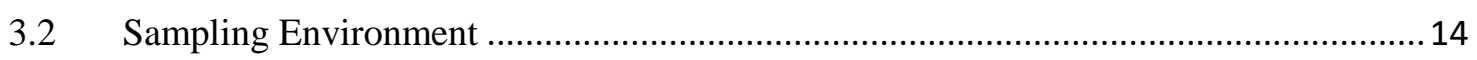

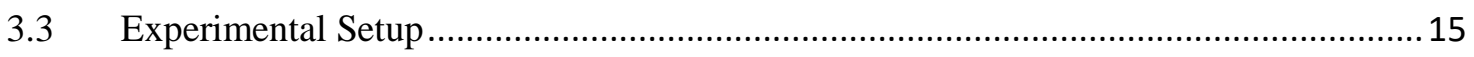

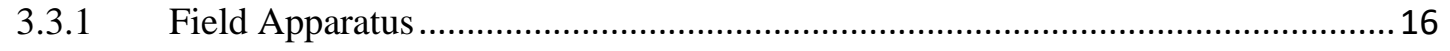

3.3.2 Quantitative Sample Analysis Apparatus .......................................................... 16

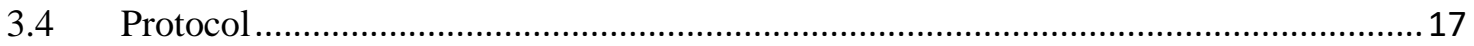

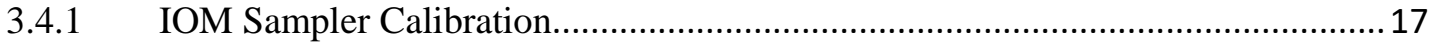

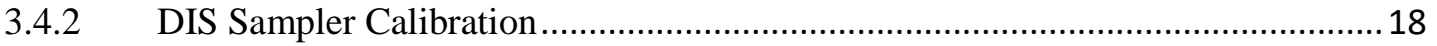

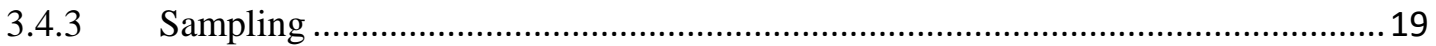

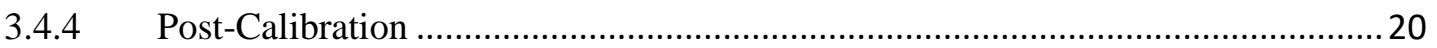

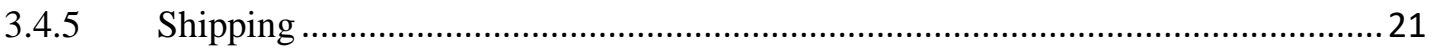

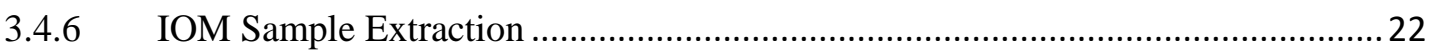

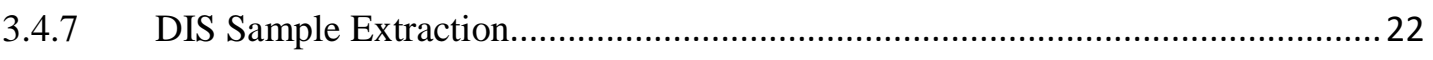

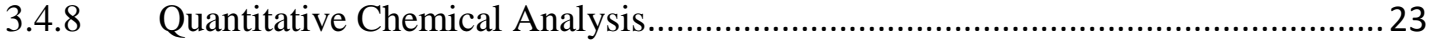




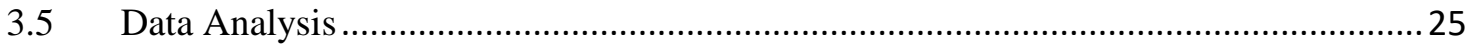

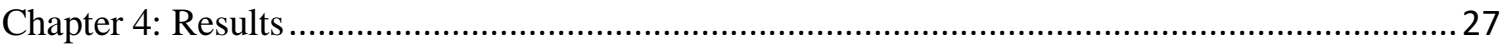

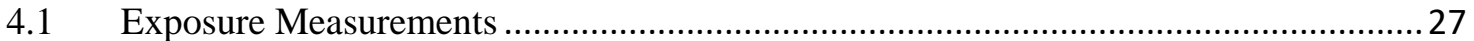

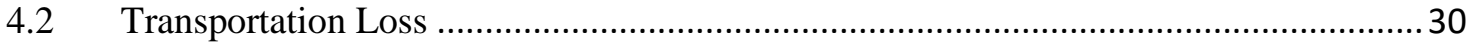

4.3 Comparison of Concentration Between DIS and IOM Sampler ...................................32

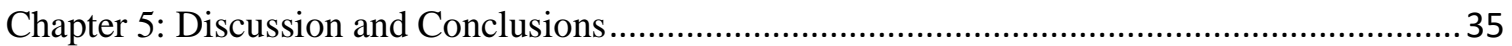

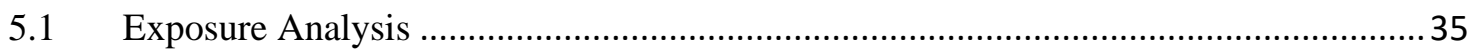

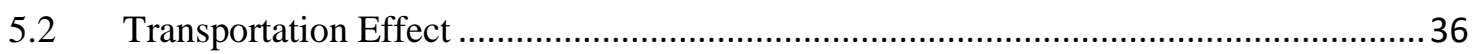

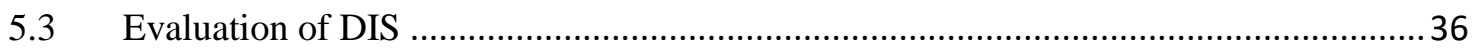

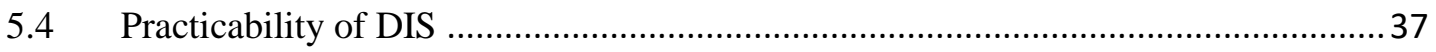

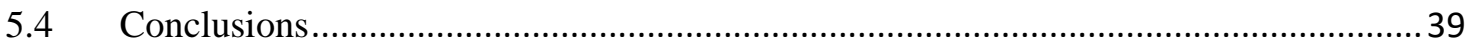

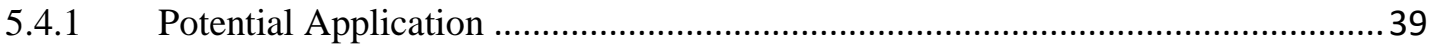

5.4.2 Limitations and Future Research ...................................................................... 40

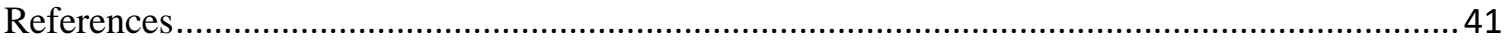

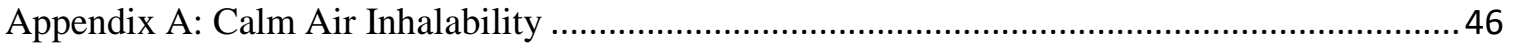

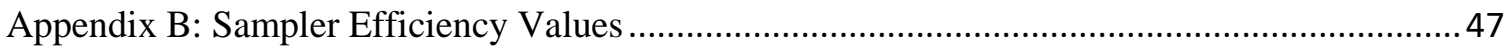

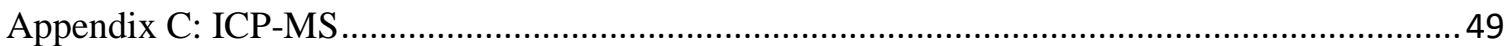

Appendix D: Calibration and Limits of Detection ....................................................................... 51

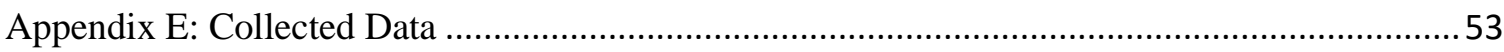

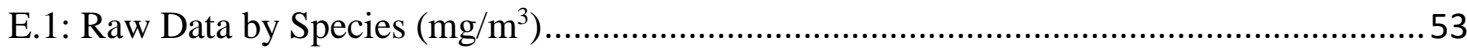

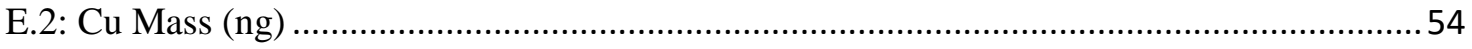

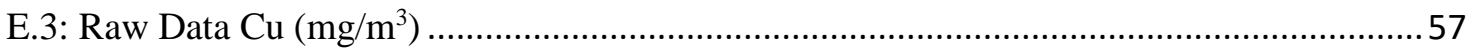

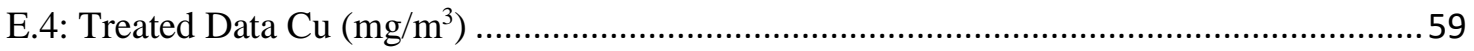




\section{Chapter I: Introduction}

The ISO (International Standards Organization), ACGIH (American Conference of Governmental Industrial Hygienists) and CEN (European Committee for Standardization) agreed to a common convention to classify airborne particulates into different aerosol fractions based on the penetration of these particles in the various regions of the respiratory tract (Lidén and Harper, 2006). Thus, conducting air sampling for particulates of a specific aerodynamic diameter $\left(\mathrm{d}_{\mathrm{ae}}\right)$ range has been a large focus of industry and research. Samplers have been produced to copy the conventions defined by ISO, ACGIH, and the CEN. The Inhalable Particulate Mass (IPM) criterion was based on the suggestion of Vincent and Armbruster (1981) as an approximation of the aspiration efficiency of particles, as a function of aerodynamic diameter, for a human (L'Orange et al., 2015). The IPM criterion as adopted by the ISO (7708) with particulates of $d_{a e} \leq 100$ $\mu \mathrm{m}$ and a wind velocity $(U)$ of $0.5<U<9 \mathrm{~m} \cdot \mathrm{s}^{-1}$ is:

$$
\mathrm{IPM}=0.5\left[1+e^{-0.06 \mathrm{~d}_{\mathrm{ae}}}\right]+10^{-5} U^{2.75} \mathrm{e}^{0.055 \mathrm{~d}_{\mathrm{ae}}}
$$

ACGIH and CEN for wind speeds below $4 \mathrm{~m} \cdot \mathrm{s}^{-1}$ :

$$
\mathrm{IPM}=0.5\left[1+e^{-0.06 \mathrm{~d}_{\mathrm{ae}}}\right]
$$

The IPM criterion was designed to include only particulates with an aerodynamic diameter of $d_{a e} \leq 100 \mu \mathrm{m}$, but large particles with systemic toxicity pose a health risk if inhaled regardless of where they deposit and research suggests the IPM criterion be revised to include particles larger than $100 \mu \mathrm{m}$ (Kennedy and Hinds, 2002). The inhalable fraction includes the thoracic fraction $\left(\mathrm{d}_{\mathrm{ae}}<30 \mu \mathrm{m}\right)$ and the respirable fraction $\left(\mathrm{d}_{\mathrm{ae}}<10\right.$ $\mu \mathrm{m})$. Depending on the particulate material, some aerosols have negligible health effects within the inhalable fraction, but have serious health effects with deeper penetration into the thoracic and respirable fractions. Typically, these are xenobiotics that have molecular 
interactions with cells and the immune system. Figure 1 illustrates the inhalability fractions adopted by ISO/CEN/ACGIH.

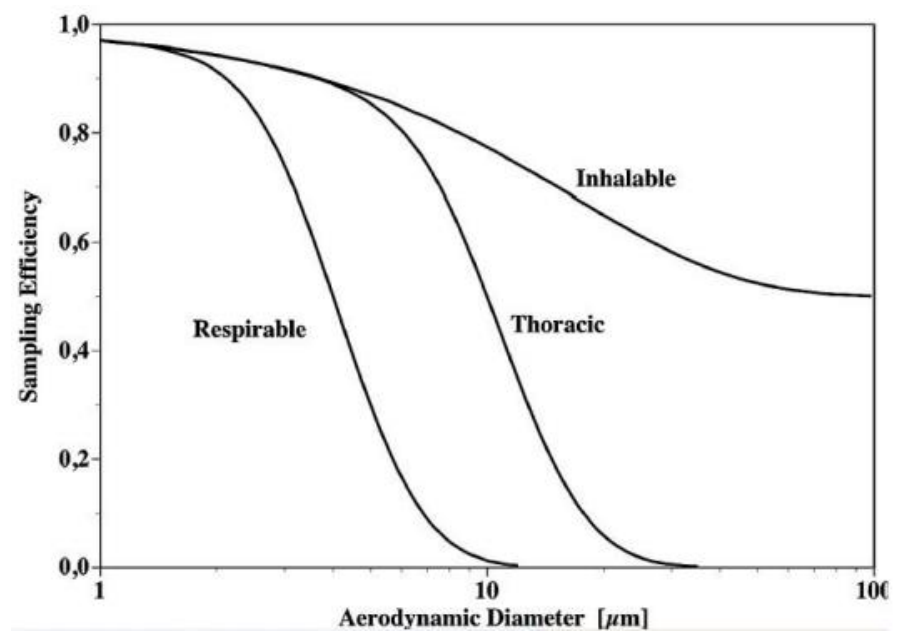

Figure 1: ISO/CEN/ACGIH sampling conventions (source: Lidén and Harper, 2006)

Current samplers are measured for their sampling efficiency in reference to the IPM convention. The most common sampler, the "closed face cassette" (CFC), usually of the $37 \mathrm{~mm}$ variety, has been shown to under-sample particulates $>30 \mu \mathrm{m}$ (Kenny et al., 1998; Gorner et al., 2010). In an effort to capture samples that are closer to the IPM criteria, the IOM and button samplers were created. The IOM sampler has a larger opening and an internal capsule designed to inhibit transport loss. The button sampler has a mesh face with small openings.

All of these samplers have drawbacks - both the IOM and CFC suffer from significant interior wall particle deposition (IPD). The IOM and CFC sampler efficiencies are also sensitive to wind velocity and direction (Witschger et al., 2004). The button sampler filter must be removed immediately after sampling, creating opportunities for field contamination and has difficultly sampling aerosols generated by wet methods (L'Orange et al., 2015). The CFC is inexpensive $(<\$ 1.00)$, whereas the button sampler (without the $\$ 305$ protective shield) retails for $\$ 275$. A nylon plastic IOM sampler retails for $\$ 85$ and a stainless-steel IOM sampler costs $\$ 269$. These prices make it attractive to use the CFC. If the samplers have been contaminated with certain materials such as beryllium, often they are not reused (Aerosol-Technology-Committee, 2011). This makes 
sampling in workplaces with beryllium at any levels > LOQ to be cost prohibitive for anything other than the CFC.

When testing the efficiency of samplers across various aerodynamic diameters, the external wind velocity has been shown throughout literature to play a large role. Prominent experts have discussed the need for adoption of a low velocity 'calm air' inhalable convention, to accommodate workplaces with air velocities $\leq 0.3 \mathrm{~m} \cdot \mathrm{s}^{-1}$ (Lidén and Harper, 2006). The workplace utilized in this performance evaluation was in a large copper electrorefinery with some air movement, but generally velocities fit that of most indoor workplaces. Many experiments have been in wind velocities of 0.5 to $4.0 \mathrm{~m} \cdot \mathrm{s}^{-1}$, but some studies suggest indoor workplaces have wind velocities that are rarely above 0.2 $\mathrm{m} \cdot \mathrm{s}^{-1}$ (Baldwin and Maynard, 1998) and thus there have been calls to revise the current inhalable particulate convention to accommodate this (Lidén and Harper, 2006; Kenny et al., 1998). Using the low-wind inhalability curve, it has been demonstrated that the IOM sampler over-samples by $>30 \%$ for particulates of 5-15 $\mu \mathrm{m}$, the CFC $(25 \mathrm{~mm})$ undersamples by $>30 \%$ for $d_{a e}>5 \mu m$, and the button sampler ranged from $-1 \%-5 \%$. For six particle fractions $(6.9-76.0 \mu \mathrm{m})$, the button sampler had the highest precision with a relative standard deviation (RSD) of $11 \%$, as compared to the RSD the IOM sampler at $14 \%$ and of $35 \%$ for the CFC. (Witschger et al., 2004)

Given that data suggests most workplaces have low-velocity air movement and the most common and cost-effective sampler does not accurately quantify aerosol concentrations, there is need for an economical sampler that has good agreement with a low-velocity inhalability convention. 


\section{Chapter 2: Literature Review}

\subsection{Health Effects}

Inhalation of particulate matter is a large contributor to occupational illness and death. Occupational exposures pertaining to aerosolized particulate matter makes up 63\% of deaths in the workplace, with unintentional injuries making up the other $37 \%$ (Nelson et al., 2005). There are at least three general classes of airborne toxic materials: highly soluble toxic materials that can be quickly absorbed into the bloodstream, materials that can have toxic effects after dissolving in the digestive tract, and particulates that are toxic at the spot in which they are deposited (Phalen et al., 1988). Inhaled particles that deposit on respiratory tract surfaces may be physically cleared by the tracheobronchial mucociliary escalator or nasal mucus flow to the throat, and then they may be either expectorated or swallowed (NIOSH, CIB 62). Although some xenobiotics such as asbestos have demonstrated limited evidence of toxicity outside of the pulmonary system (ATSDR, 2002), aerosols of toxic metals such as arsenic, beryllium, hexavalent chromium, and lead with large aerodynamic diameters incapable of penetrating into the thoracic or respirable fractions can still be absorbed by the body.

If a species of xenobiotic is enzymatically bioactivated, then toxicity can be expected in organs with high concentrations of enzymes such as the cytochrome P-450 family of hemoproteins. Human respiratory mucosa contains concentrations of P-450 that are 5\% of hepatic cells (Thorton-Manning and Dahl, 1997). As an example, arsenic is easily absorbed in the gastrointestinal tract and mainly metabolized in the liver via methylation by Arsenite methyltransferase. S-adenosylmethionine (SAM) is the main methyl group donor in arsenic methylation and most SAM is consumed in the liver (Drobna et al., 2009). The end metabolites are methylarsonic acid (MMA) and dimethylarsinic acid (DMA). Although MMA and DMA are readily excreted in urine, studies have demonstrated that formation of methylated arsenicals produce compounds with unique and potentially higher toxicity than inorganic species such as trivalent $\mathrm{As}{ }^{\mathrm{III}}$ and pentavalent $\mathrm{As}^{\mathrm{V}}$. Products of $\mathrm{iAs}$ reduction and subsequent methylation have been found to be more potent cytotoxins, genotoxins, and enzyme inhibitors (Drobna et al., 
2009). As such, even if arsenic particulates are too large to penetrate far into the respiratory tract, clearance of deposited particulates via the mucociliary escalator allows for exposure to the liver, a primary target organ of arsenic toxicity (Liu et al., 2008). Thus, it is important that sampler efficiencies are similar to human inhalability with respect to aerodynamic diameter.

\subsection{Workplace Air Velocity}

Much research has been done on quantifying the ambient air conditions of work environments and its relation to aerosol sampler efficiency (Ogden and Birkett 1977; Vincent and Mark, 1982; Vincent et al., 1990). Most of these results demonstrate that there is a correlation between wind speed and measured aerosol quantities from $1-9 \mathrm{~m} \cdot \mathrm{s}^{-1}$ and the IPM is based on 1-4 $\mathrm{m} \cdot \mathrm{s}^{-1}$ (Baldwin and Maynard, 1998). Two studies, Maynard et al. (1997) and Baldwin and Maynard (1998) indicate that at wind speeds below 0.5 $\mathrm{m} \cdot \mathrm{s}^{-1}$, inhalability deviates profoundly from the IPM criterion. Almost a dozen studies point towards a characterization of occupational setting wind velocities less than that used to create the IPM convention. Kovanen et al. (1989) examined wind speeds of 19 offices and 6 houses, demonstrating wind speeds under $0.1 \mathrm{~m} \cdot \mathrm{s}^{-1}$ for over $70 \%$ of the time (Baldwin and Maynard 1998). Matthews et al. (1989) collected data with an average wind speed of $0.05 \mathrm{~m} \cdot \mathrm{s}^{-1}$ that was also unaffected by the use of ventilation.

In a large survey covering multiple types of occupational settings, Berry and Froude (1989) investigated wind velocities, including indoor and outdoor settings. The jobs selected involved physical labor, with industrial grade equipment being used. Excluding a single sample next to a fume cupboard with a velocity of $1.8 \mathrm{~m} \cdot \mathrm{s}^{-1}$, the average occupational setting air velocity was noted as $0.2 \mathrm{~m} \cdot \mathrm{s}^{-1}$ (Berry and Froude, 1989). In an extensive survey by Baldwin and Maynard (1998), 55 work areas within 27 different factories were surveyed. Excluding a wood drying shed that was especially susceptible to outside conditions $\left(2 \mathrm{~m} \cdot \mathrm{s}^{-1}\right)$, the pooled mean of wind velocities was recorded as $0.2 \mathrm{~m} \cdot \mathrm{s}^{-1}$. Wind speeds were measured as below $0.1 \mathrm{~m} \cdot \mathrm{s}^{-1}$ for $50 \%$ of the 
time, and below $0.3 \mathrm{~m} \cdot \mathrm{s}^{-1}$ for $85 \%$ of the total time (Baldwin and Maynard, 1998). Given that multiple studies have characterized wind speeds substantially lower than $1 \mathrm{~m} \cdot \mathrm{s}^{-1}$ and that the IPM does not accurately represent inhalability at velocities below $0.5 \mathrm{~m} \cdot \mathrm{s}^{-1}$, it has been suggested by many experts in the field that a low wind velocity IPM convention should be created and utilized as a benchmark for assessing the performance of aerosol samplers.

Published in 2006 in the Journal of Occupational and Environmental Hygiene, Göran Lidén and Martin Harper wrote an article titled "The Need for an International Sampling Convention for Inhalable Dust in Calm Air”, which highlighted the importance of a calm air convention in light of substantial research illustrating typical wind velocities below $0.5 \mathrm{~m} \cdot \mathrm{s}^{-1}$ in occupational settings and evidence demonstrating that sampling efficiencies substantially change at low wind velocities (Lidén and Harper, 2006).

By reviewing a vast amount of research (Appendix A), Lidén and Harper (2006) concluded that the differences in aspiration efficiency determined in wind tunnels with velocities exceeding $1.0 \mathrm{~m} \cdot \mathrm{s}^{-1}$ and aspiration efficiency in calm air chambers are significantly different. Figure 2 illustrates the collected research pertaining to calm air human aspiration.

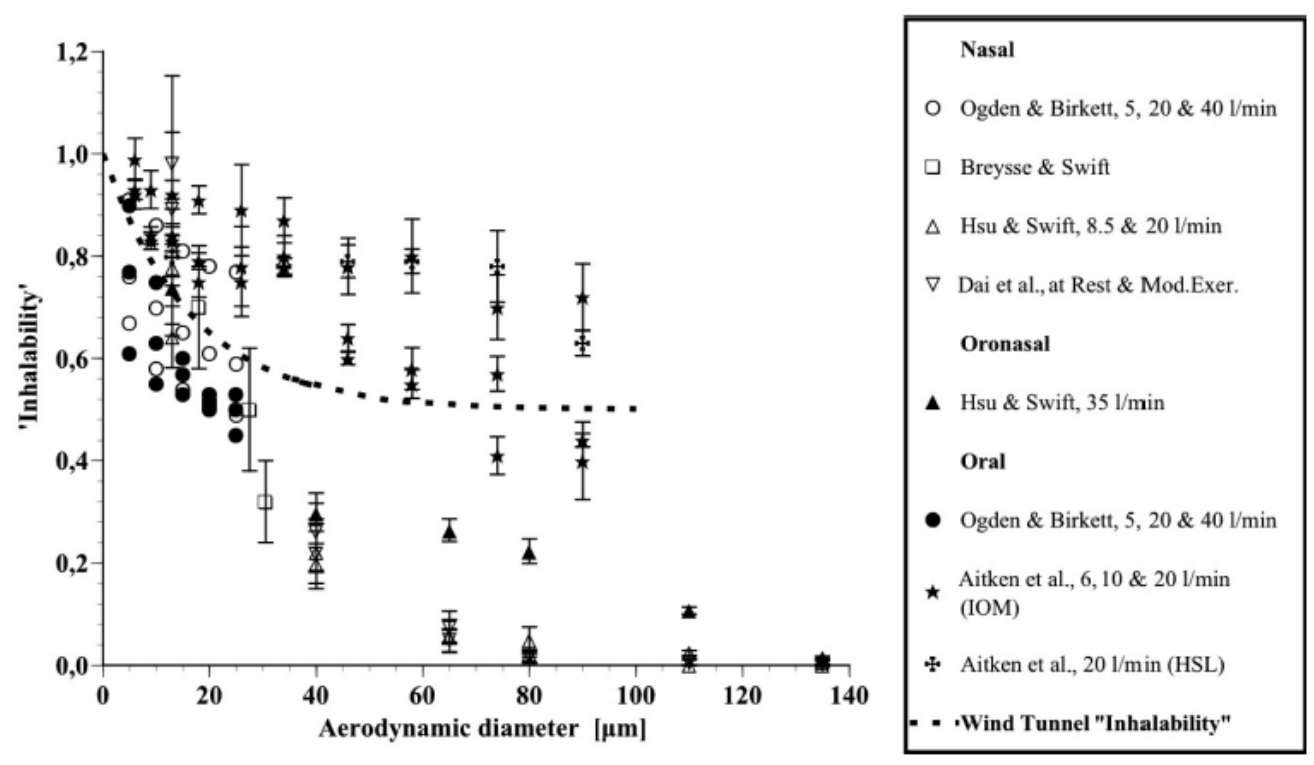

Figure 2: Experimentally determined inhalability in calm air, by different research groups. Error bars represent standard deviations (source: Lidén and Harper, 2006) 
Lidén and Harper (2006) also state that for aerosol sampling, results obtained in wind tunnels differ significantly from those obtained in indoor workplaces, and, therefore, there exists a case for revisiting the sampling convention for the inhalable aerosol fraction adopted by the International Organization for Standardization (ISO), the Comité Européen de Normalisation (CEN), and the American Conference of Governmental Industrial Hygienists (ACGIH) so that it conforms more with the conditions in most workplaces (Lidén and Harper 2006).

\subsection{Currently Available Inhalable Samplers}

As of 2017 , there are three main aerosol samplers used in the United States. The $37 \mathrm{~mm}$ closed face cassette (CFC) is the most common, and also the lowest in cost. The IOM sampler is less commonly used but more accurately aligns with the Inhalable Particulate Mass (IPM) criterion than the CFC (Kenny et al., 1998). The button sampler is the most expensive and least used, but most accurately fits the IPM criterion. The CFC retail price is less than $\$ 1$, the plastic version of the IOM retail price is $\$ 85$, and the steel version retails for \$269. The Button sampler is priced at $\$ 275$ and has an additional cost of $\$ 305$ for a protective shield. All of these are sold by $\mathrm{SKC}$, Inc. with patents still in effect for the button sampler.

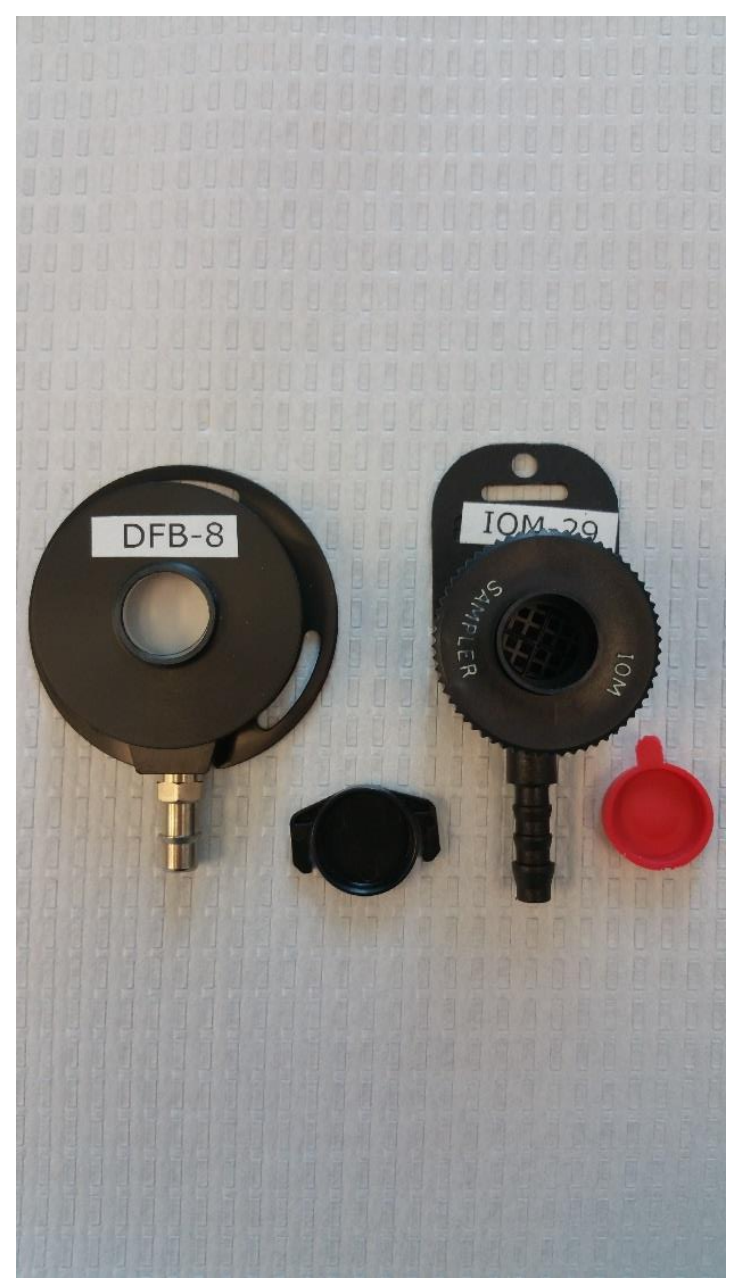

Figure 3: left: DIS sampler right: IOM sampler 


\subsubsection{Sampler Efficiency at $\geq 0.5 \mathrm{~m} \cdot \mathrm{s}^{-1}$ Wind Velocity Studies}

Aizenberg et al. (2000) published a study in which the IOM, 37mm CFC, button, and GSP samplers were all tested under wind speeds of $0.5 \mathrm{~m} \cdot \mathrm{s}^{-1}$ and $2.0 \mathrm{~m} \cdot \mathrm{s}^{-1}$ at varying angles to the aerosol source. These results were compared to the IPM. For particulates with a diameter $70 \mu \mathrm{m}$, the IPM denotes a sampling efficiency of 50.7\% regardless of the ambient conditions. Figure 4 highlights the sampling efficiencies collected by Aizenberg et al. (2000) of each sampler (IOM, GSP, CFC, and button) as compared to the IPM along with Kenny et al. (1997).

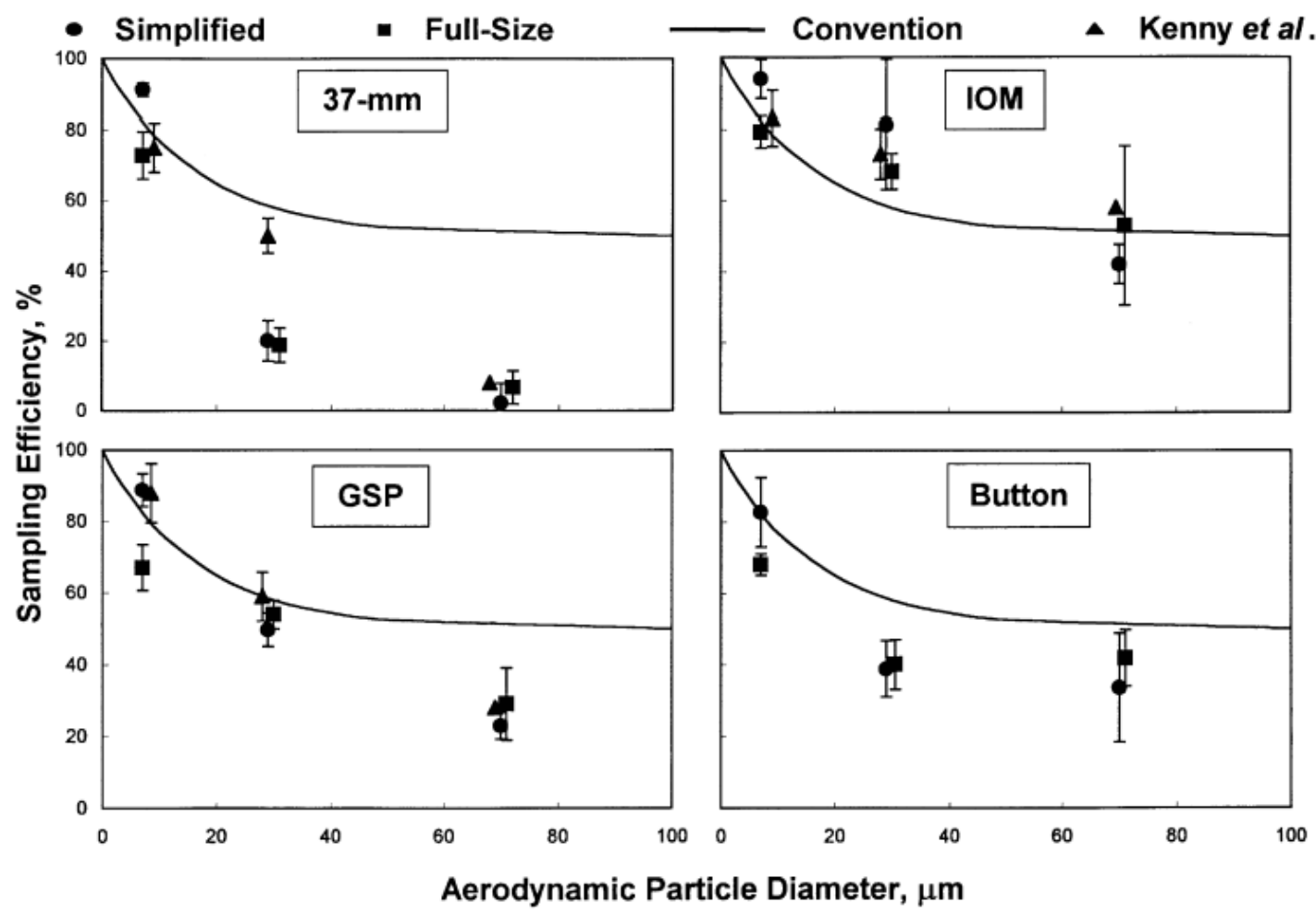

Figure 4: Direction-averaged sampling efficiencies at $0.5 \mathrm{~m} \cdot \mathrm{s}^{-1}$ (source: Aizenberg et al., 1999 and Kenny et al., 1997)

From this study, it was noted that while facing the wind, the IOM sampler oversampled by $41.5 \% \pm 9.5$ with a wind velocity of $0.5 \mathrm{~m} \cdot \mathrm{s}^{-1}$ and $293.3 \% \pm 48$ with a wind velocity of $2.0 \mathrm{~m} \cdot \mathrm{s}^{-1}$. It was also noted that the IOM under-sampled by $40.5 \% \pm 2.2$ at $0.5 \mathrm{~m} \cdot \mathrm{s}^{-1}$ and $39.8 \% \pm 7.1$ at $2.0 \mathrm{~m} \cdot \mathrm{s}^{-1}$ when oriented $90^{0}$ to the wind (Aizenberg et al. 2000). 
As shown in Figures 5 and 6 from Kenny et al. (1997), data demonstrates the sampling efficiencies for the IOM and $37 \mathrm{~mm} \mathrm{CFC}$ at varying wind velocities as compared to the IPM convention. The general trend was for the sampling efficiency of all sampler types to decrease as wind speed increased, but at low wind speeds the IOM showed a slight oversampling, similar to the results acquired by Aizenberg et al. (2000). Also shown, the IOM was closest to the IPM for $1.0 \mathrm{~m} \cdot \mathrm{s}^{-1}$ but efficiency dropped off substantially for $4.0 \mathrm{~m} \cdot \mathrm{s}^{-1}$. The CFC sampler demonstrated substantial undersampling for all particulate diameters above $\sim 25 \mu \mathrm{m}$ regardless of wind speed (Kenny et al., 1997).

It was noted that in a study comparing the IOM to the $37 \mathrm{~mm} \mathrm{CFC}$ in a workplace environment, the IOM

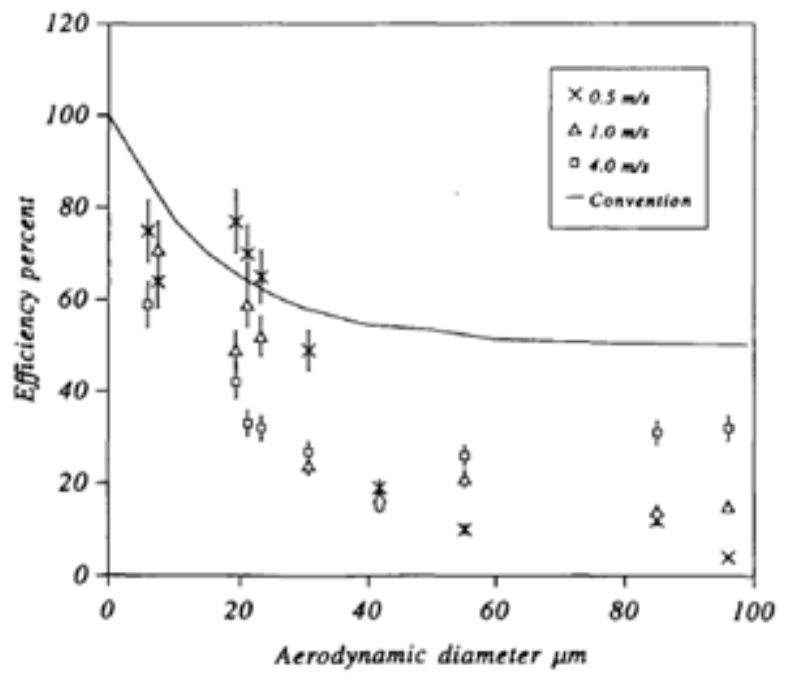

Figure 5: $37 \mathrm{~mm}$ closed-face cassette sampling efficiency (source: Kenny et al., 1997)

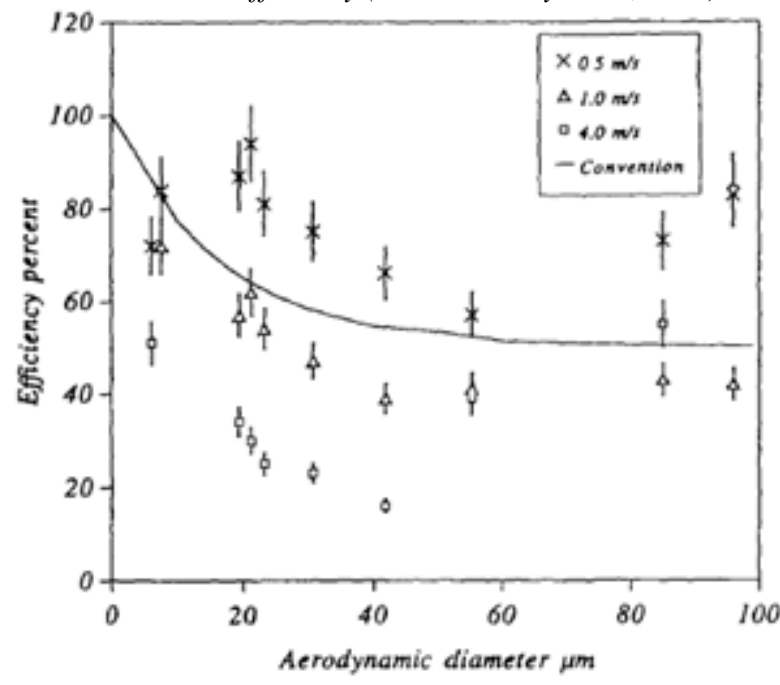

Figure 6: IOM sampling efficiency (source: Kenny et al., 1997) collected 2-3 times as much as the $37 \mathrm{~mm}$ CFC, depending on the aerosol size distribution (Kenny and Bartley, 1995), which is in contrast to a factor of 1.2-1.4 indicated in the laboratory results of from Kenny et al. (1997). This is addressed by the authors who postulate that numerous confounding variables prohibit comparison of laboratory results to field results. Primarily, the laboratory aerosols were well-mixed and the wind speeds were precise, whereas in the field there can be much larger particulates, localized aerosol sources, and very low external wind velocities. It is also noted that the laboratory samplers were given a conductive coating to reduce electrostatic effects, whereas the field-tested samplers were not. (Kenny et al., 1997). 


\subsubsection{Sampler Efficiency at $<0.5 \mathrm{~m} \cdot \mathrm{s}^{-1}$ Wind Velocity Studies}

With substantial research suggesting occupational settings have wind velocities lower than those utilized to create the IPM convention (Baldwin and Maynard, 1998), aerosol sampler efficiency studies have been conducted using velocities well below the IPM threshold, and in 'calm air' environments. In a study carried out by Kenny et al. (1998), researchers carried out a study in which aerosol sampler efficiency was tested in a calm air chamber, rather than a wind tunnel. Excess air was removed from the top of the chamber to balance the compressed air introduced in order to mix and disperse the aerosol. The air extraction rate was adjusted so the pressure inside the test chamber was equal to the external air pressure, and hence there was no net air flow within the working section of the chamber. The absence of measurable air movements within the test section of the chamber was confirmed using a hot wire anemometer, with lower measuring limit 0.05 ms 1 (Kenny et al., 1998). This study compared sampler efficiencies to not only the IPM convention, but to a low-wind inhalability convention outlined in a companion paper of the same journal issue (Aitken et al., 1999). The current IPM convention slope flattens out at $\sim 50 \%$ for particulates with an aerodynamic diameter of $>40 \mu \mathrm{m}$, but that makes assumptions for the inhalability for particulates bigger than $100 \mu \mathrm{m}$. The proposed 'calm air convention' suggested by Aitken et al. (1999) is of the form:

$$
\mathrm{I}\left(\mathrm{d}_{\mathrm{ae}}\right)=1-0.0038 \mathrm{~d}_{\mathrm{ae}}
$$

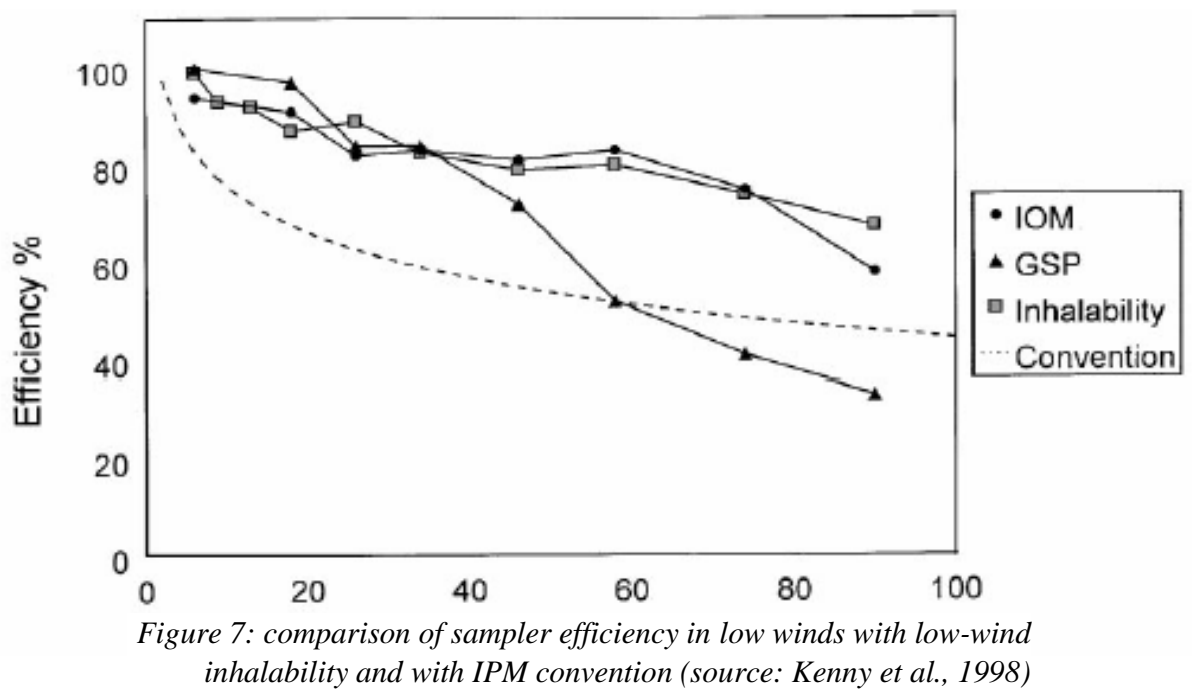


Figure 7 illustrates the substantial difference between the measured calm air inhalability of the study and the IPM convention currently utilized. Shown is data for the GSP sampler produced by Strohlien GmbH and the IOM sampler. Data was limited for the $37 \mathrm{~mm}$ CFC, but is listed in Appendix B and demonstrates a notable drop-off in efficiency, which has been noted in other studies as well. The IOM sampler, as shown in Figure 7 has substantial agreement with the low-wind inhalability, but over-samples according the IPM convention. As a precaution to error, the study noted that it seems unlikely that the increase in efficiency at large particle diameters is a real effect since the particle sedimentation velocities are very large in relation to the sampler inlet velocity (Kenny et al., 1998).

A more recent study carried out by Sleeth and Vincent (2012) built upon earlier works, and provided a great deal of data pertaining to the efficiency of aerosol samplers in low-wind environments. This study utilized a wind tunnel and a heated breathing mannequin. This study tested the IOM, button, GSP, and CFC. Each sampler was tested at wind speeds of $0.10,0.24$, and $0.42 \mathrm{~m} \cdot \mathrm{s}^{-1}$. As noted in other studies, at lower wind speeds, the IOM sampler efficiency was higher than the current IPM convention but came closer as the wind speed increased. At $0.1 \mathrm{~m} \cdot \mathrm{s}^{-1}$, the IOM sampler was

\begin{tabular}{lll}
\hline Wind speed $\left(\mathrm{m} \mathrm{s}^{-1}\right)$ & Sampler & Slope Factor $\left(R^{2}\right)$ \\
\hline 0.10 & IOM & $1.52(0.36)$ \\
& Button & $1.48^{\mathrm{a}}(0.38)$ \\
& GSP & $1.40^{\mathrm{a}}(0.51)$ \\
& CFC & $0.35(0.15)$ \\
0.24 & IOM & $1.30(0.14)$ \\
& Button & $1.12(\mathrm{n} / \mathrm{a})$ \\
& GSP & $1.10^{\mathrm{a}}(0.48)$ \\
0.42 & CFC & $0.27^{\mathrm{a}}(0.19)$ \\
& IOM & $1.18(\mathrm{n} / \mathrm{a})$ \\
& Button & $1.00(\mathrm{n} / \mathrm{a})$ \\
& GSP & $0.92^{\mathrm{a}}(0.27)$ \\
& CFC & $0.26^{2}(0.09)$ \\
\hline
\end{tabular}

Table 1: Slope factor for linear regression (forced through the origin) shown as the ratio of sampling efficiency to mannequin aspiration efficiency (source Sleeth and Vincent, 2012)

Vincent, 2012). Table 1 highlights the Slope factor for linear regression of the ratio of sampler efficiency to mannequin aspiration efficiency for each wind speed tested. It was noted that as wind speed increased, agreement between samplers and the mannequin improved. (Sleeth and Vincent, 2012). One conclusion of the study and apparent in the data represented by 
Table 1 highlights the inefficiency of the CFC, which is the most commonly used sampler in occupational hygiene. All other samplers deviated significantly from the proposed calm air convention as well, and it is suggested by researchers that if the current samplers are to be used at wind speeds $<.24 \mathrm{~m} \cdot \mathrm{s}^{-1}$, physical modifications to better correlate those sampler measurements to the inhalable aerosol fraction may be necessary (Sleeth and Vincent, 2012).

\subsection{Summary}

Even with extensive scientific research culminating in a large body of literature on the subject, there is still much work to be done regarding aerosol sampling. Stemming from the adoption of the current IPM convention, researchers have collected data that provides a strong argument for adopting a new convention which is centered on wind speeds substantially different from that of the IPM convention currently used. Multiple studies have demonstrated that most occupational environments have wind velocities < $0.5 \mathrm{~m} \cdot \mathrm{s}^{-1}$ with many averaging $<0.3 \mathrm{~m} \cdot \mathrm{s}^{-1}$ (Baldwin and Maynard, 1998; Berry and Froude, 1989). Besides occupational settings have lower wind speeds than utilized by the IPM convention, other studies have demonstrated that human aspiration of particulates deviates substantially from the current IPM convention at low wind speeds (Maynard et el., 1997; Baldwin and Maynard, 1998; Hsu and Swift, 1999).

With the literature demonstrating a need for a new IPM convention pertaining to calm air, it is apparent that aerosol samplers need to mimic human aspiration in low-wind conditions that are most prevalent in occupational settings. The current body of literature points towards a greater agreement between the Aitken et al. (1999) proposed 'calm air convention' and the IOM and button samplers. Even so, the IOM and button samplers have been noted as being significantly different from the proposed calm air convention in research carried out under calm air conditions (Sleeth and Vincent 2012). Unfortunately, the IOM and button samplers are substantially more expensive than the most commonly used $37 \mathrm{~mm}$ closed face polystyrene cassette sampler. There is substantial consensus in the literature that the CFC is not an appropriate tool for characterizing inhalable particulate concentrations. 
Overall, the literature points towards a number of conclusions:

- Occupational settings typically have calmer air than utilized for creating the current IPM convention

- The ISO/ACGIH/CEN IPM convention does not accurately portray human aspiration at low wind velocities

- A new IPM convention should include particulates $>100 \mu \mathrm{m}$

- The $37 \mathrm{~mm}$ closed face cassette suffers from poor efficiency and should not be used in characterizing inhalable particulate concentrations

- The most used current inhalable samplers (IOM and button) differ substantially from the Aitken et al. (1999) proposed calm air convention at low wind speeds 


\section{Chapter 3: Research Design and Methods}

\subsection{Objectives of Study}

Given the cost of current size-selective samplers and a push for the use of a lowvelocity IPM, a new sampler was designed by researchers at the Colorado State University Department of Mechanical Engineering that could also be disposable. This study was designed in order to assess the Disposable Inhalable Sampler (DIS) on two fronts. The first objective was to compare the efficiency of the DIS to the IOM sampler. The IOM sampler was chosen because of its agreement with proposed low-wind conventions for inhalable particulates and the current cost prohibition of size selective inhalable samplers. Given that the DIS was designed as an alternative to the IOM sampler, the IOM was selected as the comparison sampler, as opposed to the more commonly used $37 \mathrm{~mm}$ CFC. The null hypothesis of this study was that the DIS and IOM samplers had no statistically significant differences in measurements of aerosols. The second objective was to evaluate the usability of the DIS in a field application. This is important because there are many variables that are not accounted for in a lab setting that can be confounding in the field. As an example, in a field setting in which the subjects are humans, the sampler can be tested for 'wearability' and the propensity for orientation issues, which is not a concern when fixing samplers to mannequins. Another variable that is encountered in the field and absent in a laboratory is strict time constraints placed on the investigators by test subjects' schedules. In the field, the means of calibration or assembly might contribute to difficulties, but these drawbacks might be overlooked in a controlled laboratory setting.

\subsection{Sampling Environment}

The environment utilized for the field assessment was a copper electrorefinery. The area has been sampled extensively and on a regular basis. Typically, as with most copper refineries, the particulates most commonly sampled for include arsenic, silver, lead, copper, selenium, and sulfuric acid. Worker tasks included loading and unloading 
large racks of copper cathodes and anodes from the electrolyte tanks, washing copper cathodes down with hoses, processing finished cathodes, and preparing cathode starter sheets for electrorefining. No forced air ventilation was installed in the facility, except for sporadically placed fans that were turned on and off at irregular intervals. Sampling took place over the course of four days during the summer. Temperatures ranged from $30^{\circ} \mathrm{C}$ to $47^{\circ} \mathrm{C}$ during the day in the tankhouse, with an average relative humidity of $64 \%$. Photos were prohibited to protect production trade secrets.

\subsection{Experimental Setup}

The setup utilized in this study consisted of affixing two sampling pumps to subjects on opposite hips. Hosing would typically across the back and under the opposite arm. A DIS would be clipped to one lapel, while an IOM sampler would be clipped to the opposite lapel on the same worker. The pumps would be started at the same time and the subjects would go about their work in the copper electrorefinery. Some subjects had modified setups due to restrictions posed by their job. As an example, crane operators spent the majority of their day sitting, so the sampling tubes were re-routed over the front rather than across the back.

Area sampling was also utilized, in which pairs of DIS/IOM samplers were placed in areas of well-documented and consistent aerosol concentrations. Typically, these included aisles between electrorefining tanks and sections in which the acidic electrolyte was heated to a prerequisite temperature and pumped throughout the tankhouse. Table 2 summarizes the sampling done for the four days and the type of sampling carried out.

\begin{tabular}{|c|c|c|}
\hline Day & Personal & Area \\
\hline 1 & 15 & 2 \\
\hline 2 & 12 & 4 \\
\hline 3 & 0 & 15 \\
\hline 4 & 0 & 14 \\
\hline
\end{tabular}

Table 2: IOM/DIS sampling pairs per day 


\subsubsection{Field Apparatus}

In this performance evaluation study, over 30 air sampling pumps were utilized, of multiple brands. These included the Universal 44XR, PCXR4, PCXR8, Airchek 52, Airchek XR5000, and the Gilian GilAir Plus. Each pump was calibrated with the procedure prescribed depending on the type of sampler assigned to the pump, since the calibration methods for the IOM sampler and DIS were different. Workers met in the lunch hall before the start of the shift (4:00 am) and the sampling apparatus was attached by researchers. If study participants had issues with their pumps, the time and incident was reported to supervisors, who then notified researchers with the pertinent information. Pumps that had unexpectedly stopped were taken out of the data set, along with their corresponding paired pump. The most common cause of pump stoppage and subsequent loss of data was due to battery issues or flow faults.

\subsubsection{Quantitative Sample Analysis Apparatus}

After samples had been collected and all requisite pertinent data such as pre/post calibration flow rates and runtimes had been logged, the samples were delivered across the country to NIOSH/CDC in Morgantown, WV for analysis. For the purposes of this study, Inductively Coupled Plasma Mass Spectrometry (ICP-MS) was utilized in order to quantify the species concentrations in each sample with low detection limits.

ICP-MS works by aerosolizing the acid-digested sample into the torch of argon plasma. This torch is roughly $6000-10000^{\circ} \mathrm{K}$. The elements in the sample are then ionized and delivered to the mass spectrometer. The ions are separated by mass-to-charge ratio and then are quantified by their signal which is proportional to their concentration. With samples including multiple species, ICP-MS is ideal for multi-element analysis, typical of industrial hygiene applications. An internal reference standard of thallium and yttrium was utilized and the corresponding calibration data, including counts and detection limits is included in Appendix D. 


\subsection{Protocol}

Before carrying out field sampling, a strict protocol was followed to ensure properly acquired data. A standard operating procedure was created in order to uniform handling of the samplers — one for the IOM sampler and one for the DIS.

\subsubsection{IOM Sampler Calibration}

a. Use the IOM sampler in a zip-lok plastic bag (written "Calibration Only" on the bag) for all pre- and post-calibrations. In the field, use a clean location as close as logistically feasible to the sampling site (e.g. office room at the facility).

b. Attach a length of Tygon tubing to the inlet of the pump and connect to the outlet of the assembled IOM sampler.

c. Connect the outlet end of the calibrator via another length of Tygon tubing to an IOM calibration adaptor. The calibration adaptor fits over the IOM sampler to cover the inlet of the IOM sampler. Assure that the foam makes a good connection with the sampler. Tighten the calibrator clamp.

d. Switch on both pump and calibrator and allow to warm up for a minimum of five minutes.

e. Take single readings of the flow-rate, and adjust pump flow if necessary (using screw adjustment or dial-in adjustment, depending on pump) to obtain a reading between 1.9 and $2.1 \mathrm{~L} /$ minute.

f. Clear the calibrator and take a 10-reading average using the appropriate command switch.

g. Record the serial number of the pump and the average flow-rate in Sampling Pump $\log$.

h. The pump is ready for sample collection. 


\subsubsection{DIS Sampler Calibration}

a. Use the disposable inhalable sampler in a zip-lok plastic bag (written "Calibration Only" on the bag) for all pre- and post-calibrations.

b. Attach a length of Tygon tubing to the inlet of the pump and connect to the outlet of the assembled sampler.

c. Connect the outlet end of the calibrator via another length of Tygon tubing to a DIS calibration adaptor. The calibration adaptor fits over the IOM sampler to cover the inlet of the IOM sampler. Assure that the adaptor makes a good connection with the sampler.

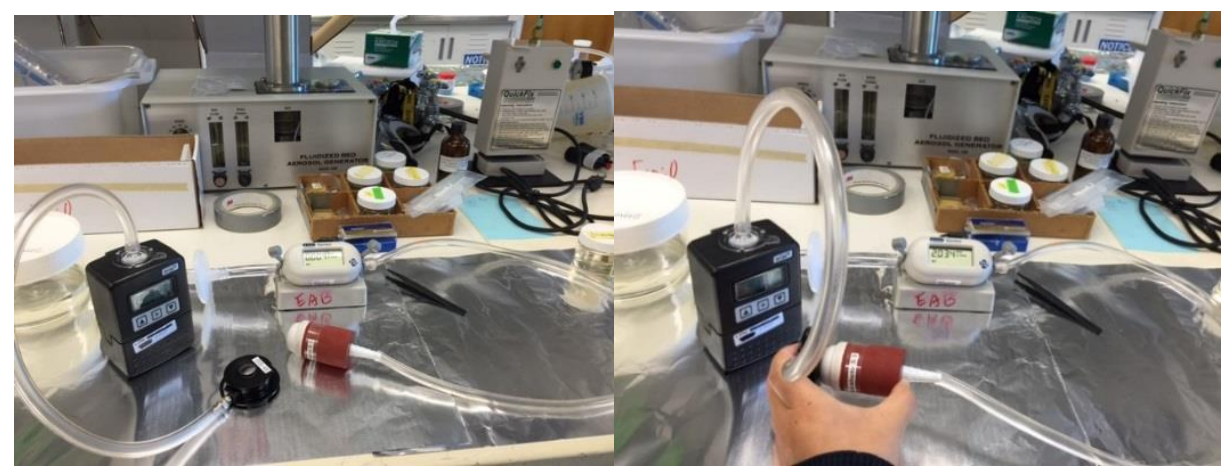

Figure 8: sampling pump calibration for IOM and DIS

d. Switch on both pump and calibrator and allow to warm up for a minimum of five minutes.

e. Take single readings of the flow-rate, and adjust pump flow if necessary (using screw adjustment or dial-in adjustment, depending on pump) to obtain a reading between 1.9 and $2.1 \mathrm{~L} / \mathrm{minute}$.

f. Clear the calibrator and take a 10-reading average using the appropriate command switch.

g. Record the serial number of the pump and the average flow-rate in the Sampling Pump Log.

h. The pump is ready for sample collection. 


\subsubsection{Sampling}

a. Wearing gloves, unscrew the knurled outer ring of an IOM sampler.

b. Select a capsule from a plastic bag, remove the cover from the capsule, place the capsule in the IOM sampler and re-assemble. Ensure a thick o-ring is under the capsule and a thin o-ring over the capsule inlet. Screw the knurled outer ring on tightly and close the inlet of the IOM sampler.

c. Place a label that matches the sampling ID of the cover on the backside of the IOM sampler.

d. Select a sampling pump that has been calibrated to the required flow-rate of 2 $\mathrm{L} /$ minute (+/- $5 \%)$ and attach a length of Tygon tubing to the inlet of the pump. Connect the other end of the tubing to the outlet of an IOM Sampler.

e. Record the sampling ID alongside that of the sampling pump on the sampling data sheet.

f. Attach the pump to a person (personal sampling) and record the worker by an identifier that will be used for any additional samples from the same worker (e.g. their initials) that does not include his/her full name or other personal information.

g. Pumps may be mounted on a worker's belt, or, if a belt is not available or is otherwise impractical, then the worker may be asked to wear a back-brace, when the pump can be attached to the webbing strap at the rear.

h. The IOM sampler is arranged within the workers breathing zone (a 30-cm radius whose center is the center point of the mouth and nose) by clipping the sampler to the shirt collar. An alternative is to duct tape the Tygon tubing and sampler clip to the shoulder strap of a back-brace so that the inlet faces forwards.

i. When two samplers are being worn by a worker at the same time, one is deployed on the left side and one on the right. The sides are randomized to the extent that no sampler is significantly weighted to one side over the other. The side (left or right) is recorded for each sampler deployed.

j. Remove the red cap of the IOM sampler and turn on the pump. The time is recorded. If multiple samplers and pumps are co-located, they are to be uncapped and switched 
on at the same time. Record the type and serial number of all samples co-located with this one.

k. The sampling period is typically 6-8 hours, but this may be varied according to professional judgment in the field

1. During the sampling period, check the operation of the pumps. If the pump has ceased to function, and it is a pump with a display of elapsed time or volume, record this and terminate all other co-located samplers.

m. In the last column of Field Survey Sample Form, record the workers major occupation(s) during the sampling period and the approximate times if more than one activity. In addition, record PPEs, status of local control and room ventilation, any other information that can affect worker's exposure.

n. For all samplers, when sampling is completed, turn off the samplers and record the time each one is switched off. Remove the sampling train(s) from the sampling location, and return them to a clean area for disassembly.

o. Disassemble the sampling train. Remove the capsule of the IOM sampler, place a red cap, place the capped capsule into a red transport clip, put it in a small plastic bad (one for each bag), and write the sample ID on the plastic bag. Keep one sample in one bag.

p. Clean the IOM sampler with wipes to be used for a next sampling. For a next sampling, ensure that the sample IDs attached to the IOM sampler and red transport clip match.

q. Evenly distribute the number of field blanks based on sampling days. Use one plastic bag for one field blank sample.

\subsubsection{Post-Calibration}

a. If the pump is dirty, clean the outside using a wet wipe. Connect the inlet of the pump to the outlet of the IOM "calibration" sampler.

b. Place the IOM calibration adaptor over the sampler and tighten. The IOM calibration adapter is then connected as described above to the outlet of the calibrator. 
c. The pump is switched on and two10-reading averages of the flow-rate are taken. The first is simply a delay to ensure the pump is running properly; record the second average as the post-calibration check.

d. The post-calibration reading is recorded alongside the pump serial number and precalibration reading in the Sampling Pump Log. The difference is calculated, and the sample is considered to be good if the post-calibration flow-rate is within $5 \%$ of the pre-calibration value. If it is outside of this range, record the result but flag the sample. If the post-calibration check is within $5 \%$ of the desired flow-rate for the following sample, it may be considered the pre-calibration for that sample.

e. Recharge the pump batteries according to the manufacturer's instructions.

\subsubsection{Shipping}

a. Plastic "peanut" packing materials should not be used. All samples must be clearly marked on the exterior surface with the serial number of the sample. All samples must be packed so that if sample identifications come loose, it will be possible to determine the serial number. Therefore, they are placed in individual "zip-lok" plastic bags. Sample packages must be placed inside larger boxes, and cushioned with packing materials. The exteriors of the larger boxes must be marked "Fragile" and "This way up".

b. Disposable inhalable samplers: Samplers are completely capped, placed in individual plastic bags, and arranged upright and tightly packed in boxes.

c. IOM samplers: Gloves must be worn when disassembling samplers. Capsules removed from the IOM bodies are capped and placed in the transport clips bearing the original serial number (check with the number written on the IOM sampler body), and placed in an individual plastic bag. They are then arranged upright and tightly packed in boxes.

d. Place a FedEx form on each box and ship back to NIOSH. 


\subsubsection{IOM Sample Extraction}

a. Prepare and label three separate digestion vials for each sample, one for the cap, filter, and IPD.

b. Prepare a squirt bottle of isopropyl alcohol and a cleaned lab benchtop.

c. Wearing gloves, remove the capped capsule from the red transport clip.

d. Remove the red cap, and with forceps, soak a clean filter in isopropyl alcohol. Wipe the inside of the cap thoroughly and deposit the wipe filter into a digestion vial. Wipe with two separate filters.

e. Carefully disassemble the capsule and with cleaned forceps remove the soiled filter and place it in the second digestion vial.

f. With two more filters soaked in isopropyl, wipe the interior walls of the capsule thoroughly twice.

g. Cap all digestion vials and check the labels. There should be a label for the sample number and whether it was a cap, interior wall, or filter vial.

\subsubsection{DIS Sample Extraction}

All steps for the DIS are the same as the IOM, up until C.

a. Remove rubber band and cover from DIS, and then remove friction sealed cap, carefully so as not to shake the internal capsule.

b. With forceps, soak a clean filter in isopropyl alcohol. Wipe the inside of the cap thoroughly and deposit the wipe filter into a digestion vial. Wipe with two separate filters.

c. Remove the polycarbonate capsule, without disturbing the soiled filter. With two more filters soaked in isopropyl, wipe the interior walls of the capsule thoroughly twice and deposit them into a second digestion vial using clean forceps. 
d. With cleaned forceps remove the soiled filter and place it in the third digestion vial.

e. Cap all digestion vials and check the labels. There should be a label for the sample number and whether it was a cap, interior wall, or filter vial.

\subsubsection{Quantitative Chemical Analysis}

Chemical Analysis was carried out in the NIOSH laboratory in Morgantown, WV. This procedure fits very closely to the NIOSH 7303 method, with some modification. Trials with various digesting agents were done with invalid samples in order to assess the most effective procedure. Initially, an Aqua Regia mixture with a molar ratio of 3:1 conc. $\mathrm{HCl}$ : conc. $\mathrm{HNO}_{3}$ was tested in order to have agreement with the NIOSH 7303 method and also due to the ability of Aqua Regia to dissolve a number of chemical species that neither $\mathrm{HCl}$ nor $\mathrm{HNO}_{3}$ can on their own.

Aqua Regia was not used for the final procedure for a number of reasons. Although Aqua Regia did dissolve the test samples well, it was a concern that the $\mathrm{HCl}$ would precipitate any silver when the dilutions were made with water. It was also noted that too much chloride in the sample aerosol could cause inaccurate readings by the ICP-MS for arsenic-containing species (Sheppard et al., 1990). The determination of low level arsenic by conventional ICP-MS is typically hampered by the ${ }^{40} \mathrm{Ar}^{35} \mathrm{Cl}^{+}$interference at with ${ }^{75} \mathrm{As}^{+}$ (Thomas, 2004). For these reasons, Aqua Regia was not used in order to eliminate the $\mathrm{HCl}$ from causing signal issues.

Each sample was analyzed in a solution of $1 \% \mathrm{C}_{2} \mathrm{H}_{6} \mathrm{O}$ (Ethanol, EtOH) because literature and internal experimentation has indicated that $\mathrm{EtOH}$ at low concentrations increases the ion signal for arsenic (Demesmay et al., 1994; Munoz et al., 2014; Thomas, 2004). This phenomenon of signal enhancement can be explained by a charge transfer reaction occurring between the positively charged carbon species and the high ionization energy As $(9.81 \mathrm{eV})$ in the central channel of the plasma (Guo et al., 2011).

For all elemental analysis, a Perkin Elmer 300 D Inductively Coupled Plasma Mass Spectrometer was used. The instrument was operated at 1400 Watts RF power and the 
mass detector was operated in Peak Hopping Mode. Measurements for Copper, selenium, arsenic, argon chloride ion, krypton and Yttrium were made in Kinetic energy discriminator mode. Yttrium-89 was the internal standard. Argon chloride-77 and krypton-84 were measured to be used in isobaric overlap corrections. Silver-107 and yttrium-89 were measured in standard mode. Raw data as counts per second were exported to Excel spreadsheets, and linear calibration curves were calculated by routines internal to the Excel spreadsheet, which can be found in Appendix D.

a. Before proceeding, make sure each sample is labeled properly, and the materials are set up to allow for a smooth flow of work and no confusion when dealing with such large quantities of samples.

b. In hood, fill water bath to a level that will not overflow when full test-tube rack is inserted. Heat water bath to $95^{\circ} \mathrm{C}$ and cover, to avoid evaporative losses. The temperature may be set higher because the insertion of the samples will inevitably bring the temperature down. Once the temperature re-approaches $95^{\circ} \mathrm{C}$ with the rack, it may be adjusted to $95^{\circ} \mathrm{C}$.

c. Under ventilation and with good working space, place a manageable number of samples in a test tube rack. Dissolving samples produces $\mathrm{NO}_{2}$ gas.

d. In each digestion tube, pipette $4.0 \mathrm{~mL}$ of concentrated $\mathrm{HNO}_{3}$ (Nitric acid). Do not cap each vial tightly, as the oxidative reaction of $\mathrm{HNO}_{3}$ produces $\mathrm{NO}_{2}$ gas that can build up pressure and explode digestion vials if it cannot escape.

e. Starting from the beginning of the order, slowly pipette $1.0 \mathrm{~mL}$ of $30 \% \mathrm{H}_{2} \mathrm{O}_{2}$ into each vial, and gently stir. It is important to pipette slowly as the introduction of $\mathrm{H}_{2} \mathrm{O}_{2}$ can cause intense bubbling that can overflow, invalidating samples.

f. After waiting one hour at room temperature, with all digestion vials loosely capped, place the full test-tube rack into the heated water bath, regularly checking the temperature to assure it is properly maintained and that digestion vials do not overflow. 
g. After filling the water bath to capacity, allow one hour for full digestion. Remove racks and cool to room temperature.

h. Dilute each sample to $40 \mathrm{~mL}$ using ultra-pure analytical grade deionized water.

i. Bring each solution up to $1 \% \mathrm{C}_{2} \mathrm{H}_{6} \mathrm{O}$ (Ethanol).

j. Spike each digested solution with Spex Claritas $10 \mu \mathrm{g} \cdot \mathrm{mL}^{-1}$ multi-element solution for use as internal standard.

k. Vortex each sample and prepare for ICP-MS uptake.

\subsection{Data Analysis}

All data for this study was exported from ICP-MS to excel. Appendix E contains all raw data associated with this study. Copper concentrations were the main focus of this experiment because the number of samples below the LOQ were small. Other elements were analyzed but there were many pairs that were below the LOQ. Other elements that were analyzed included: arsenic, silver, and selenium. In order to evaluate the performance of the DIS with respect to the IOM sampler, it was necessary to carry out a number of statistical tests. The software used to carry out the statistical analysis of this study was Statistical Analysis System (SAS version 9.4), developed by the SAS institute. The use of PROC with a MIXED procedure was utilized, as was linear regression analyses. For regression analyses, the outcome variable assessed and therefore the $y$ outcome (dependent variable) was DIS performance, since the IOM sampler was the standard of comparison. This was done for sample concentrations for:

1) $\mathrm{Cu}-\mathrm{DIS}$ total vs. $\mathrm{Cu}-\mathrm{IOM}$ total per personal, area, and all

2) $\mathrm{Cu}$-DIS filter vs. $\mathrm{Cu}-\mathrm{IOM}$ filter per personal, area, and all

Besides sample concentrations, mass totals for certain portions (wall deposits, filter, and cap) of each sample were a focus of statistical analysis. Of interest was the proportion the cap wipe samples made of the total mass for each sample. This was done in order to assess particle loss from shipping. This analysis was not separated by personal 
and area sampling, as that would be irrelevant. For this analysis, masses that were $<$ LOQ were converted to LOQ $/ \sqrt{2}$ (Croghan et al., 2003; Ogden, 2010). 


\section{Chapter 4: Results}

This study was designed to evaluate the performance of a newly developed disposable inhalable sampler (DIS) against the performance of the commercial IOM sampler and to assess the practicality of the DIS in the field.

\subsection{Exposure Measurements}

As mentioned in Method section, each sampler was analyzed separately for the concentrations of filter, wall deposits, and cap - 51 pairs of samplers generated 408 data points. Tables 3 and 4 showed summary of the exposure measurements for area samples,

personal samples, and a combined total. For the total amount $\mathrm{mg} / \mathrm{m}^{3}$, the highest recorded personal sample was $0.337 \mathrm{mg} / \mathrm{m}^{3}$ for the DIS and $0.2499 \mathrm{mg} / \mathrm{m}^{3}$ for the matching IOM sampler. The highest recorded personal sample for the IOM sampler was $0.7608 \mathrm{mg} / \mathrm{m}^{3}$ and $0.3108 \mathrm{mg} / \mathrm{m}^{3}$ for the matching DIS. For area samples, the highest recorded DIS sample was $0.1337 \mathrm{mg} / \mathrm{m}^{3}$ and the $0.0012 \mathrm{mg} / \mathrm{m}^{3}$ for the matching IOM sampler. The highest area sample for the IOM sampler was $0.7374 \mathrm{mg} / \mathrm{m}^{3}$ and $0.0349 \mathrm{mg} / \mathrm{m}^{3}$ for the matching DIS. The OSHA PEL for copper (except fume) is a time-weighted average (TWA) of $1 \mathrm{mg} / \mathrm{m}^{3}$. In order to compare the personal exposure measurements to the OSHA PEL, an 8-hour TWA exposure was calculated using Equation 1. With the highest personal sampling having a TWA of $0.801 \mathrm{mg} / \mathrm{m}^{3}$, none of the samples collected during this study exceeded the OSHA PEL.

$$
\bar{x}=\frac{\sum_{i=1}^{n} \text { Time }_{i} \text { Concentration }_{i}}{\sum_{i=1}^{n} \text { Time }_{i}}
$$

Equation 1: Time weighted average formula

For area samples, the geometric mean of the collected total concentrations was $0.0134(3.3981 \mathrm{SD}) \mathrm{mg} / \mathrm{m}^{3}$ for the IOM samplers and $0.0320\left(2.7526 \mathrm{mg} / \mathrm{m}^{3} \mathrm{SD}\right)$ for the DIS. For personal samples, the geometric mean of the collected total concentrations was $0.0397(3.8986 \mathrm{SD}) \mathrm{mg} / \mathrm{m}^{3}$ for the IOM samplers and $0.0456(2.7499 \mathrm{SD}) \mathrm{mg} / \mathrm{m}^{3}$ 
for the DIS. Considering all categories of samples combined for each sampler, the geometric means were 0.0219 (3.9958 SD) $\mathrm{mg} / \mathrm{m}^{3}$ for the IOM samplers and 0.0376 (2.7662 SD) $\mathrm{mg} / \mathrm{m}^{3}$ for the DIS. Although not a significant focus of this study and the interpretation of results, the total collected particulate mass harmonic mean was 0.0097 $\mathrm{mg} / \mathrm{m}^{3}$ for all IOM samples and $0.0175 \mathrm{mg} / \mathrm{m}^{3}$ for all DIS samples.

$A=\frac{1}{n} \sum_{i=1}^{n} a_{i}=\frac{a_{1}+a_{2}+\cdots+a_{n}}{n}$

Equation 2: Arithmetic mean

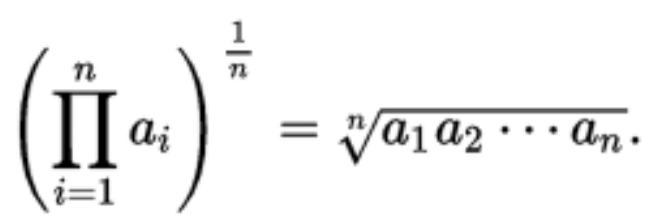

Equation 3: Geometric mean

\begin{tabular}{|c|c|c|c|c|c|c|c|c|}
\hline \multicolumn{9}{|c|}{ IOM } \\
\hline Type & component & $\mathrm{n}$ & Arithmetic Mean & Arithmetic SD & Geometric Mean & Geometric SD & Min & Max \\
\hline \multirow{4}{*}{ Area } & Filter & \multirow{4}{*}{28} & 0.0116 & 0.0097 & 0.0077 & 2.8871 & 0.0005 & 0.0467 \\
\hline & Interior & & 0.0282 & 0.1354 & 0.0023 & 4.3395 & 0.0002 & 0.7188 \\
\hline & Cap & & 0.0019 & 0.0018 & 0.0013 & 2.5484 & 0.0002 & 0.0094 \\
\hline & Total & & 0.0417 & 0.1368 & 0.0134 & 3.3981 & 0.0012 & 0.7374 \\
\hline \multirow{4}{*}{ Personal } & Filter & \multirow{4}{*}{23} & 0.0661 & 0.1237 & 0.0263 & 3.5256 & 0.0038 & 0.5697 \\
\hline & Interior & & 0.0366 & 0.0906 & 0.0062 & 3.3322 & 0.0009 & 0.3932 \\
\hline & Cap & & 0.0079 & 0.0181 & 0.0023 & 3.7724 & 0.0005 & 0.0780 \\
\hline & Total & & 0.1105 & 0.1914 & 0.0397 & 3.8986 & 0.0005 & 0.7608 \\
\hline \multirow{4}{*}{ Combined } & Filter & \multirow{4}{*}{51} & 0.0361 & 0.0868 & 0.0134 & 3.6657 & 0.0005 & 0.5697 \\
\hline & Interior & & 0.0320 & 0.1163 & 0.0036 & 5.0877 & 0.0002 & 0.7188 \\
\hline & Cap & & 0.0046 & 0.0124 & 0.0017 & 3.1627 & 0.0002 & 0.0780 \\
\hline & Total & & 0.0727 & 0.1656 & 0.0219 & 3.9958 & 0.0012 & 0.7608 \\
\hline
\end{tabular}

Table 3: IOM $\mathrm{mg} / \mathrm{m}^{3}$ summary of exposure measurements

\begin{tabular}{|c|c|c|c|c|c|c|c|c|}
\hline \multicolumn{9}{|c|}{ DIS } \\
\hline Type & component & $\mathrm{n}$ & Arithmetic Mean & Arithmetic SD & Geometric Mean & Geometric SD & Min & Max \\
\hline \multirow{4}{*}{ Area } & Filter & \multirow{4}{*}{28} & 0.0238 & 0.0180 & 0.0161 & 3.3913 & 0.0001 & 0.0772 \\
\hline & Interior & & 0.0087 & 0.0096 & 0.0051 & 3.0168 & 0.0006 & 0.0441 \\
\hline & Cap & & 0.0236 & 0.0213 & 0.0041 & 5.8002 & 0.0001 & 0.0867 \\
\hline & Total & & 0.0458 & 0.0375 & 0.0320 & 2.7526 & 0.0008 & 0.0772 \\
\hline \multirow{4}{*}{ Personal } & Filter & \multirow{4}{*}{23} & 0.0478 & 0.0559 & 0.0289 & 2.6851 & 0.0043 & 0.1977 \\
\hline & Interior & & 0.0274 & 0.0423 & 0.0110 & 3.8244 & 0.0020 & 0.1385 \\
\hline & Cap & & 0.0042 & 0.0075 & 0.0015 & 4.3317 & 0.0001 & 0.0342 \\
\hline & Total & & 0.0793 & 0.1004 & 0.0456 & 2.7499 & 0.0125 & 0.3377 \\
\hline \multirow{4}{*}{ Combined } & Filter & \multirow{4}{*}{51} & 0.0346 & 0.0412 & 0.0209 & 3.1573 & 0.0001 & 0.1977 \\
\hline & Interior & & 0.0171 & 0.0304 & 0.0072 & 3.5450 & 0.0006 & 0.1385 \\
\hline & Cap & & 0.0092 & 0.0170 & 0.0026 & 5.4336 & 0.0001 & 0.0867 \\
\hline & Total & & 0.0610 & 0.0740 & 0.0376 & 2.7662 & 0.0008 & 0.3377 \\
\hline
\end{tabular}

Table 4: DIS $\mathrm{mg} / \mathrm{m}^{3}$ summary of exposure measurements 
As expected, with all samples the filter held the most particulate mass, followed by the interior, and then the cap. Of note, the standard deviations for every type of sample were very high relative to their average particulate mass, for both IOM samples and DIS samples - but particularly for those collected by the IOM sampler. The DIS total particulate arithmetic mean was $9.8 \%$ higher than the IOM sampler for area samples and $138.8 \%$ higher for the geometric mean. The DIS arithmetic mean was $28.2 \%$ lower than the IOM sampler for personal samples and $14.9 \%$ higher for the geometric mean. The DIS arithmetic mean was $\mathbf{1 6 . 1 \%}$ lower than the IOM sampler for all sample types combined and the geometric mean was $71.7 \%$ higher. Because the geometric and arithmetic means are substantially different and the standard deviations are considerably large, this indicates that the data is skewed in one direction (i.e., towards lower concentrations in the distribution).

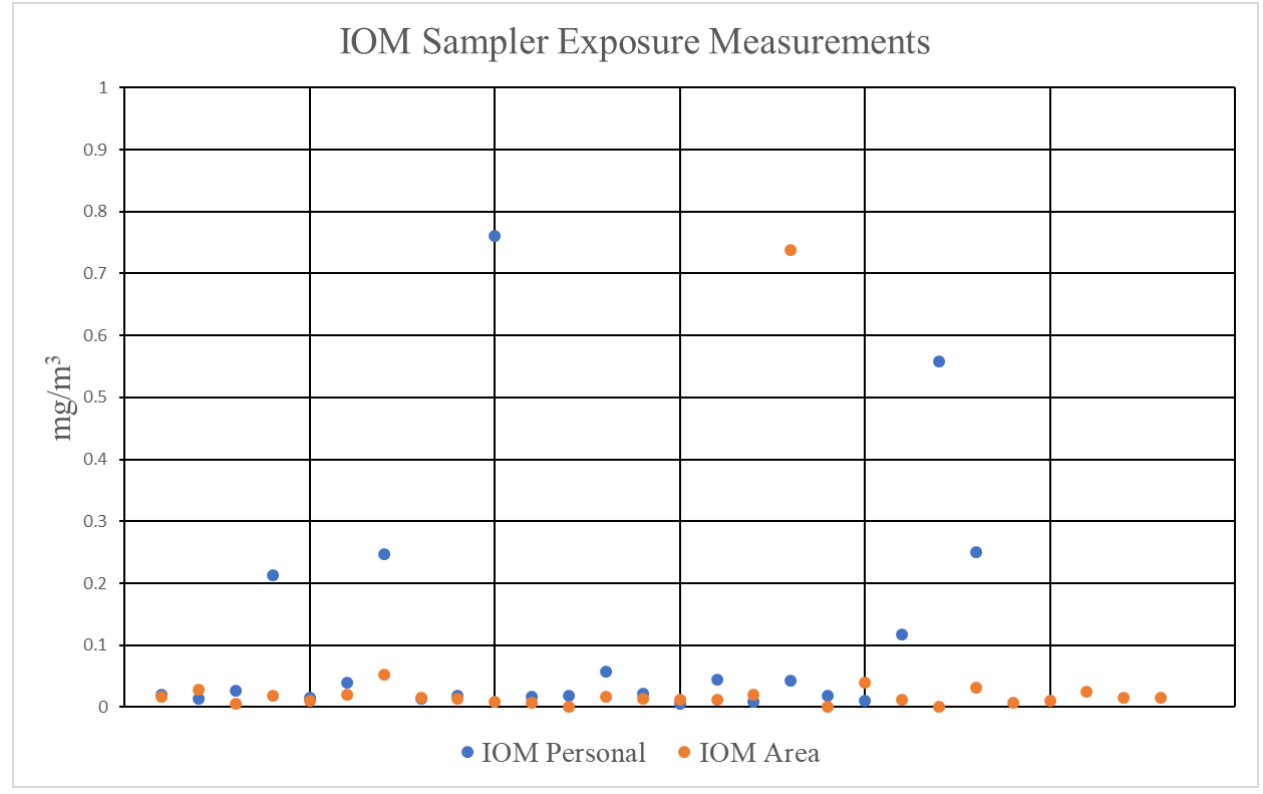

Figure 5: IOM sampler exposure measurements 


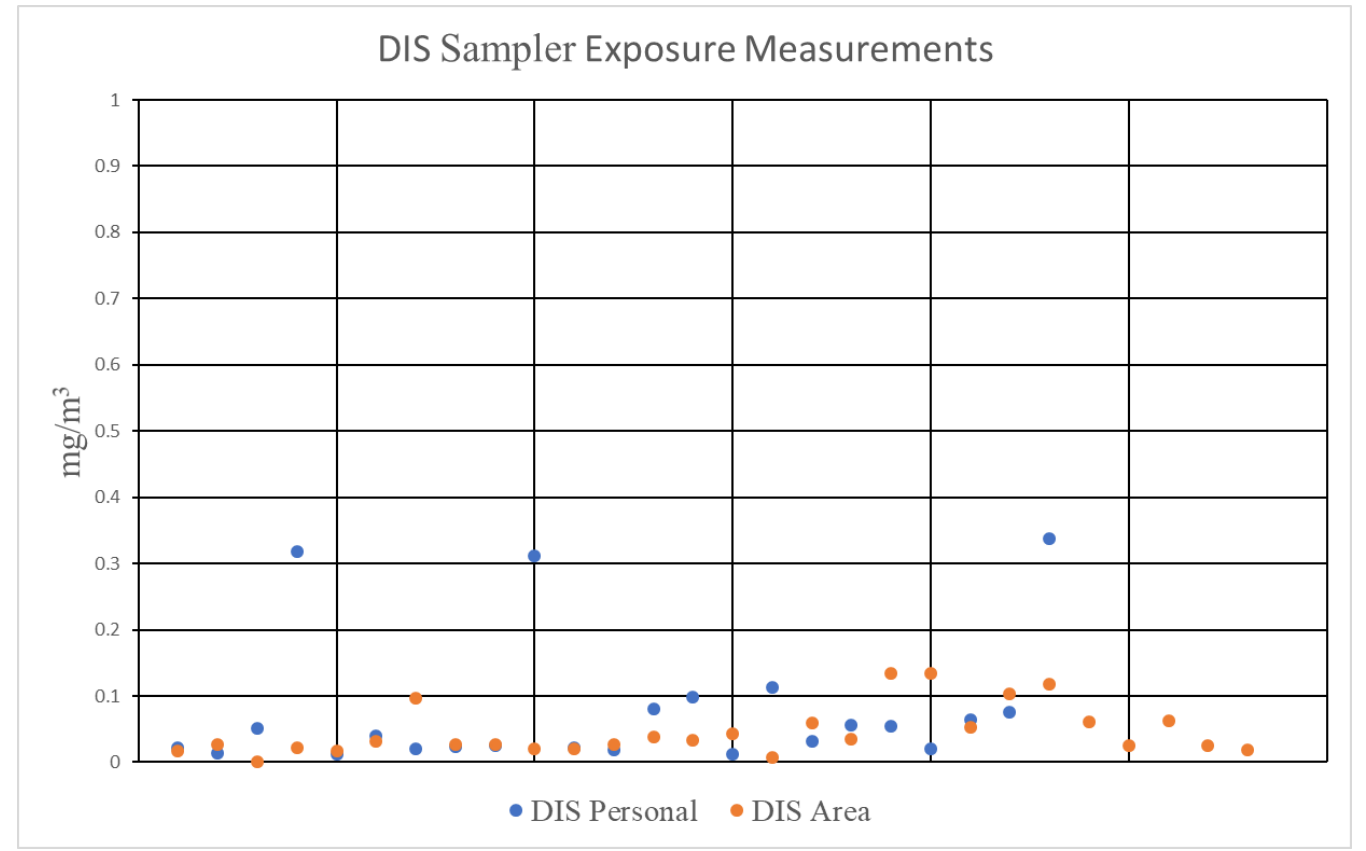

Figure 6: DIS exposure measurements

\subsection{Transportation Loss}

One important variable of interest in this study was the transportation losses for each sampler. This is defined as the particulate mass that was recovered from the cap using solvent-soaked wipes in comparison to the total sample mass, as a percentage. Tables 5 and 6 summarize the transportation losses for the IOM sampler and DIS. As stated previously, although not a significant focus of the interpretation of results, the harmonic mean was $3.43 \%$ for all IOM samples and $2.87 \%$ for all DIS samples.

\begin{tabular}{|c|c|c|c|c|c|c|}
\hline \multicolumn{7}{|c|}{ IOM } \\
\hline Type & Arithmetic Mean & Arithmetic SD & Geometric Mean & Geometric SD & Min & Max \\
\hline Area & $14.37 \%$ & $10.33 \%$ & $9.92 \%$ & $294.82 \%$ & $0.23 \%$ & $41.53 \%$ \\
\hline Personal & $9.18 \%$ & $8.92 \%$ & $5.85 \%$ & $291.02 \%$ & $0.52 \%$ & $39.90 \%$ \\
\hline Overall & $12.03 \%$ & $9.97 \%$ & $7.82 \%$ & $299.59 \%$ & $0.23 \%$ & $41.53 \%$ \\
\hline
\end{tabular}

Table 5: IOM Sampler transportation losses 


\begin{tabular}{|c|c|c|c|c|c|c|}
\hline \multicolumn{7}{|c|}{ DIS } \\
\hline Type & Arithmetic Mean & Arithmetic SD & Geometric Mean & Geometric SD & Min & Max \\
\hline Area & $21.62 \%$ & $17.59 \%$ & $12.82 \%$ & $349.79 \%$ & $0.76 \%$ & $64.90 \%$ \\
\hline Personal & $6.52 \%$ & $10.17 \%$ & $3.33 \%$ & $110.71 \%$ & $0.39 \%$ & $49.05 \%$ \\
\hline Overall & $14.81 \%$ & $16.44 \%$ & $6.98 \%$ & $117.86 \%$ & $0.39 \%$ & $64.90 \%$ \\
\hline
\end{tabular}

Table 6: DIS transportation losses

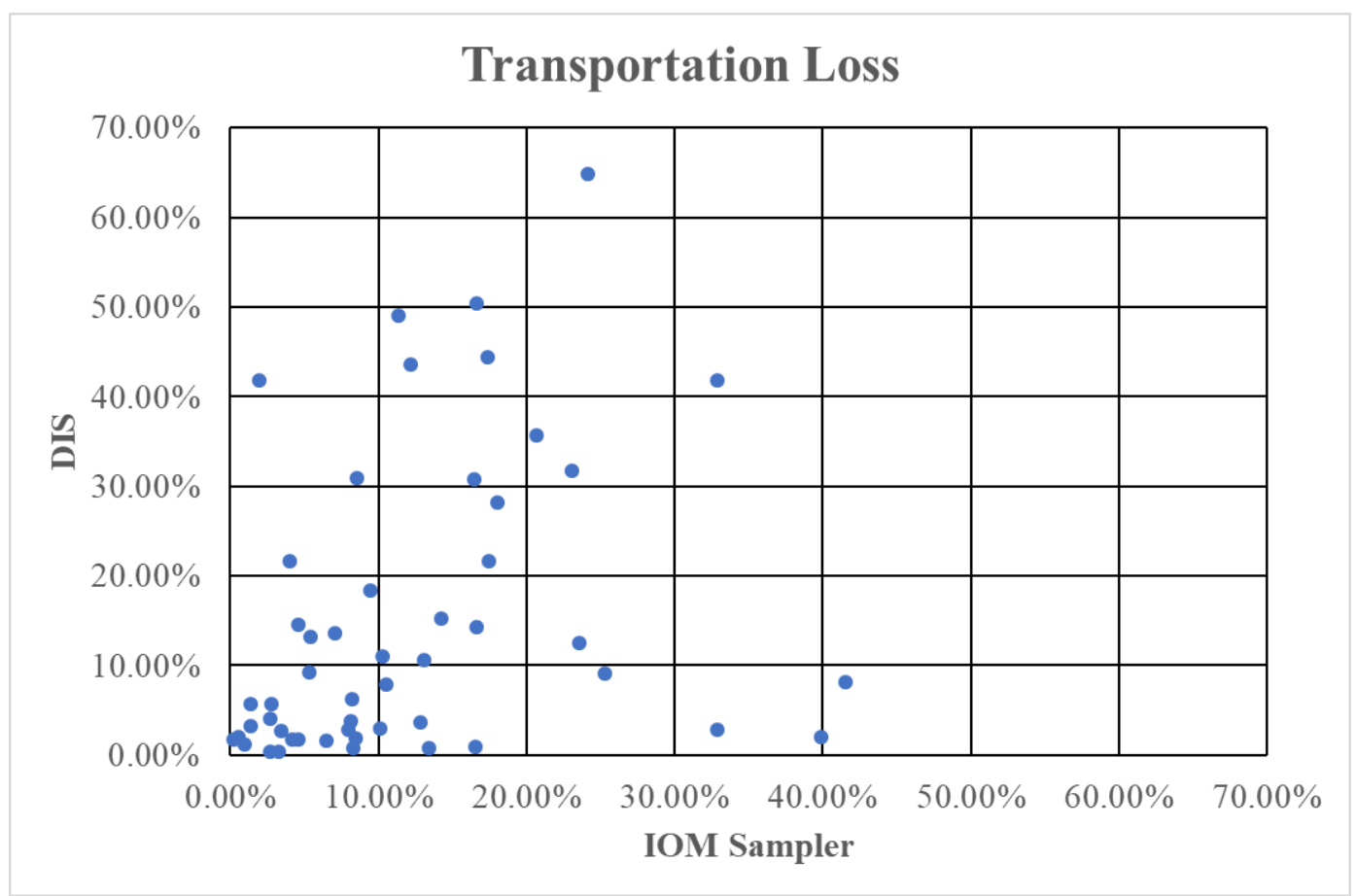

Figure 7: IOM vs. DIS transportation loss scatter plot

Overall, both the IOM sampler and the DIS follow the same trends pertaining to transportation loss. To further quantify the agreeability between the IOM sampler and the DIS in terms of transportation loss, a fixed-effect analysis of variance (ANOVA) was carried out. This test was done in order to determine if the differences between the means of the two samplers were statistically significant. The null hypothesis states that the two samplers, in respect to transportation losses, have no statistically significant differences. With $\alpha=0.05$, the P-value for the ANOVA was determined to be 0.1196 . Since in this analysis $\mathrm{P}>\alpha$, we do not reject the null hypothesis. 


\subsection{Comparison of Concentration Between DIS and IOM Sampler}

For this study, the performance of the DIS was the dependent variable compared to the IOM sampler. Raw data and log-transformed data was used to interpret data sets. Figure 6 illustrates each data pair plotted as the values of concentration ratios of DIS/IOM. If the two samplers collected the same amount of particulate matter, then the value should be 1.0, denoted by the red line on the graph. A substantial amount of these pairs is above 1.0, demonstrating that with the vast majority of pairs, the particulate mass collected by the DIS was higher than the IOM sampler.

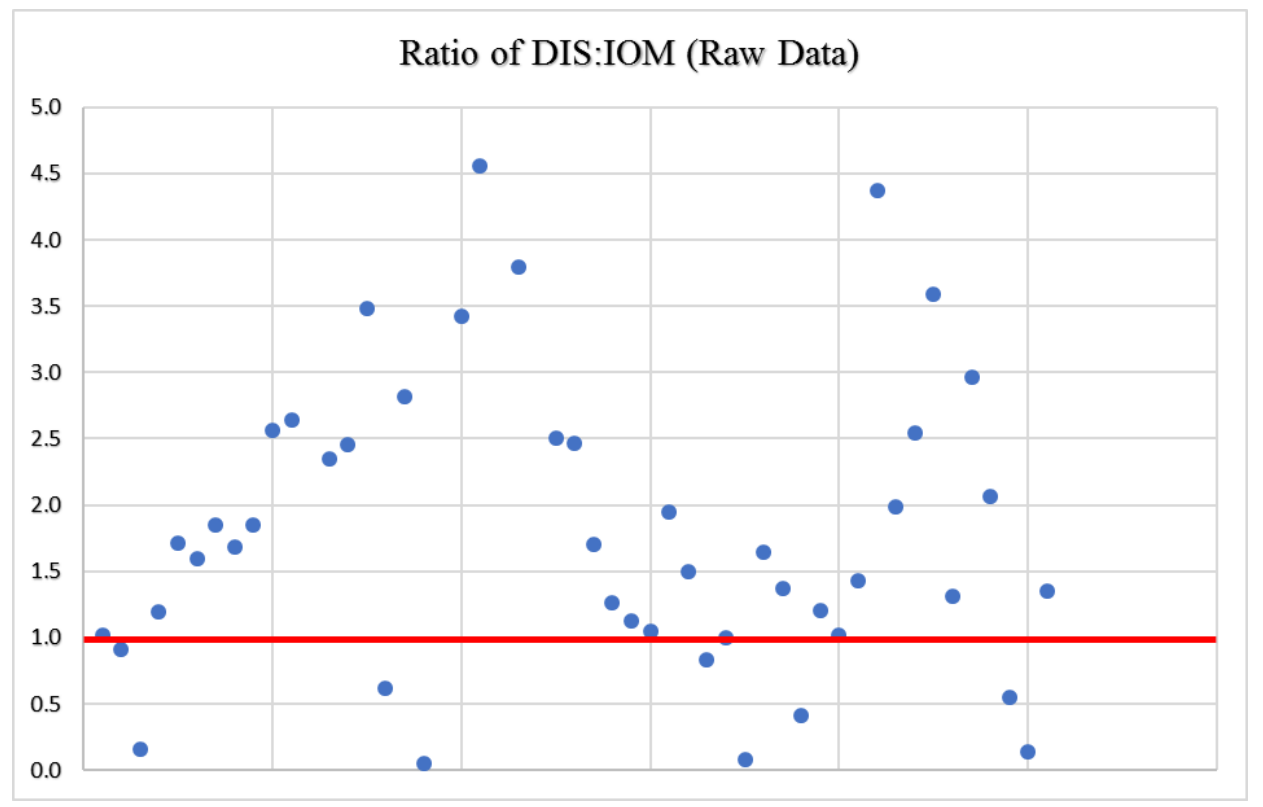

Figure 8: Ratio of concentrations between the DIS sampler and the IOM sampler using raw data (red line = 1)

In order to better understand the agreement between the DIS and IOM sampler, Figure 8 plots area and personal samples for sample pairs as a regression analysis. The data pairs are compared to a slope of 1 - an $\mathrm{R}^{2}$ value is the explained variation divided by the total variation within the data, and as such as it approaches 1, the model explains the variability of the data in respect to the mean. Figure 8 highlights that the personal samples had much better agreement compared to the area samples. 


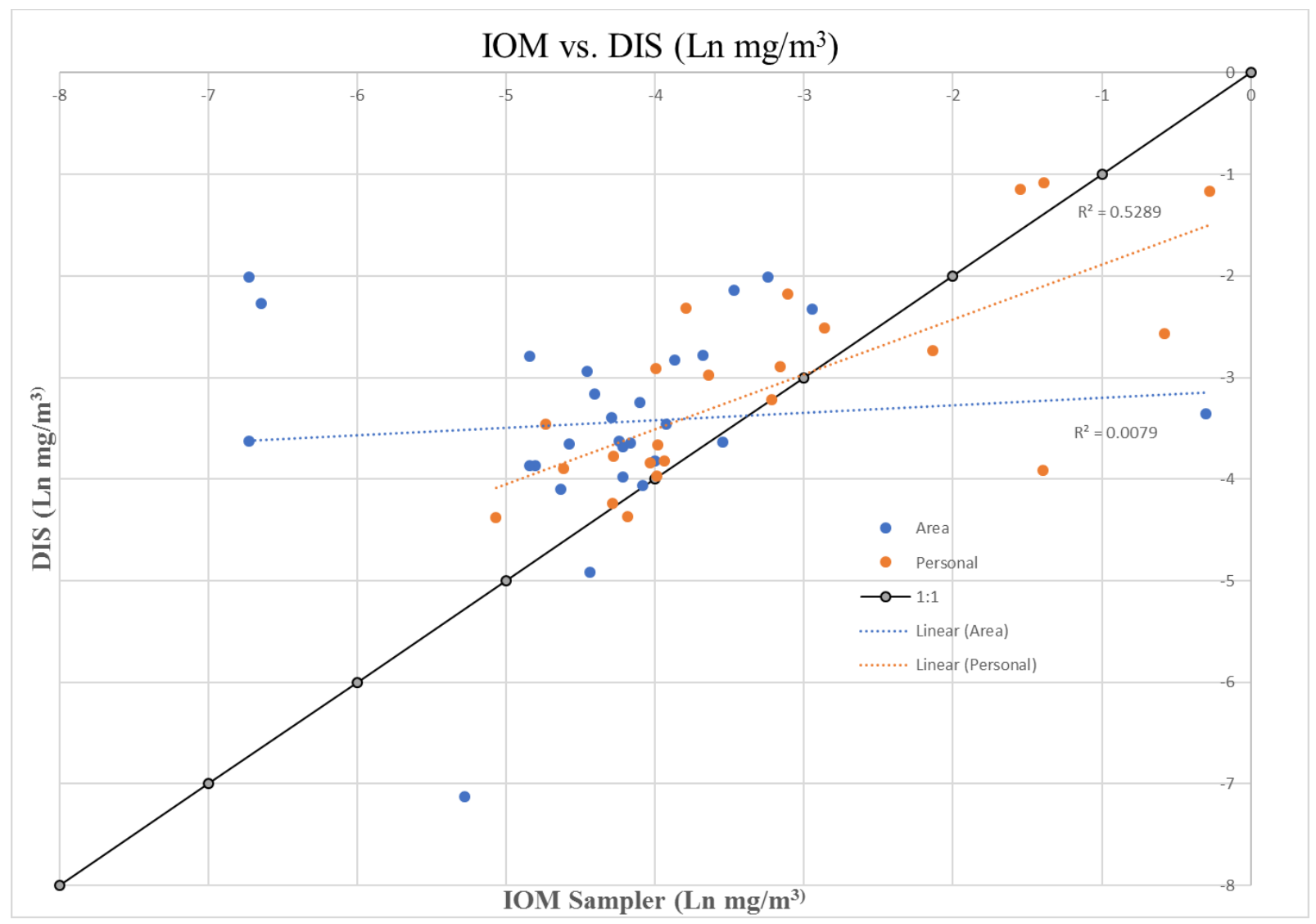

Figure 9:Log-transformed mass concentrations between pairs of samplers. The diagonal line represents 1:1 relationship.

With so many data points, it was imperative to utilize SAS to quantify the agreeability between these two samplers. With so many data points to account for each sample component for each type of sample of both samplers, statistical quantification was a large focus of this study and the interpretation of results. Regression analyses were carried out for every component of each type of sample. Pairwise comparisons were assessed using Proc Mixed and Pearson's correlation coefficients and their corresponding p-values were calculated to determine how well paired samples agreed. Table 7 is a summarization of the SAS results. The correlation coefficients for each component were substantially higher for personal samples than all others, as was the adjusted $\mathrm{R}^{2}$. 


\begin{tabular}{|c|c|c|c|c|c|}
\hline \multicolumn{6}{|c|}{ Regression Analysis } \\
\hline Component & Type & Correlation coefficient & $\mathrm{P}$-value & Regression Equation & Adjusted R-square \\
\hline \multirow{3}{*}{ Filter only } & Personal & 0.885374609 & $<.0001$ & Ln_DIS $=-1.01954+0.69400 *$ Ln_IOM & 0.7736 \\
\hline & area & 0.214712581 & 0.2725 & Ln_DIS $=-2.92760+0.24731 *$ Ln_IOM & 0.0094 \\
\hline & Combined & 0.547365115 & $<.0001$ & Ln_DIS $=-1.77724+0.48445 *$ Ln_IOM & 0.2853 \\
\hline \multirow{3}{*}{ Interior } & Personal & 0.49071277 & 0.0174 & Ln_DIS $=-2.50770+0.39402 *$ Ln_IOM & 0.2046 \\
\hline & area & 0.288813778 & 0.1361 & Ln_DIS $=-3.96113+0.21728 *$ Ln_IOM & 0.0482 \\
\hline & Combined & 0.453294706 & 0.0008 & Ln_DIS $=-2.94842+0.35263 *$ Ln_IOM & 0.1893 \\
\hline \multirow{3}{*}{ Cap } & Personal & 0.402872322 & 0.0566 & Ln_DIS $=-3.79266+0.44482 *$ Ln_IOM & 0.1224 \\
\hline & area & -0.091673491 & 0.6427 & Ln_DIS $=-6.63514+-0.17227 *$ Ln_IOM & -0.0297 \\
\hline & Combined & 0.063706537 & 0.6569 & Ln_DIS $=-5.34740+0.09365 *$ Ln_IOM & -0.0163 \\
\hline \multirow{3}{*}{ Total } & Personal & 0.727284334 & $<.0001$ & Ln_DIS $=-1.34359+0.54070 *$ Ln_IOM & 0.5065 \\
\hline & area & 0.088682453 & 0.6536 & Ln_DIS $=-3.12434+0.07341 *$ Ln_IOM & -0.0303 \\
\hline & Combined & 0.423016225 & 0.002 & Ln_DIS =-2.09441 +0.31071*Ln_IOM & 0.1622 \\
\hline
\end{tabular}

Table 7: SAS regression analysis results, including Pearson Correlation

Given the nature of this study, the ANOVA results were of great value in the interpretation of the data. This allowed for comparing the means of samples in order to assess if the differences were statistically significant. Utilized was a fixed effect ANOVA with $\alpha=0.05$. As previously mentioned, a P-value smaller than $\alpha$ indicates a rejection of the null hypothesis and it can be said that the difference between the two sample means is statistically significant. Table 8 summarizes the SAS ANOVA results, including the pvalues and log-transformed concentration estimates. The null hypothesis was rejected seven times of twelve. For every outcome for personal type samples, the null hypothesis was not rejected. For the combined samples of the cap, the null hypothesis was not rejected, as stated previously.

\begin{tabular}{|c|c|c|c|}
\hline \multicolumn{4}{|c|}{ ANOVA } \\
\hline Component & Type & P-value & Concentration Estimates (log-transformed) \\
\hline \multirow{3}{*}{ Filter only } & Personal & 0.4639 & 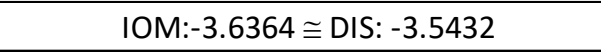 \\
\hline & area & 0.0115 & IOM:-4.8660 < DIS: -4.1310 \\
\hline & Combined & 0.0091 & IOM:-4.3115 < DIS: -3.8659 \\
\hline \multirow{3}{*}{ Interior } & Personal & 0.0915 & 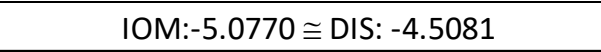 \\
\hline & area & 0.0113 & IOM:-6.1318< DIS: -5.2827 \\
\hline & Combined & 0.0022 & IOM:-5.6561 < DIS: -4.9334 \\
\hline \multirow{3}{*}{ Cap } & Personal & 0.1966 & IOM:-6.0658 DIS: -6.4909 \\
\hline & area & 0.0037 & IOM:-6.6697 < DIS: -5.4947 \\
\hline & Combined & 0.1196 & IOM:-6.3973 $\cong$ DIS: -5.9440 \\
\hline \multirow{3}{*}{ Total } & Personal & 0.4852 & IOM:-3.2263 $\cong \mathrm{DIS}:-3.0880$ \\
\hline & area & 0.0053 & IOM:-4.3096 < DIS: -3.4407 \\
\hline & Combined & 0.0055 & IOM:-3.8211 < DIS: -3.2817 \\
\hline
\end{tabular}

Table 8: SAS ANOVA results 


\section{Chapter 5: Discussion and Conclusions}

\subsection{Exposure Analysis}

The main focus of this study was to compare the performance of the DIS to the IOM sampler in the field. Each component of the samplers was individually quantified in order to measure wall deposits, transportation loss, as well as total particulate mass. As demonstrated from the data presented in Tables 3 and 4, it is noted that the geometric mean standard deviations for the samples collected was typically very large in comparison to the mean. There are a number of factors that might contribute to this pattern. Primarily for personal exposure measurements, workers involved in this sampling campaign performed different tasks - similar exposure groups were difficult to discern because of this. Had workers been designated to a smaller focus of tasks, the geometric standard deviations for each analytical assessment would have been grouped much tighter. However, since the purpose of this study was to compare the performance of the DIS sampler against the IOM sampler performance, separating workers into the similarly exposed group has not been performed in this study.

For area samples, samplers were placed at various locations covering a large range of expected exposures. Given the production schedule, exposure levels at this workplace were difficult to be compared with previous sampling campaigns. For example, some sections of the tankhouse were utilized heavily on one day, then minimal work was done on the next day. Electrolyte pumping stations, which were preferred spots for area sampling were susceptible to changes in ambient conditions depending on production output. Nevertheless, this worksite demonstrated personal exposure ranges lower than the OSHA PEL. 


\subsection{Transportation Effect}

Overall, a vast majority of the samples taken for both IOM samplers and DIS had transportation losses below 10\%. With a p-value of 0.1196 for all combined cap samples, the null hypothesis was not rejected, stating that the two samplers, in terms of transportation loss, were not statistically significant. Both samplers used mixed cellulose ester filters, although the filter diameters were different, and therefore the physical properties of each in terms of sample adhesion was as expected, to be similar. It would be difficult to discern how much of the transportation losses came from the filter and how much came from the interior, but the analysis of the collected data for this sampling campaign demonstrates that the differences in transportation losses between these samplers are not statistically significant. Nevertheless, about 7-8\% geometric mean losses from both sampler types should not be ignored and in practice, this loss can be minimized by placing cautions during shipment.

\subsection{Evaluation of DIS}

This study had two objectives: to assess and compare the efficiencies of the DIS and IOM sampler in the occupational setting of a copper refinery and to evaluate the usability of the DIS in a field application.

For the comparison of total concentrations including all three components (filter only, interior, and cap), the DIS consistently sampled higher than the IOM sampler considering the combined sample types (personal and area samples), rendering a p-value of 0.0055 when comparing the mean values of the samplers via ANOVA. Excluding area samples, the differences between the samplers was not statistically significant (p-value = 0.4852 ), with an adjusted $\mathrm{R}^{2}$ value of 0.5065 . This observation was the same when comparisons between the DIS exposures and the IOM exposures were made separately by filter only and interior. Interestingly, for the filter only, interior, and total concentrations, statistically significant differences between the DIS exposures and IOM exposures were determined from the area exposures, whereas no differences were observed from the 
personal exposures. Indeed, this observation was unexpected because for area samples the inlet of each sampling pair was positioned closely and fixed during the sampling time, unlike personal samples which sometimes an inlet of a sampler type was covered by a worker's uniform. From this study, it would be difficult to explain reasons for this phenomenon. As demonstrated from Figure 6, a number of a data points had ratios above 1.0 , and it can be concluded that a substantial portion of pairs with ratios $>1.0$ were that of area samples. This conclusion is backed up by a Pearson correlation coefficient greater than 0.72 for personal samples.

Of interest was the differences between the interior deposits between the two samplers - this component of the DIS was substantially dissimilar from the IOM sampler. The interior surface areas for each were vastly unalike, given that the IOM sampler uses a much smaller filter. The materials of each interior are also different, which furthered the conjecture they would be different. The internal volume of the DIS is larger, allowing more surface area for wall adhesions, and as such, the data acquired in this study, highlighted by table 8 demonstrates statistical differences in measurements taken by these two samplers.

\subsection{Practicability of DIS}

There are many differences in terms of the use of these two samplers in the field. They both have internal capsules, which sets them apart from the button sampler and the $\mathrm{CFC}$, but shapes, construction, and material of each are very different. The thin interior capsule of the DIS is cheaper to manufacture and more easily replaceable - the interior capsule of the IOM sampler retails for $\$ 15$, making it much less 'disposable'. The filter is not fused to the internal capsule in the IOM sampler, but per the developers of the DIS, the DIS internal capsule is fused to the filter, although this sampling campaign had unfused filters. The IOM sampler filter is snapped into place between the mesh component of the internal capsule, while the DIS filter is held in place by the friction fit

of the housing. During field testing, researchers were not completely confident in the 
overall seal of the friction fit, but no data was collected to quantify any difference between the threads of the IOM sampler and the friction fit of the DIS.

When analyzing the samples in the laboratory, processing of each interior and filter was a substantially different experience. The IOM sampler interior, given its geometry is relatively easy to wipe down, whereas the DIS is slightly more difficult and requires more time. Removing the filter from the IOM sampler internal capsule is substantially easier than the DIS, as gripping the edge of the filter while holding the internal capsule of the DIS is more difficult with forceps than removing the filter from the mesh component of the IOM sampler. The smaller filter of the IOM sampler was easier to handle and fit into digestion vials without bending - a potential source of sample loss. The data of this study does not demonstrate analytical faults with these procedures, but the DIS samples took substantially more time to process.

In the field, differences between the sampler types were noted. When calibrating samplers, the IOM sampler required the user to adjust a clamp to hold the pump in place, whereas the DIS required the user to push down on the pump hose adapter to the opening of the sampler. This caused more variability when calibrating with the DIS and a level of fatigue, especially when calibrating many sampling pumps. It cannot be said if this causes noticeable differences and further research should be conducted.

The differences in caps between the IOM sampler and DIS were quite different. The DIS used a rubber band to hold the cap on that wrapped around the back, whereas the IOM sampler uses a red rubber cap that fits over the mouth of the sampler. Although there was no problem with samplers coming undone during this sampling campaign, concern about reusing rubber bands was noted. It was also noted that when collecting large volumes of samples as was done in this study, the rubber banding of the DIS was time consuming in comparison to the IOM sampler. It would be suggested that manufacturers change the fittings of the caps and move away from the rubber bands. The IOM sampler has a barb as part of the housing that connects with the sampling pump hose, whereas the DIS has a removable barb screwed into the housing. There were no discernable differences due to this design. 
There are differences between the two that make for longer processing time in the laboratory and potential for sample loss, but those differences were not quantified in this study. The capping mechanism of the DIS is problematic as is the calibration procedure, but these can be changed with relatively minor modifications. With a retail price of $\$ 85$ for a plastic model and $\$ 269$ for a stainless-steel model for the IOM sampler, the DIS is the more economical sampler with the manufacturing cost of $\sim \$ 10$.

\subsection{Conclusions}

This study tested a currently non-commercialized prototype sampler and hope that if this sampler is to be commercialized, the recommendations made by this study be taken into consideration to improve viability. The findings of this study were based on a limited sample size (51 sample pairs including 28 area and 23 personal sample pairs) at one workplace. Given that these samplers differed on a statistically significant level, it is recommended that more sample collection at various worksites with different chemical components should be carried out prior to commercialization of the disposable inhalable sampler assessed in this study.

\subsubsection{Potential Application}

The disposable inhalable sampler attempts to tackle several issues plaguing air sampling. The most commonly used samplers do not agree with human inhalability in low-velocity conditions, which characterize a vast majority of work environments. The samplers that more closely mimic inhalability in low-velocity conditions are cost prohibitive compared to the commonly used closed face cassette sampler that retails for approximately $\$ 1$, and are for all intents and purposes not 'disposable'. With further development of the disposable inhalable sampler, air sampling measurements could potentially collect data that more closely reflects human exposures in occupational 
environments and allow for more consistent sampling by removing barriers related to the costs of sampling.

\subsubsection{Limitations and Future Research}

This study was carried out in a copper electrorefinery in which exposures to copper, arsenic, silver, lead, and selenium were the focus. The means in which these elements were aerosolized are specific and unique to that type of facility. This could have implications for particulate sizes and other considerations that could impact sampler efficiency. The high ambient temperatures and presence of other aerosols such as sulfuric acid mist could also be confounding variables when assessing the performance of the disposable inhalable sampler. Future research into the performance of the disposable inhalable sampler is recommended in environments with a range of ambient conditions, different contaminants, and other means of particulate emission. 


\section{References}

1. Aerosol-Technology-Committee. (2011) The state of the science of inhalable particles. A Science Symposium. American Industrial Hygiene Conference and Exposition. Portland, OR.

2. Aitken, R., Baldwin, P., Beaumont, G., Kenny, L., \& Maynard, A. (1999). Aerosol Inhalability in Low Air Movement Environments. Journal of Aerosol Science, 30(5), 613-626. doi:10.1016/s0021-8502(98)00762-9

3. Aizenberg, V., Grinshpun, S., Willeke, K., Smith, J., \& Baron, P. (2000). Measurement of the Sampling Efficiency of Personal Inhalable Aerosol Samplers Using a Simplified Protocol. Journal of Aerosol Science, 31(2), 169-179. doi:10.1016/s0021-8502(99)00037-3

4. Armbruster, L. and Breuer, H. (1982) Investigations into defining inhalable dust In Inhaled Particles V, ed. W. H. Walton, pp. 21-32. Pergamon Press, Oxford (ISBN 0-08-026838-2)

5. Asbestos Fibers and Other Elongate Mineral Particles: State of the Science and Roadmap for Research (Rep. No. No. 2011-159). (2011). Morgantown, WV: NIOSH.

6. Baldwin, P. E. J. and Maynard, A. D. (1998) A survey of wind speeds in indoor workplaces. Annals of Occupational Hygiene 42(5), 303-313.

7. Berry, R. D. and Froude, S. (1989) An investigation of wind conditions in the workplace to assess their effect on the quantity of dust inhaled. HSE Internal Report, IR/L/DS/89/3. Health and Safety Executive

8. Brown, J.S. (2005): Particle inhalability at low wind speeds. Inhalat. Toxicol.17:831-837

9. Brown, J. S., Gordon, T., Price, O., \& Asgharian, B. (2013). Thoracic and respirable particle definitions for human health risk assessment. Particle and Fibre Toxicology, 10(1), 12. doi:10.1186/1743-8977-10-12

10. Campbell, M. J., Demesmay, C., \& Ollé, M. (1994). Determination of total arsenic concentrations in biological matrices by inductively coupled plasma mass spectrometry. J. Anal. At. Spectrom. 9(12), 1379-1384.

doi:10.1039/ja9940901379 
11. Carter, C. M. (2012). A Comparison of "Total Dust" and Inhalable Personal Sampling for Beryllium Exposure. doi:10.2172/1043658

12. Comite' Europe'en de Normalisation (CEN) (1993) Workplace Atmospheres: Size Fraction Definitions for Measurement of Airborne Particles in the Workplace. CEN standard EN 481.

13. Croghan, C. AND P. P. Egeghy. (2003). Methods of Dealing with Values below the Limit of Detection Using SAS. Presented at Southeastern SAS User Group, St. Petersburg, FL, September 22-24.

14. Demesmay, C., Olle, M. \& Porthault, M. Fresenius J. (1994); Arsenic speciation by coupling high-performance liquid chromatography with inductively coupled plasma mass spectrometry. Anal Chem 348: 205. doi:10.1007/BF00325361

15. Drobna Z, Styblo M, Thomas DJ. An Overview of Arsenic Metabolism and Toxicity. Current protocols in toxicology / editorial board, Mahin D Maines (editor-in-chief). [et al]. 2009; 42(431):4.31.1-4.31.6. doi:10.1002/0471140856.tx0431s42.

16. Görner, P., Simon, X., Wrobel, R., Kauffer, E., Witschger, O (2010); Laboratory Study of Selected Personal Inhalable Aerosol Samplers. Ann Occup Hyg; 54 (2): 165-187. doi: 10.1093/annhyg/mep079

17. Guo, W., Hu, S., Zhang, J., Jin, L., Wang, X., Zhu, Z., \& Zhang, H. (2011). Soil monitoring of arsenic by methanol addition DRC ICP-MS after boiling aqua regia extraction. Journal of Analytical Atomic Spectrometry, 26(10), 2076. doi:10.1039/c1ja10126a

18. Hetland, S., \& Thomassen, Y. (1993). Sampling and chemical characterization of aerosols in workplace air. Pure and Applied Chemistry, 65(12). doi:10.1351/pac199365122417

19. Hsu DJ, Swift DL. (1999). The in vitro measurements of human inhalability of ultra-large aerosols in calm air conditions. J. Aerosol Sci. 30:1331-1343.

20. International Standards Organisation (ISO) (1995) Air Quality-Particle Size Fraction Definitions for Health-Related Sampling. ISO standard 7708, International Standards Organisation, Geneva

21. Kennedy, N. J., \& Hinds, W. C. (2002). Inhalability of large solid particles. Journal of Aerosol Science, 33(2), 237-255. doi:10.1016/s00218502(01)00168-9 
22. Kenny, L., \& Bartley, D. (1995). The performance evaluation of aerosol samplers tested with monodisperse aerosols. Journal of Aerosol Science, 26(1), 109-126. doi:10.1016/0021-8502(94)e0071-5

23. Kenny, L. C., Aitken, R., Chalmers, C., Fabrie`s, J. F., Gonzalez-Fernandez, E., Kromhout, H., Lide'n, G., Mark, D., Riediger, G. and Prodi, V. (1997) A collaborative European study of personal inhalable aerosol sampler performance. Annals of Occupational Hygiene 41(2), 135-153.

24. Kenny, L., Aitken, R., Baldwin, P., Beaumont, G., \& Maynard, A. (1998). The Sampling Efficiency of Personal Inhalable Aerosol Samplers in Low Air Movement Environments. Journal of Aerosol Science, 30(5), 627-638. doi:10.1016/s0021-8502(98)00752-6

25. Kovanen, K., Hanzawa, H. and Fanger, P. O. (1989) Turbulent air flow measurements in ventilated spaces. Environ. Int. 15,621-626

26. Li, S., Lundgren, D. A., \& Rovell-Rixx, D. (2000). Evaluation of Six Inhalable Aerosol Samplers. Aihaj, 61(4), 506-516. doi:10.1202/00028894(2000)061<0506:eosias>2.0.co;2

27. Lidén, Göran \& Harper, Martin (2006) The Need for an International Sampling

28. Convention for Inhalable Dust in Calm Air, Journal of Occupational and Environmental Hygiene, 3:10, D94-D101

29. Lidén, G., \& Lee, K. C. (1994). Errors in Inhalable Dust Sampling for Particles Exceeding $100100 \mu \mathrm{m}$. The Annals of Occupational Hygiene, 38(4), 373-384. doi:10.1093/annhyg/38.4.373

30. L’Orange, C., Anderson, K., Sleeth, D., Anthony, T. R., \& Volckens, J. (2015). A Simple and Disposable Sampler for Inhalable Aerosol. Annals of Occupational Hygiene, 60(2), 150-160. doi:10.1093/annhyg/mev065

31. Jie Liu, Michael P. Waalkes; Liver is a Target of Arsenic Carcinogenesis. Toxicol Sci 2008; 105 (1): 24-32. doi: 10.1093/toxsci/kfn120

32. Mark, D. and Vincent, J. H. (1986) A new personal sampler for airborne total dust in workplaces. Annals of Occupational Hygiene 30(1), 89-102.

33. Matthews, T G., Thompson, C. P , Wilson, D. L., Hawthorne, A. R. and Mage, D. T. (1989) Air velocities inside domestic environments. An important parameter in the study of indoor air quality and climate. Environ. Int. 15, 545-550. 
34. Maynard, A., Aitken, R., Kenny, L., Baldwin, P., \& Donaldson, R. (1997). Preliminary Investigation of Aerosol Inhalability at Very Low Wind Speeds. The Annals of Occupational Hygiene, 41, 1st ser., 695-699.

doi:10.1093/annhyg/41.inhaled_particles_viii.695

35. Maynard, A., \& Baldwin, P. (1997). Aerosol mass concentration measurement in calm air during sampler characterisation. Journal of Aerosol Science, 28(2), 334335. doi:10.1016/s0021-8502(97)86841-3

36. Munoz, L. P., Purchase, D., Jones, H., Feldmann, J., \& Garelick, H. (2014). Enhanced determination of As-phytochelatin complexes in Chlorella vulgaris using focused sonication for extraction of water-soluble species. Anal. Methods, 6(3), 791-797. doi:10.1039/c3ay41629a

37. Nelson, D. I., Concha-Barrientos, M., Driscoll, T., Steenland, K., Fingerhut, M., Punnett, L., Corvalan, C. (2005). The global burden of selected occupational diseases and injury risks: Methodology and summary. American Journal of Industrial Medicine, 48(6), 400-418. doi:10.1002/ajim.20211

38. Ogden, T. L. and Birkett, J. L. (1977) The human head as a dust sampler In Inhaled Particles IV, ed. W. H. Walton, pp. 93-105. Pergamon Press, Oxford (ISBN 0-08-020560-7).

39. Ogden, T. L. and Birkett, J. L. (1978) An inhalable-dust sampler for measuring the hazard from total airborne particulate. Annals of Occupational Hygiene 21, 41-50.

40. T. L. Ogden (2010). Handling results below the level of detection. Ann Occup Hyg 54 (3): 255-256. doi: 10.1093/annhyg/mep099

41. Phalen, R., Hinds, W., John, W., Lioy, P., Lippmann, M., Mccawley, M., Stuart, B. (1988). Particle Size-Selective Sampling in the Workplace: Rationale and Recommended Techniques. Inhaled Particles VI, 403-411. doi:10.1016/b978-008-034185-9.50046-2

42. Royal Society of Chemistry. (2005). Metals in Perspective: Occupational exposure assessment of metals. Journal of Environmental Monitoring, 7(5), 411. doi:10.1039/b504183j

43. Sheppard, B. S., Shen, W., Caruso, J. A., Heitkemper, D. T., \& Fricke, F. L. (1990). Elimination of the argon chloride interference on arsenic speciation in inductively coupled plasma mass spectrometry using ion chromatography. Journal of Analytical Atomic Spectrometry, 5(6), 431. doi:10.1039/ja9900500431 
44. Sleeth, D. K., \& Vincent, J. H. (2012). Performance Study of Personal Inhalable Aerosol Samplers at Ultra-Low Wind Speeds. The Annals of Occupational Hygiene, 56(2), 207-220. doi:10.1093/annhyg/mer089

45. Thomas, R. (2004). Practical guide to ICP-MS. New York: Dekker.

46. Toxicological Profile for Asbestos. (2002). ATSDR's Toxicological Profiles. doi:10.1201/9781420061888_ch34

47. Thornton-Manning J. \& Dahl A.R. (1997). Metabolic capacity of nasal tissue: interspecies comparisons of xenobiotic-metabolizing enzymes. Mutat Res. 380:43-59.

48. Vincent, J. H. and Armbruster, L. (1981) On the quantitative definition of the inhalability of airborne dust. Annals of Occupational Hygiene 24(2), 245-248.

49. Vincent, J. H. and Mark, D. (1982) Applications of blunt sampler theory to the definition and measurement of inhalable dust In Inhaled Particles V, ed. W. H. Walton, pp. 3-19. Pergamon Press, Oxford (ISBN 0-08-026838-2).

50. Vincent, J.H., D. Mark, B.G. Miller, L. Armbruster, and T.L. Ogden. (1990). Aerosol inhalability at higher wind speeds. J. Aerosol Sci. 21:577-586

51. Vincent, J. H. (Ed.) (1999) Particle Size-Selective Sampling of Particulate Air Contaminants ACGIH, Cincinnati, OH 45240-1634, USA (ISBN 1-882417-30-5).

52. Witschger, O., Grinshpun, S. A., GRINSH, Fauvel, S., \& Basso, G. (2004). Performance of Personal Inhalable Aerosol Samplers in Very Slowly Moving Air When Facing the Aerosol Source. The Annals of Occupational Hygiene, 48(4), 351-368. doi:10.1093/annhyg/meh006

53. Wood, J. D. and Birkett, J. L. (1979) External airflow effects on personal sampling. Annals of Occupational Hygiene 22(3), 299-310.

54. Work-Related Lung Disease Surveillance Report 2007 (Rep. No. No. 2008-143a). (2008). Morgantown, WV: DHHS/NIOSH.

55. Zhou, Y., \& Cheng, Y. (2009). Evaluation of IOM Personal Sampler at Different Flow Rates. Journal of Occupational and Environmental Hygiene, 7(2), 88-93. doi: 10.1080/15459620903418746 


\section{Appendix A: Calm Air Inhalability}

Ogden and Birkett: An inhalable-dust sampler, for measuring the hazard from total airborne particulate. Ann. Occup. Hyg. 21:41-50 (1978)

Breathing mannequin inhaling a steady flow by nose or mouth (recalculated into $\dot{V}_{e}=5,20$, and $40 \mathrm{~L} / \mathrm{min}$ )

Fluorescent-tagged bis(2-ethylhexyl)sebacate (DOS) particles generated by a spinning disc, and suspended in a $1 \mathrm{~m}^{3}$-chamber Filters inside mouth and nostrils

Reference concentration measured by a horizontal and vertical cones with $10-\mathrm{mm}$ entrance and aspirated at $8 \mathrm{~L} / \mathrm{min}$

Breysse and Swift: Inhalability of large particles into the human nasal passage: In vivo studies in still air. Aerosol Sci. Technol. 13:459-464 (1990)

Human test subjects nose-inhaling- 8 breaths in $34 \mathrm{sec}$

Radioactively labeled pollen spores $(18-30 \mu \mathrm{m})$ and wood dust suspended in a vertical tube

Radioactivity in nose measured after experiment

Reference concentration measured by a horizontal open-face 37-mm filter cassette, corrected according to Kaslow and Emrich (1.00-0.84)

Hsu and Swift: The measurement of human inhalability of ultralarge aerosols in calm air using mannikins. J. Aerosol Sci. 30(10):1331-1343 (1999)

Breathing mannequin inhaling by nose $\left(\dot{V}_{e}=8.5\right.$ and $\left.20 \mathrm{~L} / \mathrm{min}\right)$ and by nose+mouth (elliptic tube $\emptyset=30 \mathrm{~mm}, \dot{V}_{e}=35 \mathrm{~L} / \mathrm{min}$ )

Aluminium oxide particles $(13-135 \mu \mathrm{m})$ sedimenting in a shower cabinet $(0.9 \times 0.9 \mathrm{~m})$

Cotton wads in nostrils and cotton pad in mouth

Reference concentration measured by sedimentation onto 37-mm GF filter.

Aitken et al.: Aerosol inhalability in low air movement environments. J. Aerosol Sci. 30(5):613-626 (1999)

Rotating breathing mannequin inhaling by mouth (elliptic tube $\varnothing=22 \mathrm{~mm}, \dot{V}_{e}=6,10$ and $20 \mathrm{~L} / \mathrm{min}$ )—At $60 \mu \mathrm{m}, 0.06$ difference to oronasal inhalation

Aluminium oxide particles $(6-90 \mu \mathrm{m})$ sedimenting in a calm-air chamber

Filter inside mouth

Reference concentration measured by circling "pseudo isokinetic" sampler

Dai et al.: In-vivo measurements of inhalability of ultralarge aerosol particles in calm air by humans. J. Aerosol Sci.

37(10):967-973 (2006)

Human test subjects nose-inhaling-12 and 20 breaths per min for $3 \mathrm{~min}$

Aluminium oxide particles $(13-135 \mu \mathrm{m})$ sedimenting in a cabinet $(0.9 \times 0.9 \mathrm{~m})$

Cotton wads in nostrils

Reference concentration measured by sedimentation onto cups

Note 1: $\dot{V}_{e}=$ minute volume.

Note 2: The report by D.E. Kaslow and R.J. Emrich "Particle Sampling Efficiencies for an Aspiring Blunt, Thick-Walled Tube in Calm Air" (Report No. 25) was published by the Physics Department of Lehigh University, Bethlehem, Pa. 


\section{Appendix B: Sampler Efficiency Values}

\begin{tabular}{|c|c|c|c|c|c|c|c|c|c|}
\hline \multirow[b]{2}{*}{ Sampler } & \multirow[b]{2}{*}{ Dae } & \multicolumn{3}{|c|}{ Manikin front } & \multicolumn{3}{|c|}{ Manikin back } & \multirow{2}{*}{$\begin{array}{l}\text { On manikin } \\
\text { mean (std) }\end{array}$} & \multirow{2}{*}{$\begin{array}{l}\text { Off manikir } \\
\text { mean }\end{array}$} \\
\hline & & Left & Centre & Right & Left & Centre & Right & & \\
\hline IOM & $\begin{array}{l}6 \\
6\end{array}$ & 100.78 & 99.44 & $\begin{array}{r}77.54 \\
105.34\end{array}$ & 94.58 & 89.51 & $\begin{array}{l}90.05 \\
91.60\end{array}$ & $\begin{array}{c}93.6 \\
(8.6)\end{array}$ & 100.2 \\
\hline IOM & $\begin{array}{l}26 \\
26\end{array}$ & 94.45 & $\begin{array}{r}91.81 \\
101.28\end{array}$ & $\begin{array}{r}101.73 \\
92.33\end{array}$ & 90.11 & $\begin{array}{r}93.09 \\
104.21\end{array}$ & $\begin{array}{l}77.80 \\
65.83\end{array}$ & $\begin{array}{r}91.3 \\
(11.7)\end{array}$ & 86.1 \\
\hline IOM & $\begin{array}{l}58 \\
58\end{array}$ & $\begin{array}{r}106.70 \\
88.41\end{array}$ & 82.63 & $\begin{array}{r}123.77 \\
59.99\end{array}$ & $\begin{array}{l}70.61 \\
57.36\end{array}$ & 70.88 & $\begin{array}{r}104.57 \\
60.86\end{array}$ & $\begin{array}{l}82.6 \\
(22.8)\end{array}$ & 86.81 \\
\hline IOM & $\begin{array}{l}74 \\
74\end{array}$ & $\begin{array}{r}86.09 \\
114.75\end{array}$ & 91.26 & 104.22 & $\begin{array}{l}64.41 \\
91.21\end{array}$ & 80.27 & 87.40 & $\begin{array}{c}90.0 \\
(15.1)\end{array}$ & 89.8 \\
\hline IOM & $\begin{array}{l}90 \\
90\end{array}$ & $\begin{array}{r}86.82 \\
141.82\end{array}$ & $\begin{array}{r}88.86 \\
117.58\end{array}$ & $\begin{array}{r}105.65 \\
93.05\end{array}$ & $\begin{array}{l}86.50 \\
96.32\end{array}$ & $\begin{array}{l}73.78 \\
82.58\end{array}$ & $\begin{array}{l}95.24 \\
66.69\end{array}$ & $\begin{array}{l}94.6 \\
(20.0)\end{array}$ & 90.8 \\
\hline 7-H & $\begin{array}{l}6 \\
6\end{array}$ & $\begin{array}{l}99.7 \\
99.48\end{array}$ & 95.74 & 93.04 & $\begin{array}{l}88.26 \\
90.1\end{array}$ & 92.34 & 91.01 & $\begin{array}{l}93.7 \\
(4.2)\end{array}$ & \\
\hline 7-H & $\begin{array}{l}26 \\
26\end{array}$ & $\begin{array}{l}91.34 \\
80.72\end{array}$ & 85.36 & $\begin{array}{l}86.62 \\
94.3\end{array}$ & $\begin{array}{l}81.02 \\
80.96\end{array}$ & 85.57 & $\begin{array}{l}73.42 \\
75.4\end{array}$ & $\begin{array}{l}83.5 \\
(6.5)\end{array}$ & \\
\hline 7-H & $\begin{array}{l}58 \\
58\end{array}$ & $\begin{array}{l}63.33 \\
36.06\end{array}$ & $\begin{array}{l}41.73 \\
49.33\end{array}$ & 33.49 & $\begin{array}{l}39.83 \\
23.5\end{array}$ & $\begin{array}{l}58.76 \\
34.22\end{array}$ & 32.19 & $\begin{array}{l}41.2 \\
(12.5)\end{array}$ & \\
\hline 7-H & $\begin{array}{l}74 \\
74\end{array}$ & 50.17 & $\begin{array}{l}43.43 \\
37.19\end{array}$ & 40.16 & 39.4 & $\begin{array}{l}45.01 \\
27.74\end{array}$ & 20.06 & $\begin{array}{l}37.9 \\
(9.7)\end{array}$ & \\
\hline $7-\mathrm{H}$ & $\begin{array}{l}90 \\
90\end{array}$ & $\begin{array}{l}41.32 \\
55.7\end{array}$ & $\begin{array}{l}50.6 \\
38.54\end{array}$ & $\begin{array}{l}48.81 \\
52.59\end{array}$ & $\begin{array}{l}23.62 \\
36.41\end{array}$ & $\begin{array}{l}50.6 \\
38.54\end{array}$ & $\begin{array}{l}27.49 \\
52.59\end{array}$ & $\begin{array}{c}37.3 \\
(11.8)\end{array}$ & \\
\hline 37 & $\begin{array}{l}6 \\
6\end{array}$ & 111.12 & $\begin{array}{l}90.43 \\
92.7\end{array}$ & 89.83 & 85.57 & $\begin{array}{l}77.14 \\
83.44\end{array}$ & 88.33 & $\begin{array}{l}89.8 \\
(9.9)\end{array}$ & 92.50 \\
\hline 37 & $\begin{array}{l}26 \\
26\end{array}$ & $\begin{array}{l}15.37 \\
28.93\end{array}$ & $\begin{array}{l}33.21 \\
25.33\end{array}$ & 24.64 & 30.5 & $\begin{array}{l}30.3 \\
26.5\end{array}$ & 21.16 & $\begin{array}{l}25.6 \\
(5.5)\end{array}$ & 38.25 \\
\hline 37 & $\begin{array}{l}58 \\
58\end{array}$ & 4.25 & $\begin{array}{l}8.24 \\
289\end{array}$ & $\begin{array}{l}3.79 \\
3.5\end{array}$ & 3.18 & $\begin{array}{l}7.54 \\
3.26\end{array}$ & $\begin{array}{l}4.18 \\
3.85\end{array}$ & $\begin{array}{c}4.5 \\
(1.9)\end{array}$ & 5.15 \\
\hline 37 & $\begin{array}{l}74 \\
74\end{array}$ & 7.65 & 7.49 & $\begin{array}{r}10.29 \\
5.63\end{array}$ & 7.74 & 10.02 & $\begin{array}{l}9.18 \\
4.74\end{array}$ & $\begin{array}{c}7.8 \\
(2.0)\end{array}$ & 11.16 \\
\hline 37 & $\begin{array}{l}90 \\
90\end{array}$ & $\begin{array}{l}21.62 \\
25.75\end{array}$ & $\begin{array}{l}18.72 \\
17.92\end{array}$ & $\begin{array}{l}17.55 \\
16.2\end{array}$ & $\begin{array}{l}21.49 \\
25.04\end{array}$ & $\begin{array}{l}17.92 \\
17.92\end{array}$ & $\begin{array}{l}17.64 \\
23.24\end{array}$ & $\begin{array}{l}19.3 \\
(2.5)\end{array}$ & 19.8 \\
\hline
\end{tabular}

Appendix B 1: Efficiency values (\%) (Source: Kenny et al., 1999)

\begin{tabular}{|c|c|c|c|c|c|c|c|}
\hline \multirow[b]{2}{*}{$\begin{array}{l}\text { Aloxite } \\
\text { grade }\end{array}$} & \multirow[b]{2}{*}{ (Dae) } & \multicolumn{2}{|c|}{$37 \mathrm{~mm}$ sampler } & \multicolumn{2}{|c|}{ GSP sampler } & \multicolumn{2}{|c|}{ IOM sampler } \\
\hline & & $\begin{array}{l}\text { Efficiency } \\
(\%) \text { mean }\end{array}$ & $\begin{array}{l}\text { Standard } \\
\text { deviation }\end{array}$ & $\begin{array}{l}\text { Efficiency } \\
(\%) \text { mean }\end{array}$ & $\begin{array}{l}\text { Standard } \\
\text { deviation }\end{array}$ & $\begin{array}{l}\text { Efficiency } \\
(\%) \text { mean }\end{array}$ & $\begin{array}{l}\text { Standard } \\
\text { deviation }\end{array}$ \\
\hline f1200 & 6 & 85.31 & 3.46 & 100.61 & 5.36 & 94.18 & 3.39 \\
\hline f600 & 18 & & & 97.12 & 7.50 & 90.99 & 6.97 \\
\hline f500 & 26 & 27.69 & 4.3 & 84.16 & 4.76 & 82.00 & 10.08 \\
\hline f 400 & 34 & & & 79.95 & 7.02 & 83.06 & 7.76 \\
\hline$f 360$ & 46 & 6.39 & 0.99 & 72.69 & 11.76 & 80.86 & 4.60 \\
\hline $\mathrm{f} 320$ & 58 & 1.02 & 0.60 & 51.85 & 9.96 & 83.01 & 5.77 \\
\hline f 280 & 74 & & & 40.52 & 2.54 & 74.6 & 6.84 \\
\hline f 240 & 90 & & & 33.22 & 9.26 & 58.2 & 3.82 \\
\hline
\end{tabular}

Appendix B 2: Efficiency values measured for isolated samplers (source: Kenny et al., 1999) 


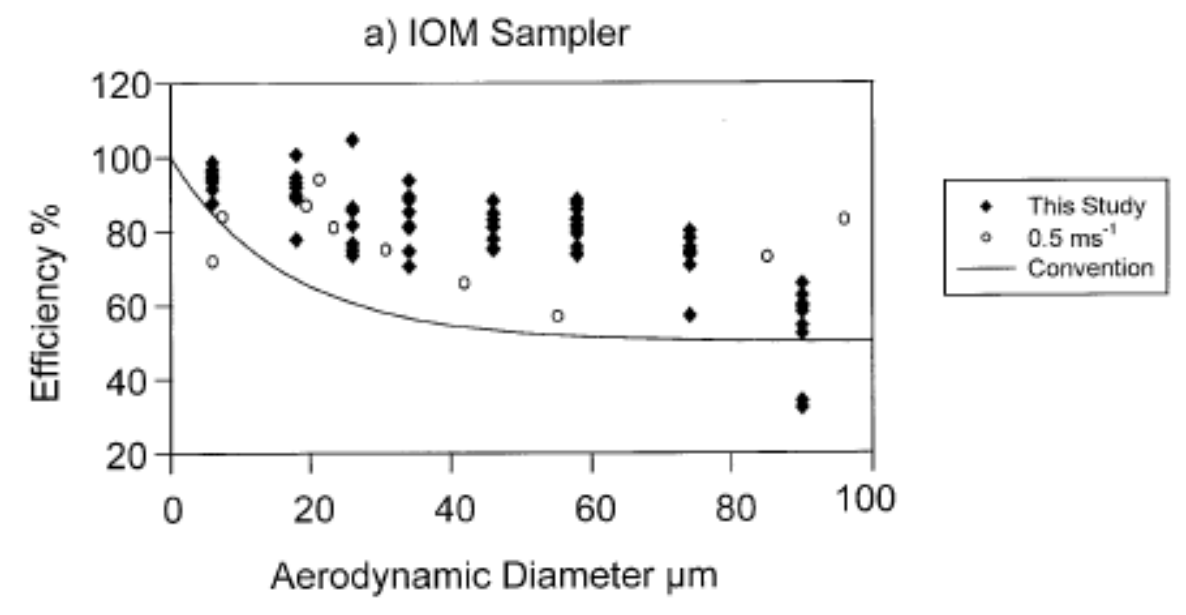

Appendix B 3: Efficiency values measured for isolated samplers (source: Kenny et al., 1999)

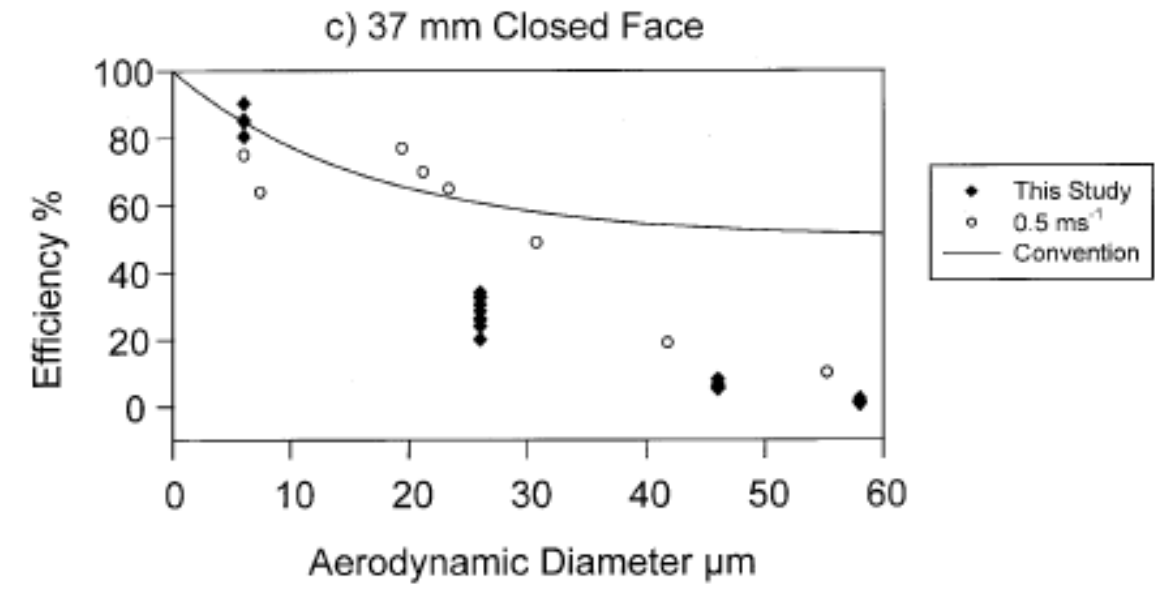

Appendix B 4: Efficiency values measured for isolated samplers (source: Kenny et al., 1999) 


\section{Appendix C: ICP-MS}

The NexION 300D includes a dual-channel Universal Cell and the ability to use Dynamic Reaction Cell ${ }^{\mathrm{TM}}$ (DRC ${ }^{\mathrm{TM}}$ ) technology. The ICP-MS is gives analysts the choice of using Kinetic Energy Discrimination (KED) and/or the use of a scanning quadrupole in a DRC.

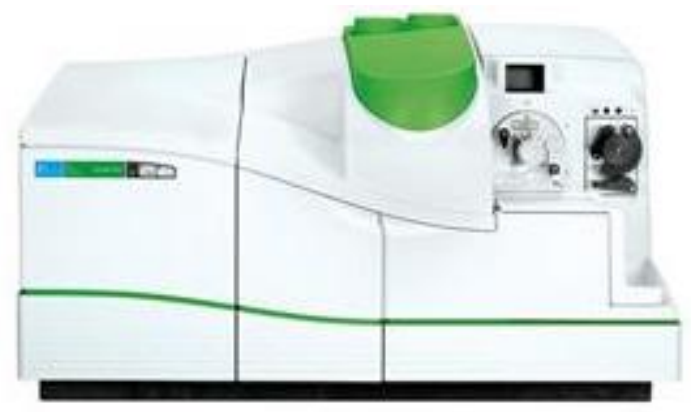

\section{Detection limits}

Based on three times the standard deviation of the blank using three-second integration time and peak hopping at 1-point per mass.

$\begin{array}{ll}\text { Element } & \text { ng/ } \text { (ppt) } \\ { }^{9} \mathrm{Be} & <1 \\ { }^{59} \mathrm{Co} & <1 \\ { }^{115} \mathrm{n} & <0.5 \\ { }^{238} \mathrm{U} & <0.5\end{array}$

$\begin{array}{ll}\text { Sensitivity } & \\ \text { Element } & \text { M cps/mg/L } \\ { }^{9} \mathrm{Be} & >3 \\ { }^{24} \mathrm{Mg} & >20 \\ { }^{115} \mathrm{In} & >50 \\ { }^{238} \mathrm{U} & >40\end{array}$

\section{Oxide and doubly-charged species}

Measured without the use of a desolvation device such as a chilled spray chamber and under identical operating conditions used to achieve sensitivity and detection-limit specifications.

$\mathrm{CeO}^{+} / \mathrm{Ce}^{+}<0.025$

$\mathrm{Ce}^{++} / \mathrm{Ce}^{+}<0.03$

\section{Background signal}

Mass $220<1 \mathrm{cps}$

\section{Short-term precision}

Defined as the relative standard deviation (\% RSD) for a 1-10 $\mu \mathrm{g} / \mathrm{L}$ multielement solution, automatically cycling between cell and non-cell modes, using a 3-second integration time, without internal standardization. $<3 \%$ RSD 


\section{Long-term stability}

Relative stability after a one-hour warm-up period. Defined as the relative standard deviation of the mean signal for a 1-10 $\mu \mathrm{g} / \mathrm{L}$ multielement solution, automatically cycling between cell and non-cell modes, measured once every 10 minutes, without internal standardization.

$<4 \%$ RSD over 4 hours

\section{Isotope-ratio precision}

Defined for the isotope ratio of ${ }^{107} \mathrm{Ag} /{ }^{109} \mathrm{Ag}$. Obtained using single-point peak hopping.

$<0.08 * \%$ RSD (*or within a factor of two of the counting statistics limit)

\section{Mass calibration stability}

Measured using a $1 \mu \mathrm{g} / \mathrm{L}$ multielement solution containing ${ }^{7} \mathrm{Li},{ }^{24} \mathrm{Mg}$, ${ }^{115} \mathrm{n}$ and ${ }^{238} \mathrm{U}$. Defined in terms of the shift in spectral position corresponding to maximum spectral peak intensity for each element, obtained without the use of multiple-point, peak-searching algorithms.

$<0.05$ amu over 8 hours of continuous operation

\section{Quadrupole peak hop (slew) speed}

Defined as the maximum rate at which the quadrupole can change from the minimum mass to the maximum mass without affecting the precision of the analytical measurement.

$1.6 \mathrm{M}$ amu/sec

\section{Quadrupole scan speed}

Defined as the maximum rate at which the quadrupole can be scanned while acquiring continuous spectral data at every mass from the minimum to the maximum mass of the instrument (1-285 amu).

$5000 \mathrm{amu} / \mathrm{sec}$

\section{Abundance sensitivity}

Defined as the intensity of a given isotope at spectral peak maximum, relative to the intensity of that isotope at 1 amu lower and at 1 amu higher than the mass position corresponding to peak maximum.

Measured at ${ }^{23} \mathrm{Na}$

Better than $1.0 \times 10^{-5}$ at low mass side of peak

Better than $1.0 \times 10^{-7}$ at high mass side of peak

\section{Detector linear range}

The Simulscan" detection system operates from $<0.1 \mathrm{cps}$ to $>10^{9} \mathrm{cps}$. This provides over 10 orders of magnitude of linear dynamic range in a single continuous scan.

Transient data acquisition speed

$>3000$ temporal data points/sec maximum 


\section{Appendix D: Calibration and Limits of Detection}

\begin{tabular}{|c|c|c|}
\hline \multicolumn{3}{|c|}{$\begin{array}{l}\text { Chemical characterization: Mixtures } \\
\text { Description: Mixture of the substances listed below with nonhazardous additions. }\end{array}$} \\
\hline \multicolumn{3}{|c|}{ Dangerous components: } \\
\hline $7697-37-2$ & nitric acid & $5.0 \%$ \\
\hline \multicolumn{3}{|c|}{ Chemical identification of the substance/preparation } \\
\hline $7440-29-1$ & Thorium from Thorium nitrate hydrate & $0.001 \%$ \\
\hline $7440-64-4$ & Ytterbium from Ytterbium (III) oxide & $0.001 \%$ \\
\hline $7440-30-4$ & Thulium from Thulium oxide & $0.001 \%$ \\
\hline $7440-65-5$ & Yttrium from Yttrium oxide & $0.001 \%$ \\
\hline $7440-10-0$ & Praseodymium from Praseodymium(III,IV) oxide & $0.001 \%$ \\
\hline $7440-19-9$ & Samarium from Samarium (III) oxide & $0.001 \%$ \\
\hline $7439-94-3$ & Lutetium from Lutetium (III) Oxide & $0.001 \%$ \\
\hline $7440-52-0$ & Erbium from Erbium(III) oxide & $0.001 \%$ \\
\hline $7440-54-2$ & Gadolinium from Digadolinium trioxide & $0.001 \%$ \\
\hline $7440-60-0$ & Holmium from Holmium oxide & $0.001 \%$ \\
\hline $7440-27-9$ & Terbium from Terbium (III,IV) oxide & $0.001 \%$ \\
\hline $7440-00-8$ & Neodymium from Neodymium Oxide & $0.001 \%$ \\
\hline $7440-45-1$ & Cerium from Cerium(III) nitrate hexahydrate & $0.001 \%$ \\
\hline $7440-20-2$ & Scandium from Scandium oxide & $0.001 \%$ \\
\hline $7439-91-0$ & Lanthanum from Lanthanum(III) nitrate hexahydrate & $0.001 \%$ \\
\hline $7440-53-1$ & Europium from Europium(III) oxide & $0.001 \%$ \\
\hline $7429-91-6$ & Dysprosium from Didysprosium trioxide & $0.001 \%$ \\
\hline $7732-18-5$ & water, distilled, conductivity or of similar purity & $94.983 \%$ \\
\hline
\end{tabular}

\section{http://www.spexcertiprep.com/MSDS/CLMS-1.pdf}

\begin{tabular}{|c|c|c|c|c|c|c|c|c|c|c|}
\hline Sample Id & $\mathbf{R}$ & $\begin{array}{c}\mathrm{Cu}-263 \\
\text { (counts) }\end{array}$ & $\begin{array}{c}\text { ArCl } 77 \\
\text { (counts) }\end{array}$ & $\begin{array}{r}\text { As-1 } 75 \\
\text { (counts) }\end{array}$ & $\begin{array}{c}\text { Se } 82 \\
\text { (counts) }\end{array}$ & $\begin{array}{c}\text { Y } 89 \\
\text { (counts) }\end{array}$ & $\begin{array}{c}\mathrm{Kr} 84 \\
\text { (counts) }\end{array}$ & $\begin{array}{c}\text { Ag } 107 \\
\text { (counts) }\end{array}$ & $\begin{array}{r}\text { Ag-1 } 109 \\
\text { (counts) }\end{array}$ & $\begin{array}{c}\text { Y-1 89 } \\
\text { (counts) }\end{array}$ \\
\hline 665 & & 379140.0 & 138.3 & 23350.7 & 87.6 & 288525.5 & 489.0 & 4442.8 & 5023.9 & 588898.0 \\
\hline 666 & & 41836.1 & 125.0 & 941.0 & 47.6 & 289604.5 & 465.0 & 3190.9 & 3451.6 & 602796.6 \\
\hline 667 & & 40996.9 & 93.0 & 1070.0 & 30.6 & 289040.3 & 446.3 & 1665.1 & 1839.7 & 603139.8 \\
\hline $1985.0 \mathrm{ppb} \mathrm{Cu}$ As & & 168944.3 & 89.3 & 70117.3 & 10.7 & 346847.2 & 391.6 & 188.7 & 174.3 & 754239.9 \\
\hline $2045.0 \mathrm{ppb}$ Ag Se & & 156483.6 & 5274.6 & 66665.9 & 6843.8 & 352419.6 & 383.6 & 304439.8 & 298684.6 & 762674.6 \\
\hline 665 & & 382073.6 & 138.7 & 24029.8 & 95.0 & 290722.9 & 403.9 & 4917.6 & 5230.3 & 610780.7 \\
\hline 666 & & 42260.0 & 137.0 & 990.4 & 66.3 & 294433.7 & 420.3 & 3347.6 & 3561.6 & 617805.0 \\
\hline 667 & & 41702.2 & 101.0 & 1113.7 & 31.7 & 293935.9 & 406.1 & 1782.1 & 1899.1 & 614926.4 \\
\hline $1985.0 \mathrm{ppb} \mathrm{Cu}$ As & & 169057.9 & 96.3 & 70581.1 & 12.4 & 350559.0 & 400.5 & 212.3 & 176.0 & 766556.6 \\
\hline $2045.0 \mathrm{ppb}$ Ag Se & & 156343.8 & 5307.0 & 67411.2 & 6966.9 & 354137.0 & 381.7 & 310028.0 & 299333.2 & 778011.5 \\
\hline 665 & & 392034.7 & 148.7 & 24420.2 & 102.4 & 297431.3 & 409.0 & 5060.6 & 5330.3 & 627323.4 \\
\hline 666 & & 42816.7 & 124.0 & 999.4 & 48.7 & 297464.5 & 411.7 & 3362.6 & 3571.3 & 623285.4 \\
\hline 667 & & 41660.5 & 101.0 & 1122.7 & 36.4 & 299086.5 & 411.6 & 1816.1 & 1892.8 & 634285.6 \\
\hline $1985.0 \mathrm{ppb} \mathrm{Cu}$ As & & 170244.9 & 92.0 & 70983.1 & 10.8 & 354680.2 & 354.8 & 238.7 & 204.7 & 791870.3 \\
\hline $2045.0 \mathrm{ppb} \mathrm{Ag} \mathrm{Se}$ & & 158077.7 & 5438.0 & 67499.8 & 6954.9 & 360872.1 & 366.0 & 318534.8 & 303202.7 & 801886.3 \\
\hline 665 & & 389424.0 & 145.0 & 24256.4 & 104.7 & 299376.9 & 411.1 & 5184.0 & 5441.7 & 635349.9 \\
\hline 666 & & 42635.4 & 118.3 & 991.0 & 57.3 & 297491.1 & 377.8 & 3548.0 & 3693.7 & 637907.3 \\
\hline 667 & & 42125.0 & 100.0 & 1125.4 & 34.4 & 298339.2 & 418.4 & 1866.4 & 1846.7 & 634490.5 \\
\hline $1985.0 \mathrm{ppb} \mathrm{Cu}$ As & & 171817.3 & 88.3 & 71330.2 & 14.8 & 354654.3 & 369.9 & 275.3 & 221.0 & 802361.2 \\
\hline $2045.0 \mathrm{ppb} \mathrm{Ag} \mathrm{Se}$ & & 156314.5 & 5415.4 & 67744.6 & 6987.9 & 357159.5 & 362.5 & 317647.7 & 301461.1 & 799146.7 \\
\hline 665 & & 388095.6 & 155.3 & 24418.6 & 97.3 & 296623.6 & 400.6 & 5293.3 & 5430.4 & 633651.8 \\
\hline 666 & & 42560.6 & 128.3 & 986.4 & 52.7 & 295948.7 & 397.2 & 3619.0 & 3665.3 & 638670.6 \\
\hline 667 & & 41434.0 & 105.0 & 1129.4 & 18.3 & 296046.7 & 412.5 & 1914.4 & 1942.4 & 639901.8 \\
\hline $1985.0 \mathrm{ppb} \mathrm{Cu}$ As & & 171556.4 & 89.3 & 71258.4 & 6.4 & 357671.5 & 378.9 & 265.7 & 232.3 & 831173.8 \\
\hline $2045.0 \mathrm{ppb} \mathrm{Ag} \mathrm{Se}$ & & 69167.3 & 2322.9 & 29313.3 & 3057.8 & 158369.9 & 1309.7 & 25.7 & 18.7 & 26.3 \\
\hline 665 & & 382201.5 & 141.3 & 23415.1 & 89.2 & 294641.5 & 424.6 & 5239.3 & 5425.4 & 633407.2 \\
\hline 666 & & 42551.6 & 117.3 & 987.7 & 48.2 & 294242.0 & 422.7 & 3542.6 & 3623.0 & 636564.3 \\
\hline 667 & & 41716.9 & 95.0 & 1156.4 & 29.7 & 295949.8 & 440.0 & 1888.7 & 1959.4 & 643945.9 \\
\hline
\end{tabular}




\begin{tabular}{|c|c|c|c|c|c|}
\hline & \multicolumn{5}{|c|}{$\mathrm{Cu}$} \\
\hline & 665 & 666 & 667 & $1985.0 \mathrm{ppb} \mathrm{Cu}$ As & 2045.0 ppb Ag Se \\
\hline & 379140.0 & 41836.1 & & 168944.3 & \\
\hline & 382073.6 & 42260.0 & & 169057.9 & \\
\hline & 392034.7 & 42816.7 & & 170244.9 & \\
\hline & 389424.0 & 42635.4 & & 171817.3 & \\
\hline & 388095.6 & 42560.6 & & 171556.4 & \\
\hline & 382201.5 & 42551.6 & & & \\
\hline STDEV & 5057.8 & 347.6 & & 1347.4 & \\
\hline MEAN & 385494.9 & & & 170324.1 & \\
\hline Slope from $5 p p b$ stds & & & & 34064.82992 & \\
\hline Quant Limit ppb & & & & 0.395534426 & \\
\hline \multirow[t]{9}{*}{ Quant Limit ng in sample } & & & & 158.2137703 & \\
\hline & \multicolumn{5}{|c|}{ As } \\
\hline & 665 & 666 & 667 & $1985.0 \mathrm{ppb} \mathrm{Cu}$ As & 2045.0 ppb Ag Se \\
\hline & 23350.7 & 941.0 & & 70117.3 & \\
\hline & 24029.8 & 987.7 & & 70581.1 & \\
\hline & 24420.2 & 999.4 & & 70983.1 & \\
\hline & 24256.4 & 991.0 & & 71330.2 & \\
\hline & 24418.6 & 986.4 & & 71258.4 & \\
\hline & 23415.1 & 987.7 & & & \\
\hline STDEV & 485.81743 & 20.7146 & & 506.017267 & \\
\hline Average & & & & 70854.0 & \\
\hline Slope from $5 p p b$ stds & & & & 14170.79837 & \\
\hline Quant Limit ppb & & & & 0.357084515 & \\
\hline \multirow[t]{9}{*}{ Quant Limit ng in sample } & & & & 142.8338061 & \\
\hline & \multicolumn{5}{|c|}{ Se } \\
\hline & 665 & 666 & 667 & 1985.0 ppb Cu As & 2045.0 ppb Ag Se \\
\hline & 87.6 & & & & 6843.8 \\
\hline & 95.0 & & & & 6966.9 \\
\hline & 102.4 & & & & 6954.9 \\
\hline & 104.7 & & & & 6987.9 \\
\hline & 97.3 & & & & \\
\hline & 89.2 & & & & \\
\hline STDEV & & & & & 64.49757639 \\
\hline Average & & & & & 6938.4 \\
\hline Slope from $5 \mathrm{ppb}$ stds & & & & & 1387.674392 \\
\hline Quant Limit ppb & & & & & 0.046478898 \\
\hline \multirow[t]{9}{*}{ Quant Limit ng in sample } & & & & & 18.59155915 \\
\hline & \multicolumn{5}{|c|}{$\mathrm{Ag}$} \\
\hline & 665 & 666 & 667 & 1985.0 ppb Cu As & 2045.0 ppb Ag Se \\
\hline & 4442.8 & & & & 304439.8 \\
\hline & 4917.6 & & & & 310028.0 \\
\hline & 5060.6 & & & & 318534.8 \\
\hline & 5184.0 & & & & 317647.7 \\
\hline & 3619.0 & & & & \\
\hline & 3542.6 & & & & \\
\hline STDEV & & & & & 6680.54925 \\
\hline Average & & & & & 312662.5692 \\
\hline Slope from 5 ppb stds & & & & & 62532.51384 \\
\hline Quant Limit ppb & & & & & 0.106833211 \\
\hline Quant Limit ng in sample & & & & & 42.73328443 \\
\hline
\end{tabular}




\section{Appendix E: Collected Data}

\section{E.1: Raw Data by Species $\left(\mathrm{mg} / \mathrm{m}^{3}\right)$}

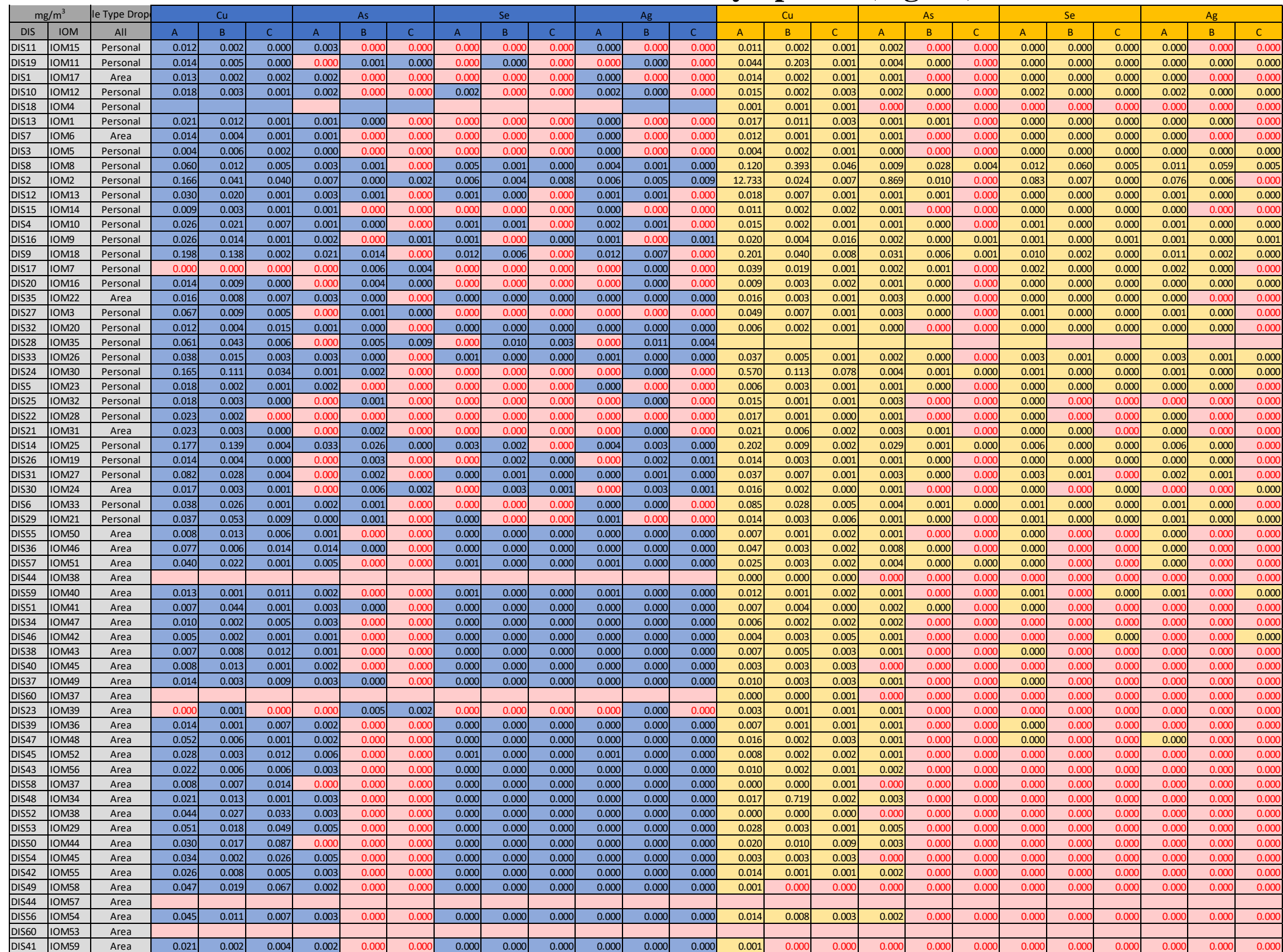




\section{E.2: Cu Mass (ng)}

\begin{tabular}{|c|c|c|c|c|c|c|c|c|c|c|}
\hline \multirow[t]{2}{*}{ DIS } & \multirow[t]{2}{*}{$\mathrm{IOM}$} & \multirow[t]{2}{*}{ Type } & \multicolumn{4}{|c|}{$\mathrm{Cu}$ - mass (ng) - DIS } & \multicolumn{4}{|c|}{$\mathrm{Cu}-$ mass (ng) - IOM } \\
\hline & & & Filter & Interior & Cap & Total & Filter & Interior & Cap & Total \\
\hline DIS1 & IOM17 & Area & 11830.71 & 2212.48 & 1445.95 & 15489.15 & 12569.89 & 1592.95 & 778.23 & 14941.07 \\
\hline DIS10 & IOM12 & Personal & 16545.84 & 2741.01 & 717.21 & 20004.07 & 14170.52 & 1443.29 & 2336.21 & 17950.02 \\
\hline DIS11 & IOM15 & Personal & 10845.71 & 1771.22 & 390.32 & 13007.25 & 10091.98 & 1544.93 & 992.00 & 12628.91 \\
\hline DIS12 & IOM13 & Personal & 25961.98 & 17807.62 & 776.95 & 44546.56 & 15970.07 & 5830.48 & 919.17 & 22719.72 \\
\hline DIS14 & IOM25 & Personal & 151528.58 & 118904.55 & 3219.64 & 273652.77 & 164680.05 & 7067.44 & 1594.02 & 173341.52 \\
\hline DIS15 & IOM14 & Personal & 4607.27 & 1506.19 & 529.87 & 6643.32 & 5767.03 & 1162.79 & 793.84 & 7723.67 \\
\hline DIS16 & IOM9 & Personal & 21657.92 & 11725.69 & 689.06 & 34072.67 & 17375.93 & 3636.32 & 13948.13 & 34960.39 \\
\hline DIS19 & IOM11 & Personal & 12078.21 & 4581.65 & 299.34 & 16959.20 & 37726.03 & 175177.92 & 1164.01 & 214067.96 \\
\hline DIS20 & IOM16 & Personal & 11488.77 & 7772.03 & 186.47 & 19447.28 & 7268.52 & 2366.50 & 1919.59 & 11554.61 \\
\hline DIS21 & IOM31 & Area & 20618.61 & 2883.92 & 195.58 & 23698.12 & 18784.52 & 5031.50 & 2182.79 & 25998.81 \\
\hline DIS22 & IOM28 & Personal & 20714.18 & 1828.31 & 51.77 & 22594.26 & 15387.24 & 834.88 & 427.97 & 16650.09 \\
\hline DIS23 & IOM39 & Area & 96.12 & 650.44 & 98.32 & 844.87 & 3159.03 & 774.35 & 1195.96 & 5129.34 \\
\hline DIS24 & IOM30 & Personal & 171721.89 & 115562.05 & 35497.03 & 322780.97 & 586842.63 & 116596.46 & 80341.23 & 783780.32 \\
\hline DIS25 & \begin{tabular}{|l|} 
IOM32 \\
\end{tabular} & Personal & 15982.58 & 2704.51 & 362.82 & 19049.91 & 13717.94 & 1249.17 & 1365.03 & 16332.14 \\
\hline DIS26 & IOM19 & Personal & 13013.32 & 3628.69 & 285.09 & 16927.10 & 12883.64 & 2765.50 & 1079.80 & 16728.95 \\
\hline DIS27 & IOM3 & Personal & 59818.37 & 8315.62 & 4047.70 & 72181.69 & 43796.25 & 6709.45 & 745.54 & 51251.24 \\
\hline DIS29 & \begin{tabular}{|l|} 
IOM 21 \\
\end{tabular} & Personal & 33432.54 & 47845.67 & 8150.33 & 89428.53 & 12806.03 & 2575.65 & 5167.55 & 20549.23 \\
\hline DIS3 & IOM5 & Personal & 3627.64 & 5333.86 & 1632.47 & 10593.98 & 3135.47 & 1270.52 & 746.94 & 5152.92 \\
\hline DIS30 & IOM24 & Area & 15151.51 & 2948.36 & 802.43 & 18902.30 & 14102.49 & 1783.84 & 410.20 & 16296.53 \\
\hline
\end{tabular}




\begin{tabular}{|c|c|c|c|c|c|c|c|c|c|c|}
\hline DIS31 & IOM27 & Personal & 71134.16 & 23949.68 & 3208.04 & 98291.88 & 31810.57 & 5759.90 & 513.71 & 38084.18 \\
\hline DIS32 & IOM20 & Personal & 10048.63 & 3758.21 & 13215.84 & 27022.68 & 5057.00 & 1361.93 & 843.55 & 7262.48 \\
\hline DIS33 & IOM26 & Personal & 33345.18 & 13111.61 & 2857.66 & 49314.46 & 32589.51 & 4170.48 & \begin{tabular}{|l|}
1089.05 \\
\end{tabular} & 37849.04 \\
\hline DIS34 & IOM47 & Area & 9956.73 & 1628.84 & 5207.00 & 16792.58 & 6491.63 & 1644.33 & \begin{tabular}{|l|}
1629.99 \\
\end{tabular} & 9765.95 \\
\hline DIS35 & IOM22 & Area & 15975.85 & 8148.77 & 6657.32 & 30781.95 & 16033.78 & 2735.57 & \begin{tabular}{|l}
785.35 \\
\end{tabular} & 19554.71 \\
\hline DIS36 & IOM46 & Area & 81705.11 & 6441.48 & 15027.09 & 103173.69 & 48877.83 & 3645.83 & 2478.78 & 55002.44 \\
\hline DIS37 & \begin{tabular}{|l|} 
IOM49 \\
\end{tabular} & Area & 13809.14 & 2963.77 & 9243.26 & 26016.18 & 9558.35 & 2685.86 & 3159.17 & 15403.39 \\
\hline DIS38 & IOM43 & Area & 6995.62 & 7418.71 & 11459.28 & 25873.61 & 6397.88 & 5179.10 & 2473.27 & 14050.25 \\
\hline DIS39 & IOM36 & Area & 13661.79 & 698.63 & 6505.82 & 20866.23 & 6632.13 & 838.77 & 650.05 & 8120.95 \\
\hline DIS4 & IOM10 & Personal & 24776.73 & 20030.18 & 7072.13 & 51879.04 & 13996.81 & 2325.33 & 1194.12 & 17516.27 \\
\hline DIS40 & IOM45 & Area & 7553.37 & 12354.18 & 625.56 & 20533.12 & 2507.66 & 2635.25 & 2566.68 & 7709.59 \\
\hline DIS41 & IOM59 & Area & 10892.68 & 830.05 & 1958.40 & 13681.12 & 498.44 & 54.98 & 65.69 & 619.12 \\
\hline DIS42 & IOM55 & Area & 13708.57 & 4082.40 & 2683.69 & 20474.66 & 7537.35 & 709.33 & 502.27 & 8748.95 \\
\hline DIS43 & IOM56 & Area & 11063.34 & 2860.14 & 3171.83 & 17095.30 & 5340.15 & 1098.33 & 681.58 & 7120.05 \\
\hline DIS45 & IOM52 & Area & 14135.15 & 1319.42 & 6061.69 & 21516.26 & 4134.65 & 1049.95 & 1153.52 & 6338.12 \\
\hline DIS46 & IOM42 & Area & 4478.52 & 2061.03 & 631.61 & 7171.16 & 3637.18 & 3267.80 & 4846.23 & 11751.21 \\
\hline DIS47 & IOM48 & Area & 50829.09 & 5716.34 & 500.13 & 57045.55 & 15398.37 & 1598.80 & 2684.85 & 19682.02 \\
\hline DIS48 & IOM34 & Area & 10722.70 & 6906.32 & 307.08 & 17936.09 & 8735.25 & 370488.78 & 861.13 & 380085.15 \\
\hline DIS49 & IOM58 & Area & 24740.75 & 10270.15 & 35653.67 & 70664.57 & 523.85 & 49.17 & 36.33 & 609.36 \\
\hline DIS5 & IOM23 & Personal & 15932.90 & 1796.40 & 550.74 & 18280.04 & 5535.31 & 2376.03 & 847.46 & 8758.80 \\
\hline DIS50 & IOM44 & Area & 15083.06 & 8689.41 & 43994.34 & 67766.80 & 9790.15 & 4685.13 & 4579.26 & 19054.54 \\
\hline DIS51 & \begin{tabular}{|l|} 
IOM41 \\
\end{tabular} & Area & 7661.97 & 45162.27 & 1394.46 & 54218.71 & 6860.15 & 4630.68 & 441.67 & 11932.50 \\
\hline
\end{tabular}




\begin{tabular}{|l|l|l|l|l|l|l|l|l|l|l|}
\hline DIS52 & IOM38 & Area & 22373.17 & 13613.81 & 16767.89 & 52754.87 & 240.42 & 245.67 & 165.56 & 651.64 \\
\hline DIS53 & IOM29 & Area & 25942.15 & 9288.71 & 25274.52 & 60505.38 & 14350.62 & 1353.51 & 317.22 & 16021.34 \\
\hline DIS54 & IOM45 & Area & 17747.50 & 797.60 & 13295.89 & 31840.99 & 2507.66 & 2635.25 & 2566.68 & 7709.59 \\
\hline DIS55 & IOM50 & Area & 8218.66 & 13272.29 & 5884.88 & 27375.83 & 7573.09 & 1450.77 & 1855.53 & 10879.39 \\
\hline DIS56 & IOM54 & Area & 23320.10 & 5784.01 & 3445.51 & 32549.62 & 7108.87 & 4258.31 & 1701.44 & 13068.61 \\
\hline DIS59 & IOM40 & Area & 13169.67 & 1399.55 & 11234.55 & 25803.78 & 12655.43 & 730.37 & 1794.62 & 15180.43 \\
\hline DIS6 & IOM33 & Personal & 33437.26 & 22278.09 & 972.84 & 56688.19 & 73697.80 & 24345.81 & 4703.94 & 102747.55 \\
\hline DIS7 & IOM6 & Area & 12602.65 & 3152.34 & 594.63 & 16349.62 & 10848.37 & 1107.18 & 1040.64 & 12996.20 \\
\hline DIS8 & IOM8 & Personal & 52649.51 & 10558.10 & 4193.49 & 67401.09 & 105491.93 & 346031.85 & 40359.89 & 491883.67 \\
\hline DIS9 & IOM18 & Personal & 161503.33 & 113121.27 & 1259.59 & 275884.18 & 167808.53 & 33691.83 & 6884.15 & 208384.51 \\
\hline
\end{tabular}




\section{E.3: Raw Data $\mathrm{Cu}\left(\mathrm{mg} / \mathrm{m}^{3}\right)$}

\begin{tabular}{|c|c|c|c|c|c|c|c|c|c|c|}
\hline $\mathrm{mg} / \mathrm{m} 3$ & & Type & \multicolumn{4}{|c|}{ Cu-DIS (mg/m3) } & \multicolumn{4}{|c|}{$\mathrm{Cu}-\mathrm{IOM}(\mathrm{mg} / \mathrm{m} 3)$} \\
\hline DIS & IOM & & Filter & Interior & Cap & Total & Filter & Interior & Cap & Total \\
\hline DIS1 & IOM17 & Area & 0.0131 & 0.0025 & 0.0016 & 0.0172 & 0.0142 & 0.0018 & 0.0009 & 0.0169 \\
\hline DIS10 & IOM12 & Personal & 0.0182 & 0.0030 & 0.0008 & 0.0220 & 0.0154 & 0.0016 & 0.0025 & 0.0195 \\
\hline DIS11 & IOM15 & Personal & 0.0120 & 0.0020 & 0.0004 & 0.0144 & 0.0111 & 0.0017 & 0.0011 & 0.0138 \\
\hline DIS12 & IOM13 & Personal & 0.0298 & 0.0204 & 0.0009 & 0.0511 & 0.0184 & 0.0067 & 0.0011 & 0.0262 \\
\hline DIS14 & IOM25 & Personal & 0.1765 & 0.1385 & 0.0038 & 0.3188 & 0.2020 & 0.0087 & 0.0020 & 0.2126 \\
\hline DIS15 & IOM14 & Personal & 0.0088 & 0.0029 & 0.0010 & 0.0127 & 0.0113 & 0.0023 & 0.0016 & 0.0152 \\
\hline DIS16 & IOM9 & Personal & 0.0255 & 0.0138 & 0.0008 & 0.0401 & 0.0199 & 0.0042 & 0.0160 & 0.0401 \\
\hline DIS19 & IOM11 & Personal & 0.0143 & 0.0054 & 0.0004 & 0.0200 & 0.0437 & 0.2028 & 0.0013 & 0.2478 \\
\hline DIS20 & IOM16 & Personal & 0.0135 & 0.0091 & 0.0002 & 0.0229 & 0.0088 & 0.0029 & 0.0023 & 0.0139 \\
\hline DIS21 & IOM31 & Area & 0.0228 & 0.0032 & 0.0002 & 0.0263 & 0.0209 & 0.0056 & 0.0024 & 0.0289 \\
\hline DIS22 & IOM28 & Personal & 0.0235 & 0.0021 & 0.0001 & 0.0256 & 0.0173 & 0.0009 & 0.0005 & 0.0187 \\
\hline DIS23 & IOM39 & Area & 0.0001 & 0.0006 & 0.0001 & 0.0008 & 0.0031 & 0.0008 & 0.0012 & 0.0051 \\
\hline DIS24 & IOM30 & Personal & 0.1653 & 0.1113 & 0.0342 & 0.3108 & 0.5697 & 0.1132 & 0.0780 & 0.7608 \\
\hline DIS25 & IOM32 & Personal & 0.0179 & 0.0030 & 0.0004 & 0.0214 & 0.0148 & 0.0014 & 0.0015 & 0.0177 \\
\hline DIS26 & IOM19 & Personal & 0.0145 & 0.0040 & 0.0003 & 0.0188 & 0.0143 & 0.0031 & 0.0012 & 0.0185 \\
\hline DIS27 & $10 M 3$ & Personal & 0.0674 & 0.0094 & 0.0046 & 0.0813 & 0.0487 & 0.0075 & 0.0008 & 0.0570 \\
\hline DIS29 & IOM21 & Personal & 0.0367 & 0.0526 & 0.0090 & 0.0983 & 0.0140 & 0.0028 & 0.0057 & 0.0225 \\
\hline DIS3 & IOM5 & Personal & 0.0043 & 0.0063 & 0.0019 & 0.0125 & 0.0038 & 0.0015 & 0.0009 & 0.0063 \\
\hline DIS30 & $10 M 24$ & Area & 0.0174 & 0.0034 & 0.0009 & 0.0218 & 0.0158 & 0.0020 & 0.0005 & 0.0183 \\
\hline DIS31 & IOM27 & Personal & 0.0818 & 0.0276 & 0.0037 & 0.1131 & 0.0372 & 0.0067 & 0.0006 & 0.0445 \\
\hline DIS32 & IOM20 & Personal & 0.0118 & 0.0044 & 0.0155 & 0.0316 & 0.0062 & 0.0017 & 0.0010 & 0.0088 \\
\hline DIS33 & IOM26 & Personal & 0.0376 & 0.0148 & 0.0032 & 0.0556 & 0.0366 & 0.0047 & 0.0012 & 0.0425 \\
\hline DIS34 & IOM47 & Area & 0.0098 & 0.0016 & 0.0051 & 0.0166 & 0.0064 & 0.0016 & 0.0016 & 0.0097 \\
\hline DIS35 & IOM22 & Area & 0.0163 & 0.0083 & 0.0068 & 0.0314 & 0.0161 & 0.0028 & 0.0008 & 0.0197 \\
\hline DIS36 & IOM46 & Area & 0.0772 & 0.0061 & 0.0142 & 0.0975 & 0.0467 & 0.0035 & 0.0024 & 0.0526 \\
\hline DIS37 & IOM49 & Area & 0.0139 & 0.0030 & 0.0093 & 0.0261 & 0.0096 & 0.0027 & 0.0032 & 0.0155 \\
\hline DIS38 & IOM43 & Area & 0.0072 & 0.0076 & 0.0118 & 0.0266 & 0.0066 & 0.0053 & 0.0025 & 0.0144 \\
\hline DIS39 & IOM36 & Area & 0.0137 & 0.0007 & 0.0065 & 0.0210 & 0.0067 & 0.0008 & 0.0007 & 0.0082 \\
\hline DIS4 & IOM10 & Personal & 0.0260 & 0.0210 & 0.0074 & 0.0545 & 0.0147 & 0.0024 & 0.0013 & 0.0184 \\
\hline
\end{tabular}




\begin{tabular}{|l|l|l|l|l|l|l|l|l|l|l|}
\hline DIS40 & IOM45 & Area & 0.0077 & 0.0125 & 0.0006 & 0.0209 & 0.0026 & 0.0027 & 0.0026 & 0.0079 \\
\hline DIS41 & IOM59 & Area & 0.0211 & 0.0016 & 0.0038 & 0.0265 & 0.0010 & 0.0001 & 0.0001 & 0.0012 \\
\hline DIS42 & IOM55 & Area & 0.0260 & 0.0077 & 0.0051 & 0.0388 & 0.0142 & 0.0013 & 0.0009 & 0.0165 \\
\hline DIS43 & IOM56 & Area & 0.0218 & 0.0056 & 0.0062 & 0.0337 & 0.0103 & 0.0021 & 0.0013 & 0.0137 \\
\hline DIS45 & IOM52 & Area & 0.0280 & 0.0026 & 0.0120 & 0.0425 & 0.0080 & 0.0020 & 0.0022 & 0.0122 \\
\hline DIS46 & IOM42 & Area & 0.0046 & 0.0021 & 0.0006 & 0.0073 & 0.0037 & 0.0033 & 0.0049 & 0.0118 \\
\hline DIS47 & IOM48 & Area & 0.0524 & 0.0059 & 0.0005 & 0.0589 & 0.0163 & 0.0017 & 0.0028 & 0.0209 \\
\hline DIS48 & IOM34 & Area & 0.0209 & 0.0134 & 0.0006 & 0.0349 & 0.0169 & 0.7188 & 0.0017 & 0.7374 \\
\hline DIS49 & IOM58 & Area & 0.0468 & 0.0194 & 0.0674 & 0.1337 & 0.0010 & 0.0001 & 0.0001 & 0.0012 \\
\hline DIS5 & IOM23 & Personal & 0.0178 & 0.0020 & 0.0006 & 0.0204 & 0.0063 & 0.0027 & 0.0010 & 0.0099 \\
\hline DIS50 & IOM44 & Area & 0.0297 & 0.0171 & 0.0867 & 0.1336 & 0.0200 & 0.0096 & 0.0094 & 0.0390 \\
\hline DIS51 & IOM41 & Area & 0.0075 & 0.0441 & 0.0014 & 0.0529 & 0.0067 & 0.0045 & 0.0004 & 0.0116 \\
\hline DIS52 & IOM38 & Area & 0.0438 & 0.0267 & 0.0328 & 0.1033 & 0.0005 & 0.0005 & 0.0003 & 0.0013 \\
\hline DIS53 & IOM29 & Area & 0.0506 & 0.0181 & 0.0493 & 0.1180 & 0.0279 & 0.0026 & 0.0006 & 0.0311 \\
\hline DIS54 & IOM45 & Area & 0.0343 & 0.0015 & 0.0257 & 0.0615 & 0.0026 & 0.0027 & 0.0026 & 0.0079 \\
\hline DIS55 & IOM50 & Area & 0.0078 & 0.0125 & 0.0056 & 0.0258 & 0.0072 & 0.0014 & 0.0018 & 0.0103 \\
\hline DIS56 & IOM54 & Area & 0.0445 & 0.0110 & 0.0066 & 0.0622 & 0.0137 & 0.0082 & 0.0033 & 0.0252 \\
\hline DIS59 & IOM40 & Area & 0.0129 & 0.0014 & 0.0110 & 0.0252 & 0.0124 & 0.0007 & 0.0018 & 0.0148 \\
\hline DIS6 & IOM33 & Personal & 0.0383 & 0.0255 & 0.0011 & 0.0650 & 0.0848 & 0.0280 & 0.0054 & 0.1182 \\
\hline DIS7 & IOM6 & Area & 0.0144 & 0.0036 & 0.0007 & 0.0187 & 0.0123 & 0.0013 & 0.0012 & 0.0148 \\
\hline DIS8 & IOM8 & Personal & 0.0597 & 0.0120 & 0.0048 & 0.0764 & 0.1199 & 0.3932 & 0.0459 & 0.5589 \\
\hline DIS9 & IOM18 & Personal & 0.1977 & 0.1385 & 0.0015 & 0.3377 & 0.2013 & 0.0404 & 0.0083 & 0.2499 \\
\hline
\end{tabular}




\section{E.4: Treated Data $\mathrm{Cu}\left(\mathrm{mg} / \mathrm{m}^{3}\right)$}

\begin{tabular}{|c|c|c|c|c|c|c|c|c|c|c|}
\hline \multirow{2}{*}{$\begin{array}{l}\mathrm{mg} / \mathrm{m} 3 \\
\mathrm{DIS}\end{array}$} & \multirow[b]{2}{*}{ IOM } & \multirow[t]{2}{*}{ Type } & \multicolumn{4}{|c|}{$\mathrm{Cu}-\mathrm{DIS}(\mathrm{mg} / \mathrm{m} 3)$} & \multicolumn{4}{|c|}{$\mathrm{Cu}-\mathrm{IOM}(\mathrm{mg} / \mathrm{m} 3)$} \\
\hline & & & Filter & Interior & Cap & Total & Filter & Interior & Cap & Total \\
\hline DIS1 & IOM17 & Area & 0.0131 & 0.0025 & 0.0016 & 0.0172 & 0.0142 & 0.0018 & 0.0009 & 0.0169 \\
\hline DIS10 & IOM12 & Personal & 0.0182 & 0.0030 & 0.0008 & 0.0220 & 0.0154 & 0.0016 & 0.0025 & 0.0195 \\
\hline DIS11 & IOM15 & Personal & 0.0120 & 0.0020 & 0.0004 & 0.0144 & 0.0111 & 0.0017 & 0.0011 & 0.0138 \\
\hline DIS12 & IOM13 & Personal & 0.0298 & 0.0204 & 0.0009 & 0.0511 & 0.0184 & 0.0067 & 0.0011 & 0.0262 \\
\hline DIS14 & IOM25 & Personal & 0.1765 & 0.1385 & 0.0038 & 0.3188 & 0.2020 & 0.0087 & 0.0020 & 0.2126 \\
\hline DIS15 & IOM14 & Personal & 0.0088 & 0.0029 & 0.0010 & 0.0127 & 0.0113 & 0.0023 & 0.0016 & 0.0152 \\
\hline DIS16 & IOM9 & Personal & 0.0255 & 0.0138 & 0.0008 & 0.0401 & 0.0199 & 0.0042 & 0.0160 & 0.0401 \\
\hline DIS19 & IOM11 & Personal & 0.0143 & 0.0054 & 0.0004 & 0.0200 & 0.0437 & 0.2028 & 0.0013 & 0.2478 \\
\hline DIS20 & IOM16 & Personal & 0.0135 & 0.0091 & 0.0002 & 0.0229 & 0.0088 & 0.0029 & 0.0023 & 0.0139 \\
\hline DIS21 & IOM31 & Area & 0.0228 & 0.0032 & 0.0002 & 0.0263 & 0.0209 & 0.0056 & 0.0024 & 0.0289 \\
\hline DIS22 & IOM28 & Personal & 0.0235 & 0.0021 & 0.0001 & 0.0256 & 0.0173 & 0.0009 & 0.0005 & 0.0187 \\
\hline DIS23 & IOM39 & Area & 0.0001 & 0.0006 & 0.0001 & 0.0008 & 0.0031 & 0.0008 & 0.0012 & 0.0051 \\
\hline DIS24 & IOM30 & Personal & 0.1653 & 0.1113 & 0.0342 & 0.3108 & 0.5697 & 0.1132 & 0.0780 & 0.7608 \\
\hline DIS25 & IOM32 & Personal & 0.0179 & 0.0030 & 0.0004 & 0.0214 & 0.0148 & 0.0014 & 0.0015 & 0.0177 \\
\hline DIS26 & IOM19 & Personal & 0.0145 & 0.0040 & 0.0003 & 0.0188 & 0.0143 & 0.0031 & 0.0012 & 0.0185 \\
\hline DIS27 & IOM3 & Personal & 0.0674 & 0.0094 & 0.0046 & 0.0813 & 0.0487 & 0.0075 & 0.0008 & 0.0570 \\
\hline DIS29 & IOM21 & Personal & 0.0367 & 0.0526 & 0.0090 & 0.0983 & 0.0140 & 0.0028 & 0.0057 & 0.0225 \\
\hline DIS3 & IOM5 & Personal & 0.0043 & 0.0063 & 0.0019 & 0.0125 & 0.0038 & 0.0015 & 0.0009 & 0.0063 \\
\hline DIS30 & IOM24 & Area & 0.0174 & 0.0034 & 0.0009 & 0.0218 & 0.0158 & 0.0020 & 0.0005 & 0.0183 \\
\hline DIS31 & IOM27 & Personal & 0.0818 & 0.0276 & 0.0037 & 0.1131 & 0.0372 & 0.0067 & 0.0006 & 0.0445 \\
\hline DIS32 & IOM20 & Personal & 0.0118 & 0.0044 & 0.0155 & 0.0316 & 0.0062 & 0.0017 & 0.0010 & 0.0088 \\
\hline DIS33 & IOM26 & Personal & 0.0376 & 0.0148 & 0.0032 & 0.0556 & 0.0366 & 0.0047 & 0.0012 & 0.0425 \\
\hline DIS34 & IOM47 & Area & 0.0098 & 0.0016 & 0.0051 & 0.0166 & 0.0064 & 0.0016 & 0.0016 & 0.0097 \\
\hline DIS35 & IOM22 & Area & 0.0163 & 0.0083 & 0.0068 & 0.0314 & 0.0161 & 0.0028 & 0.0008 & 0.0197 \\
\hline DIS36 & IOM46 & Area & 0.0772 & 0.0061 & 0.0142 & 0.0975 & 0.0467 & 0.0035 & 0.0024 & 0.0526 \\
\hline DIS37 & IOM49 & Area & 0.0139 & 0.0030 & 0.0093 & 0.0261 & 0.0096 & 0.0027 & 0.0032 & 0.0155 \\
\hline DIS38 & IOM43 & Area & 0.0072 & 0.0076 & 0.0118 & 0.0266 & 0.0066 & 0.0053 & 0.0025 & 0.0144 \\
\hline DIS39 & IOM36 & Area & 0.0137 & 0.0007 & 0.0065 & 0.0210 & 0.0067 & 0.0008 & 0.0007 & 0.0082 \\
\hline
\end{tabular}




\begin{tabular}{|c|c|c|c|c|c|c|c|c|c|c|}
\hline DIS4 & IOM10 & Personal & 0.0260 & 0.0210 & 0.0074 & 0.0545 & 0.0147 & \begin{tabular}{|l|l|}
0.0024 \\
\end{tabular} & 0.0013 & 0.0184 \\
\hline DIS40 & IOM45 & Area & 0.0077 & 0.0125 & 0.0006 & 0.0209 & 0.0026 & 0.0027 & 0.0026 & 0.0079 \\
\hline DIS41 & IOM59 & Area & 0.0211 & 0.0016 & 0.0038 & 0.0265 & 0.0010 & 0.0002 & 0.0002 & .0012 \\
\hline DIS42 & IOM55 & Area & 0.0260 & 0.0077 & 0.0051 & 0.0388 & 0.0142 & 0.0013 & 0.0009 & 0.0165 \\
\hline DIS43 & IOM56 & Area & 0.0218 & 0.0056 & 0.0062 & 0.0337 & 0.0103 & 0.0021 & 0.0013 & 0.0137 \\
\hline DIS45 & IOM52 & Area & 0.0280 & 0.0026 & 0.0120 & 0.0425 & 0.0080 & 0.0020 & 0.0022 & 0.0122 \\
\hline DIS46 & IOM42 & Area & 0.0046 & 0.0021 & 0.0006 & 0.0073 & 0.0037 & 0.0033 & 0.0049 & 0.0118 \\
\hline DIS47 & IOM48 & Area & 0.0524 & 0.0059 & 0.0005 & 0.0589 & 0.0163 & 0.0017 & 0.0028 & 0.0209 \\
\hline DIS48 & IOM34 & Area & 0.0209 & 0.0134 & 0.0006 & 0.0349 & 0.0169 & 0.7188 & 0.0017 & 0.7374 \\
\hline DIS49 & IOM58 & Area & 0.0468 & 0.0194 & 0.0674 & 0.1337 & 0.0010 & 0.0002 & 0.0002 & 0.0012 \\
\hline DIS5 & IOM23 & Persona & 0.0178 & 0.0020 & 0.0006 & 0.0204 & 0.0063 & 0.0027 & 0.0010 & 0.0099 \\
\hline DIS50 & IOM44 & Area & 0.0297 & 0.0171 & 0.0867 & 0.1336 & 0.0200 & 0.0096 & 0.0094 & 0.0390 \\
\hline DIS51 & IOM41 & Area & 0.0075 & 0.0441 & 0.0014 & 0.0529 & 67 & 0.0 & 0.0004 & 16 \\
\hline DIS52 & IOM38 & Area & 0.0438 & 0.0267 & 0.0328 & 0.1033 & 0.0 & 0.0 & 0.0003 & 0.0013 \\
\hline DIS53 & IOM29 & Area & 0.0506 & 0.0181 & 0.0493 & 0.1180 & 0.0279 & 0.0026 & 0.0006 & 0.0311 \\
\hline DIS54 & IOM45 & Area & 0.0343 & 0.0015 & 0.0257 & 0.0615 & 0.0026 & 0.0027 & 0.0026 & 0.0079 \\
\hline DIS55 & IOM50 & Area & 0.0078 & 0.0125 & 0.0056 & 0.0258 & 0.0072 & 0.0014 & 0.0018 & 0.0103 \\
\hline DIS56 & IOM54 & Area & 0.0445 & 0.0110 & 0.0066 & 0.0622 & 0.0137 & 0.0082 & 0.0033 & 0.0252 \\
\hline DIS59 & IOM40 & Area & 0.0129 & 0.0014 & 0.0110 & 0.0252 & 0.0124 & 0.0007 & 0.0018 & 0.0148 \\
\hline DIS6 & IOM33 & Person & 0.0383 & 0.0255 & 0.0011 & 0.0650 & 0.0848 & 0.0280 & 0.0054 & 0.1182 \\
\hline DIS7 & IOM6 & Area & 0.0144 & 0.0036 & 0.0007 & 0.0187 & 0.0123 & 0.0013 & 0.0012 & 0.0148 \\
\hline DIS8 & IOM8 & Perso & 0.0597 & 0.0120 & 0.0048 & 0.0764 & 0.1199 & 0.3932 & 0.0459 & 0.5589 \\
\hline DIS9 & IOM18 & Personal & 0.1977 & 0.1385 & 0.0015 & 0.3377 & 0.2013 & 0.0404 & 0.0083 & 0.2499 \\
\hline
\end{tabular}


